\title{
DETERMINING ACTUAL PURCHASE BEHAVIOUR FROM WILLINGNESS TO PAY: \\ EXAMINING THE SALE OF ETHICAL COTTON T-SHIRTS WITHIN A FESTIVAL CONTEXT
}

\author{
by \\ Brittany Jenkins \\ Bachelor of Science in Marine Biology, Dalhousie University, 2013 \\ A thesis presented to Ryerson University \\ in partial fulfillment of the \\ requirements for the degree of \\ Master of Applied Science \\ in the Program of \\ Environmental Applied Science and Management
}

Toronto, Ontario, Canada, 2017

(C) Brittany Jenkins 2017 


\section{Author's Declaration}

I hereby declare that I am the sole author of this thesis. This is a true copy of the thesis, including any required final revisions, as accepted by my examiners.

I authorize Ryerson University to lend this thesis to other institutions or individuals for the purpose of scholarly research.

I further authorize Ryerson University to reproduce this thesis by photocopying or by other means, in total or in part, at the request of other institutions or individuals for the purpose of scholarly research.

I understand that my thesis may be made electronically available to the public. 


\title{
DETERMINING ACTUAL PURCHASE BEHAVIOUR FROM WILLINGNESS TO PAY: \\ EXAMINING THE SALE OF ETHICAL COTTON T-SHIRTS WITHIN A FESTIVAL CONTEXT
}

\author{
Brittany Jenkins \\ Master of Applied Science, 2017 \\ Environmental Applied Science and Management \\ Ryerson University
}

\begin{abstract}
The sale and purchase of socially and environmentally responsible festival clothing is a way for both attendees and event organizers to engage in ethical consumption. While existing research examines hypothetical willingness to pay for ethical festival clothing, there has been no research done on actual purchase behaviour. This study examined if attendees at Mariposa Folk Festival in Ontario, Canada would pay a premium for ethical festival t-shirts, and examined variables that influenced their purchase decision. A natural field experiment recorded the purchase of 350 festival t-shirts, and from this sample 181 purchasers participated in a supplementary survey. Results revealed that attendees paid a premium for the ethical festival t-shirts, and that purchase decision was effected by the visibility of the ethical certification, cost, and promotion of the ethical festival t-shirts at the t-shirt emporium. These results provide insight into what consumers are actually willing to pay for ethical festival clothing and the motivations behind their purchase decisions.
\end{abstract}




\section{Acknowledgements}

I would like to thank my supervisor Dr. Rachel Dodds from the Ted Rogers School of Management at Ryerson University. Her enthusiasm, honesty, and support helped me to become a better writer and researcher. I would not be where I am without your guidance and I am beyond appreciative.

I would also like to thank Dr. Robert Pitts and Dr. Wayne Smith, from the College of Charleston in South Carolina, for their valuable feedback in regards to developing and piloting the online survey questions, being a sounding board for the experimental design, and for their knowledge on statistical testing.

I would like to thank the Coordinators of Mariposa Folk Festival, Pam Carter and CarrieAnne Lauder for their interest in the research, and willingness to collaborate and conduct the study at Mariposa Folk Festival.

I would also like to thank Dr. Corey Searcy, Dr. Philip Walsh, and Dr. Kelly McKay, for agreeing to act as my thesis defense committee and taking the time to provide me with valuable feedback.

Thank you to all the attendees of Mariposa Folk Festival who agreed to take the time to participate in the survey, and provide honest answers to the survey questions.

To my team of volunteers, thank you for your hard work in helping me run the research experiment and collect survey responses.

To my parents, I would like to express my gratitude for your unwavering encouragement and support for my academic endeavours. 


\section{Table of Contents}

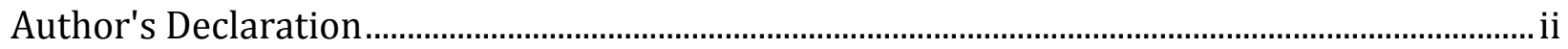

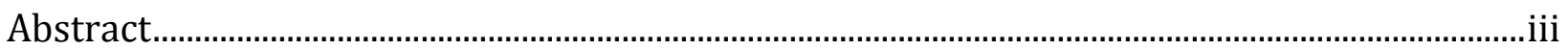

Acknowledgements .......................................................................................................................... iv

List of Tables ..................................................................................................................................... vii

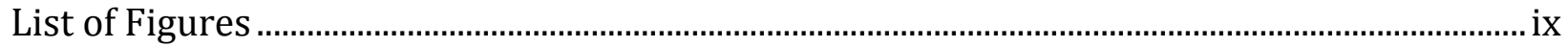

1.0 Introduction

1.1 Research Questions and Hypotheses ………………………………………………………. 4

1.2 Outline of Thesis Structure …………………………….............................................................

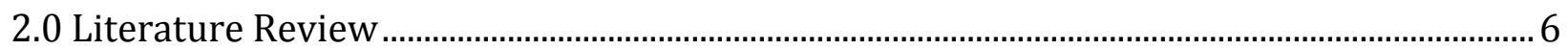

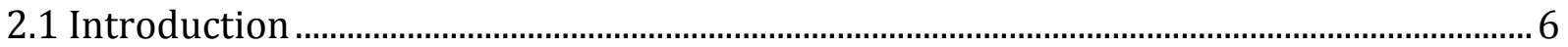

2.2 Consumption and Environmental Degradation ........................................................................ 7

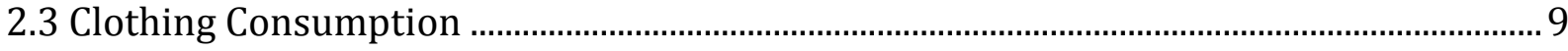

2.3.1 Environmental Issues Associated with the Clothing Industry ................................... 11

2.3.2 Environmental Responsibility within the Clothing Industry .................................... 13

2.3.3 Social Issues Associated with the Clothing Industry ………………………………... 15

2.3.4 Social Responsibility within the Clothing Industry ........................................................ 16

2.4 Theoretical Approaches to Ethical Consumption............................................................... 18

2.4.1 Self-determination Theory and Ethical Consumption ................................................ 19

2.4.2 Value-Belief-Norm Theory and Ethical Consumption................................................... 21

2.5 Willingness to Pay for Ethical Products ........................................................................... 25

2.5.1 Indirect Approaches to Measure Willingness to Pay ................................................... 26

2.5.2 Direct Approaches to Measure Willingness to Pay....................................................... 28

2.5.2.1 Measuring Actual Purchase Behaviour in WTP Studies............................................ 30

2.6 Influencing Willingness to Pay by Promoting Ethical Consumption ................................. 31

2.6.1 Barriers to Ethical Clothing Consumption ................................................................ 32

2.6.2 Marketing Ethical Clothing ……………………....................................................... 34

2.7 Using Festivals as Venues to Promote Ethical Consumption ............................................. 36

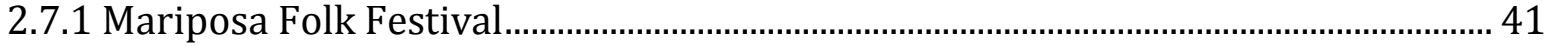

2.8 Conclusions \& Need for the Current Study …………………………………………….... 42

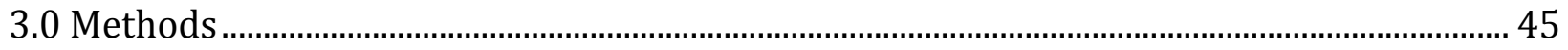




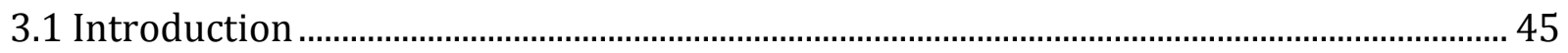

3.1.1 Research Questions and Hypotheses ........................................................................ 45

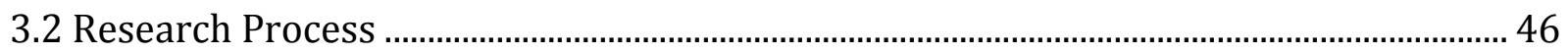

3.3 Literature Review ........................................................................................................ 46

3.4 Primary Research.................................................................................................................. 4 .

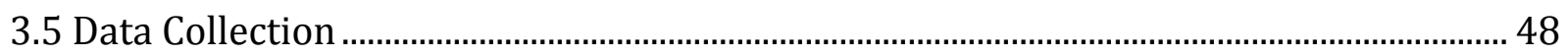

3.5.1 Field Experiment ……………………………………................................................... 49

3.5.1.1 Description of the \$20.00 CAN Festival T-shirt........................................................ 52

3.5.1.2 Description of the $\$ 25.00$ CAN Festival T-shirt......................................................... 53

3.5.1.3 Description of the $\$ 30.00$ CAN Festival T-shirt......................................................... 54

3.5.1.4 Marketing Treatments .......................................................................................... 56

3.5.2 Online Survey …………………………………………………………………….... 58

3.6 Survey Sample Size.......................................................................................................... 61

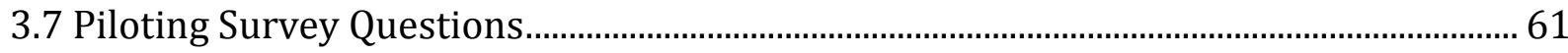

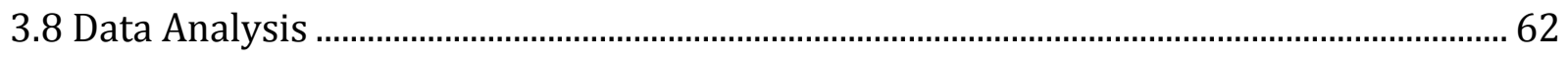

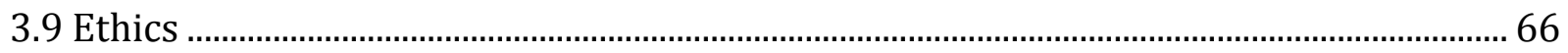

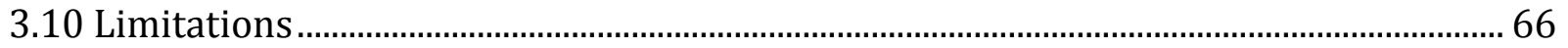

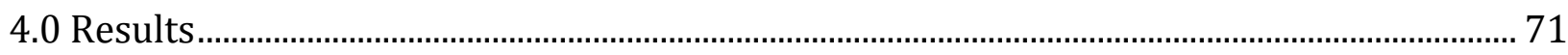

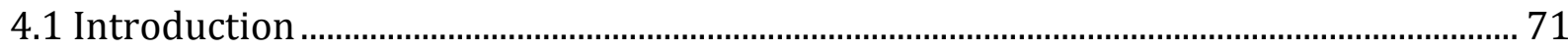

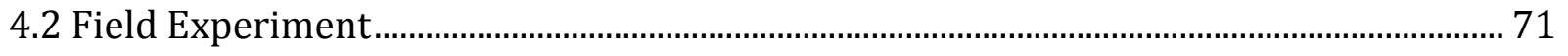

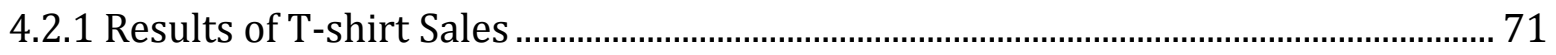

4.2.2 Influence of the Marketing Treatments ……………................................................... 73

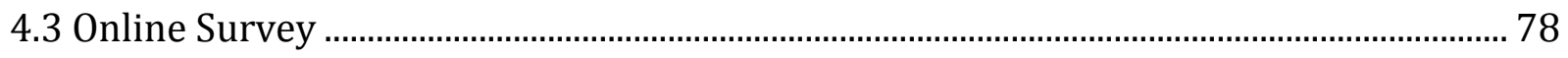

4.3.1 Comparison of T-shirt Sales ..................................................................................... 79

4.3.2 Demographics of Survey Respondents.................................................................... 80

4.3.3 Variables that Influenced the Type of Festival T-shirt Purchased ............................ 82

4.3.3.1 Influence of Cost ........................................................................................................... 84

4.3.3.2 Influence of Certification Visibility …………………………………………....... 84

4.3.3.3 Influence of Marketing Promotions at the T-shirt Emporium.................................. 85

4.3.3.4 Influence of Environmental Awareness ....................................................................... 86 
4.3.4 Variables that Influence General Clothing Purchases ..................................................... 88

4.3.5 Consumers' Perception of Ethical Products ............................................................................ 89

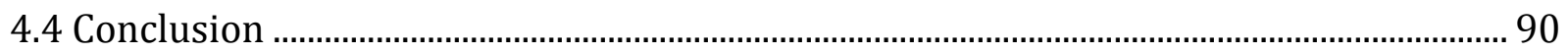

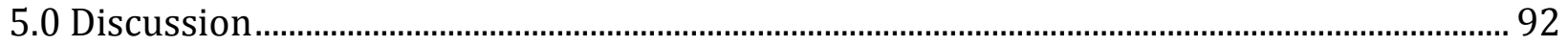

5.1 Actual Purchase Behaviour of Ethical Clothing ................................................................. 92

5.2 Influence of Marketing Treatments on Ethical Clothing Acquisition................................. 94

5.3 Influence of Cost on Ethical Clothing Purchases ..................................................................... 96

5.4 Influence of Certification Visibility on Ethical Clothing Purchases ................................... 97

5.5 Influence of Design on Clothing Purchases .............................................................................. 98

5.6 Environmental Awareness and Ethical Consumption ........................................................ 98

5.7 Consumers' Perception of Ethical Products …………………...............................................100

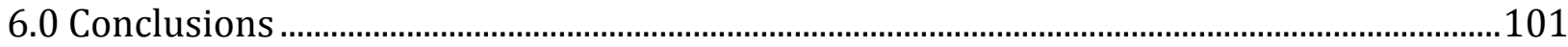

6.1 Summary of Key Findings..............................................................................................

6.1.1 Paying a Premium for Ethical Festival T-shirts ...........................................................102

6.1.2 Influencing Purchase Decisions .................................................................................... 102

6.2 Contribution of the Research .........................................................................................103

6.3 Implications of the Research ............................................................................................104

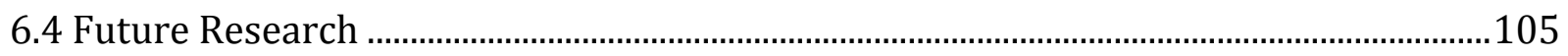

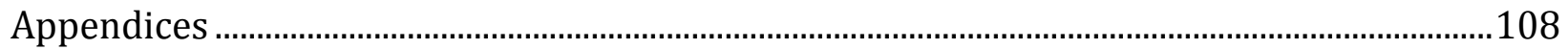

Appendix A: Script Used in Marketing Treatment One .............................................................108

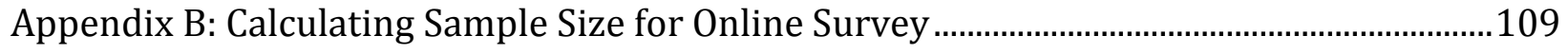

Appendix C: Online Survey Questions (Before Piloting)..............................................................110

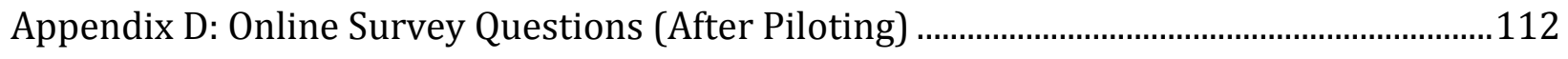

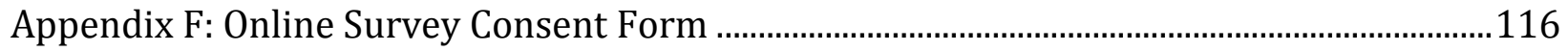

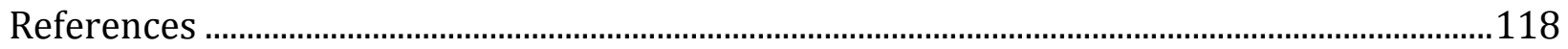




\section{List of Tables}

Table 1: Countries with the highest household clothing consumption expenditures, 2014...9

Table 2: Description of the three festival t-shirts sold during the field experiment. ............. 49

Table 3: Time-phased schedule for marketing treatments and control groups........................ 56

Table 4: List of survey questions and the corresponding studies that helped establish each

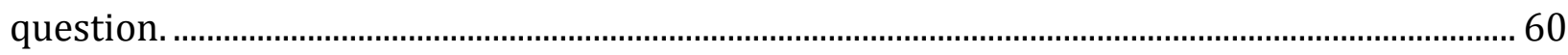

Table 5: Chi-square test results for the total number of each type of t-shirt sold................... 72

Table 6: Chi-square test results for ethical and conventional festival t-shirt sales. ................ 73

Table 7: Chi-square test results for the number of each type of $t$-shirt sold during treatment

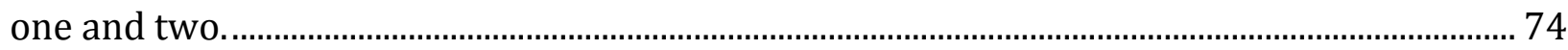

Table 8: Chi-square test results for the number of ethical and conventional t-shirts sold during treatment one and two................................................................................................ 75

Table 9: Chi-square test results for the effectiveness of marketing treatment one (Saturday). 76

Table 10: Chi-square test results for the effectiveness of marketing treatment two (Sunday). 77

Table 11: Chi-square test results for the number of each type of festival t-shirt sold during the control and combined treatment phases. 78

Table 12: Results of chi-square test comparing the proportion of t-shirt sales from the field experiment with the survey responses. .................................................................................... 80

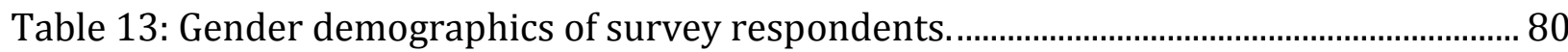

Table 14: Chi-square test results for t-shirt sales by gender ..................................................... 81

Table 15: Age demographics of survey respondents............................................................... 81

Table 16: Chi-square test results for $\mathrm{t}$-shirt sales by age.......................................................... 82

Table 17: Variables that may have influenced the type of festival t-shirt purchased............. 83 Table 18: Chi-square results for the influence of cost on type of festival t-shirt purchased.83 Table 19: Chi-square test results for the influence of certification visibility on the sale of the $\$ 30.00$ CAN festival t-shirts.

Table 20: Chi-square test results comparing the promotion of the fair trade/organic cotton $\mathrm{t}$-shirts at the $\mathrm{t}$-shirt emporium and the type of festival t-shirt purchased............................... 86

Table 21: Survey responses self-reported level of environmental awareness.......................... 86 Table 22: Contingency table comparing the level of environmental awareness and the type

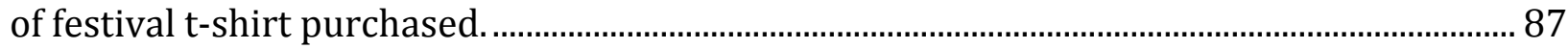

Table 23: Variables that may influence respondents' general clothing purchases.................. 89

Table 24: Respondents' perception of how ethical products are marketed. ............................. 90 


\section{List of Figures}

Figure 1: Relative environmental impacts associated with each stage in the lifecycle of

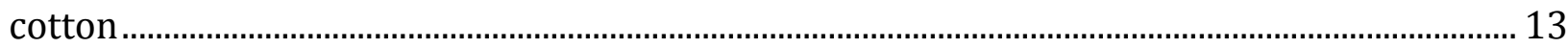

Figure 2: Schematic model of the value-belief-norm theory.................................................... 22

Figure 3: Sequential research process...................................................................................... 46

Figure 4: Map of Mariposa Folk Festival grounds. ................................................................. 51

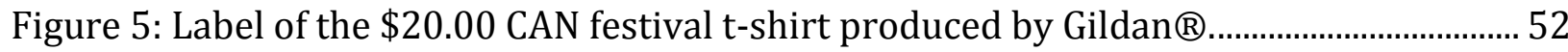

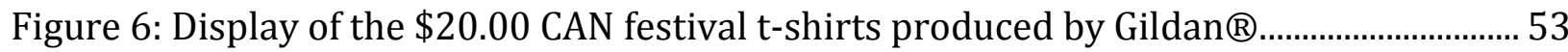

Figure 7: Label of the $\$ 25.00$ CAN festival t-shirt produced by Redwood Classics................. 53

Figure 8: Display of the $\$ 25.00$ CAN festival t-shirts produced by Redwood Classics............ 54

Figure 9: Label of the \$30.00 CAN festival t-shirt produced by Canadian Union Apparel......56 Figure 10: Display of the $\$ 30.00$ CAN festival t-shirts produced by Canadian Union Apparel.

Figure 11: External certifications printed on the \$30.00 CAN festival t-shirt, produced by

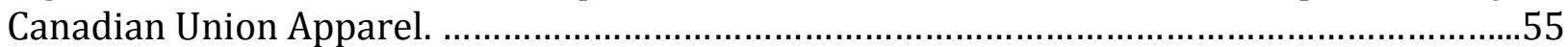

Figure 12: Visual aid used during marketing treatment one ..............................................57

Figure 13: Location of the jumbotron displaying promotional messages of the fair trade/organic festival t-shirts for treatment two of the experiment 


\subsection{Introduction}

The clothing industry provides excellent context to explore sustainability issues, as it has substantial holding in global markets and raises major concerns regarding the social and environmental impacts of the industry (Ha-Brookshire and Norum, 2011). The global clothing market is currently valued at approximately three trillion USD, with global clothing exports grossing \$483 billion USD in 2014 (World Trade Organization, 2015; International Apparel Federation, 2015). Canada alone grossed $\$ 30,185,000$ CAN in clothing sales in 2015 (Statistics Canada, 2016). As the clothing industry has such a large market share, it is important to address the social and environmental effects of clothing production.

Negative impacts of the clothing industry that have garnered much attention in recent years include the volume of clothing consumption, the use of pesticides and chemicals in the manufacturing process, poor or unfair working conditions for employees in manufacturing facilities, and the disposal of apparel (Birtwistle and Moore, 2007). The entire production process; from growing or manufacturing the textiles, to dying, printing, transporting, and disposing of clothing products, leaves an environmental footprint by means of energy consumption, resource consumption, and pollution (Cherrett et al., 2005; Ha-Brookshire and Norum, 2011; Hiller-Connell, 2011). Globalization of this industry has also led many clothing companies to seek out low-cost manufacturing locations in developing countries, such as China and India. Outsourcing to developing countries allows clothing companies to take advantage of reduced purchasing prices and lax labour laws and 
environmental regulations, resulting in various social issues regarding workers' health and safety (Cepolina, 2012).

There are ways in which the clothing production process can be made more socially and environmentally responsible; each step in the supply chain can be modified to reduce the impacts. Companies can choose textiles or means of producing textiles that are less resource-intensive, work with manufacturing facilities that ensure fair treatment of workers, and choose production technology that helps ensure they are in compliance with environmental standards (Cherrett et al., 2005; Chen and Burns, 2006). As the industry works towards being more environmentally conscious, it is equally important to involve consumers by encouraging ethical consumption of clothing (Hiller-Connell, 2011). Ethical consumption can be defined as purchasing products that are more environmentally and socially responsible or have fewer socio-environmental impacts compared to conventional products (Arnot et al. 2006; Hoek et al. 2013).

To better understand the potential market for ethical clothing, research has begun to examine the following concepts: how consumers perceive and value clothing products, variables that influence consumers' purchasing behaviours, and how much consumers are willing to pay for clothing that is environmentally and socially responsible. These concepts will provide context for the current study, which explores consumer purchase behaviour, in regards to ethical clothing, within a festival setting. The reason a festival was chosen as an ideal research venue is because festivals can act as platforms to effectively address environmental issues and encourage ethical consumer behaviours; as one can communicate messages of social and environmental responsibility to a large number of 
individuals simultaneously (Laing and Frost, 2010; Mair and Laing, 2012; Dodds et al., 2016). Previous research also indicates that encouraging ethical consumer behaviour within a festival setting, or attending a festival with an environmental focus, may result in increased environmental awareness and result in consumers engaging in more ethical behaviour outside of the event (Laing and Mair, 2013). One potential means of encouraging ethical consumer behaviour at festivals is through the sale of socially and environmentally responsible festival clothing. The sale of festival clothing is important to any event as festival clothing is a means of advertisement, is a significant source of revenue, and allows attendees to show their support for the festival (Dodds et al., 2016). The sale and purchase of ethical festival clothing, over conventional alternatives, is also a way for both attendees and festival organizers to demonstrate their environmental commitment.

Dodds, Pitts, and Smith (2016) was the first study to examine this by means of surveying attendees of Mariposa Folk Festival, located in Orillia, Ontario, on their hypothetical willingness to pay (WTP) for ethical festival clothing. The researchers measured attendee's WTP for four different festival t-shirts that varied in regards to fair trade certification, visibility of fair trade certification, and environmental messaging. The survey respondents in this study indicated they would be willing to pay the most for a festival t-shirt bearing both a visible environmental message and a fair trade certification. Dodds et al. (2016) indicated that future studies can build on their research by employing "an experimental design to control intra-subject effects and the use of actual clothing to measure behaviour rather than intent" (p.288). This provided an opportunity for the current study to further explore WTP for ethical festival clothing, by means of examining attendees' actual purchase behaviour and the motivations behind their purchase decisions. While collecting 
information on self-reported or hypothetical WTP is a good starting point, without any real incentive festival attendees may have overstated their WTP for the ethical festival t-shirts. The current study will allow for a more accurate representation of attendees' purchasing behaviours, and to examine hypothetical WTP in comparison to actual purchase behaviour.

\subsection{Research Questions and Hypotheses}

The current study seeks to answer the following research question; will individuals at Mariposa Folk Festival pay a premium for ethical festival t-shirts, and will certain variables influence their purchase decision? For the context of this study, ethical festival t-shirts refer to either festival t-shirts that are produced locally from a socially responsible company or festival t-shirts produced locally that are certified fair trade and organic cotton. To answer the research questions, the following four hypotheses were tested:

H1: Individuals will pay a premium to purchase the ethical festival $t$-shirts over the conventional alternative.

H2: Employing marketing treatments that promote the ethical festival t-shirts will increase the number of ethical festival $t$-shirts sold in a given time period.

H3: The visibility of the fair trade/ organic certification label will influence individuals' willingness to purchase the fair trade/ organic festival t-shirts.

H4: Survey participants who express greater environmental awareness will be more likely to purchase an ethical festival $t$-shirt.

This information will provide festival organizers with insight into how much consumers will pay for ethical festival clothing, and the variables that influence consumers' purchase decisions. The sale of environmentally and socially responsible t-shirts at Mariposa Folk Festival will allow attendees to actively demonstrate ethical purchasing behaviour. Simultaneously, festival organizers can gain a better understanding of consumer 
preferences and merchandising capabilities (Dodds et al., 2016). Understanding how much of a premium attendees will pay for socially and environmentally responsible t-shirts may also help to increase profits in future years, as well as contribute to Mariposa Folk Festivals' environmental commitment.

\subsection{Outline of Thesis Structure}

This thesis examines whether or not attendees of Mariposa Folk Festival will pay a premium for ethical festival t-shirts, as well as the variables that influenced their purchase decision. The first step towards accomplishing the research objectives was to conduct a review of the existing literature on the following topics, so to provide context for the current study and see where the study fits in with existing literature: the social and environmental impacts of the clothing industry, motivations and barriers to ethical purchase behaviour amongst consumers, theoretical and empirical means of measuring ethical consumption, marketing ethical clothing, and the use of festivals as a setting to explore environmentally responsible consumer behaviour. Following the literature review, the subsequent chapter outlines the methodological approach chosen to conduct this study. Next, the results chapter details all of the research findings and explains which of the four hypotheses were accepted or rejected. Afterwards, a chapter that discusses and reflects upon the significant findings will follow. This discussion chapter will also describe how the results of this study relate back to the existing literature. The final section of this dissertation will summarize the key themes of the study, draw conclusions, and consider the implications of the research. A schematic of the steps taken within the research process is outlined in research methods, section 3.2. 


\subsection{Literature Review}

\subsection{Introduction}

This research focuses on merchandising and the sale of ethical clothing at festivals. The following literature review starts by introducing consumption and its effects on the environment. Consumption is then further examined within the context of the clothing industry, and specific social and environmental issues surrounding the clothing industry are outlined. This includes review of the socio-environmental impacts associated with manufacturing various textiles. Cotton production is further examined, as this is the textile is relevant to the current study. Next, the concept of ethical consumption is introduced as a potential solution to alleviate some of the social and environmental pressures caused by excessive consumption. Both theoretical and empirical approaches to studying ethical consumption are considered. Review of theoretical approaches to studying ethical consumption help elucidate the complex process that determines consumers' purchasing behaviours. Research on the motivations and barriers to ethical consumption is reviewed. Empirical approaches to studying ethical consumption concentrate on the use of willingness to pay studies as a means of measuring consumers' social and environmental commitment. Willingness to pay is defined, and both indirect and direct approaches to studying consumers' willingness to pay are reviewed. Following this, literature on marketing and influencing consumers to purchase ethical clothing is reviewed; this includes promotional techniques and the use of particular venues to promote ethical consumption. One of the venues emphasized is festivals; as such the use of festivals as venues to encourage ethical consumption and pro-environmental behaviours is further explored. This includes information on Mariposa Folk Festival, the venue for the current 
study. This section will conclude by identifying knowledge gaps within the existing literature that the current study seeks to address.

\subsection{Consumption and Environmental Degradation}

Today's society is driven by consumption, the socio-economic phenomenon in which individuals consume goods and services for materialistic purposes that go beyond basic use-value (Kutucuoglu et al., 2013). Trentmann (2009) posits that consumption is becoming a prevalent lifestyle that defines and drives contemporary society. Over time consumption has moved away being a basic function to satisfy needs and become a structure that defines social status (Kutucuoglu et al., 2013). Global consumption has grown significantly over the twentieth century, with consumption expenditures reaching \$24 trillion (USD) in the year 2000, six times greater than in 1950 (United Nations Development Programme, 2001). Even over the past 15 years global gross domestic product (GDP) has increased by 55\%, with the global GDP in 2015 totalling $\$ 74$ trillion (USD) (The World Bank, 2016). Consumption has also been expedited by globalization, the process in which businesses and organizations operate on an international scale (Alden et al., 2006). Globalization pushes nations towards a global economy, and international transmission of media, lifestyles, and attitudes is blurring cultural borders (Alden et al., 2006).

Kilbourne and Pickett (2008) relate the centrality of consumption in the Western industrial lifestyle to the declining environmental condition of our planet. Increased consumption and demand for products and services has led to increased production resulting in increased resource consumption, environmental outputs, and accumulation of waste (Kilbourne and Beckmann, 1998; Carrier, 2007). Adrangi, Dhanda, and Hill (2004) examine the 
relationship between consumption and environmental degradation, using nations' percapita GDP to represent consumption behaviour and per-capita carbon dioxide emissions to represent environmental degradation. The researchers found a positive correlation between carbon dioxide $\left(\mathrm{CO}_{2}\right)$ emissions and GDP values across nations. This supports the common notion that the world's most dominant consumers are concentrated in developed, industrialized countries. Countries with the highest per capita GDP were also responsible for the highest level of carbon emissions. For example, the United States had the highest per capita GDP at $\$ 4,900$ (USD) as well as the highest levels of $\mathrm{CO}_{2}$ emission at 5,700 Mt $\mathrm{CO}_{2}$. Another interesting finding was that countries with lower GDP levels were producing emissions at a greater absolute rate than nations with higher GDP levels (Adrangi et al., 2004). Upon completion of this study, this projection was soon realized when China surpassed the USA in carbon emissions in 2005 , and has continued to grow at a near exponential rate (The World Bank, 2016). The increased growth rate in carbon emissions in developing countries relates back to globalization. Globalization allows businesses in developed countries to outsource the production of their goods to low-wage developing countries in order to reduce the manufacturing costs and produce goods more efficiently. Productions of goods are being outsourced to countries that do not have the resources necessary to effectively control emissions proportional to economic development (Adrangi et al., 2004; Alden et al., 2006; Trentmann, 2009). With consumption on the rise it is important to understand how the products and resources being consumed are produced, as well as the social and environmental impacts that are associated with said production. As the study at hand pertains to merchandising ethical clothing, consumption is further explored within the context of the clothing industry. 


\subsection{Clothing Consumption}

Clothing acquisition is a behaviour that most consumers engage in, which is validated by the clothing industry's substantial global market share. The clothing industry produces approximately \$3 trillion (USD) in global revenue, contributing significantly to global socioeconomic development (World Trade Organization, 2015). As was previously discussed, the highest levels of consumption are associated with highly developed, industrialized countries. This trend is reflected in clothing consumption (Table 1).

\section{Table 1}

Countries with the highest household clothing consumption expenditures, 2014.

\begin{tabular}{|c|c|}
\hline Country & Clothing Consumption Expenditure of Households (USD) \\
\hline USA & $385,705,000,000$ \\
\hline Japan & $94,112,336,487$ \\
\hline India & $80,651,829,654$ \\
\hline Germany & $77,741,085,320$ \\
\hline Italy & $64,305,089,797$ \\
\hline France & $47,493,093,703$ \\
\hline China (Hong Kong Region) & $35,788,903,225$ \\
\hline Canada & $33,287,562,553$ \\
\hline
\end{tabular}

(Source: United Nations Statistics Division, 2016)

According to the United Nations Statistics Division (2016) the USA possessed the highest clothing consumption expenditure of households, valued at approximately $\$ 385$ billion (USD) in 2014. Canada ranked eighth with approximately $\$ 33$ billion (USD) in household clothing expenditures; relative to Canada's population this is high, as Canada's population in 2014 was roughly nine times smaller than the USA (United Nations Statistics Division, 2016). Globalization has also changed the dynamics of the clothing market, as more companies opt to outsource production to low-cost manufacturing locations in developing countries, such as China and India. Producing clothing in developing countries such as 
these, allows companies to take advantage of reduced purchasing prices and lax labour laws and environmental regulations (Chen and Burns, 2006; Cepolina, 2012).

Trends towards outsourcing clothing production were expedited in 2005 when the World Trade Organization (WTO) passed the 'Agreement on Textiles and Clothing' (ATC), replacing the 'Multifibre Arrangement' (MFA), which restricted clothing imports and exports (Mair, Druckman, and Jackson, 2016). The MFA governed all trade and tariffs associated with the global clothing industry between 1974 and 2005, and placed quotas on clothing imports. From 1974 to 1994 the annual growth rate quota for clothing imports was six percent. The first phase of increase occurred in 1995, when the new net growth rate was increased by a factor of $16 \%$, this increased again by a factor of $25 \%$ in 1998 , and again by a factor of $27 \%$ in 2002 . All remaining quotas were eliminated in 2005 by the implementation of the ATC (WTO, 2015; Mair et al., 2016; Government of Canada, 2017).

Today 76\% all off North American clothing imports are from Asia, with China as the leading exporter (WTO, 2015). In 2014, China exported approximately $\$ 200$ billion USD of clothing products. This is significantly more than Italy and Bangladesh, the second and third largest clothing exporters, who each exported approximately $\$ 25$ billion USD of clothing products in the same year (WTO, 2015). In Canada the value of clothing made domestically has steadily decreased since 2011, while clothing imports have increased by $8.3 \%$ annually to \$9.5 billion USD in 2015 (Government of Canada, 2017). Ultimately globalization and increased clothing consumption has converged to produce 'fast fashion' movement, where cheap clothing is produced at increasingly lower prices to the point where a consumer can 
only wear a garment a couple of times before it is unwearable (Claudio, 2007; Niinimäki and Hassi, 2011; Ozdamar and Atik, 2015).

As clothing production grows and moves towards trends of outsourcing and fast fashion, it is important to address the social and environmental impacts of the clothing production process. Negative impacts of the clothing industry include the volume of clothing consumption, the use of pesticides and chemicals in the manufacturing process, poor or unfair working conditions for employees in manufacturing facilities, and the disposal of apparel (Cherrett et al., 2005; Chen and Burns, 2006; Birtwistle and Moore, 2007; Cepolina, 2012). These issues are discussed in further detail in the subsequent sub-sections.

\subsubsection{Environmental Issues Associated with the Clothing Industry}

As the clothing industry has such a large market share, it is important to address the resultant environmental impacts. In 2010, global textile consumption was estimated at 70 million tonnes per year, resulting in tremendous environmental costs throughout the production process (International Cotton Advisory Committee, 2013).

To date little research has been done on measuring the environmental outputs associated with clothing production. Cherrett et al. (2005), Chen and Burns (2006), and Cepolina (2012) are among the few studies that analyze the environmental impacts of producing various clothing textiles. Chen and Burns (2006) discuss that every textile, both natural and synthetic, produces some sort of adverse environmental impact, and state that all clothing textiles use chemicals in the dying process. For any textile product, pollution emissions can take place during fibre production (i.e. during agriculture or chemical synthesis), the dyeing and printing process, at home maintenance of the product, and disposal (Chen and 
Burns, 2006). In terms of highest rate of production, the most popular synthetic fabrics are polyester and nylon, and the most popular natural fabrics are cotton and wool. Both polyester and nylon are produced from the by-product of non-renewable petroleum resources, hence they are not biodegradable. Producing polyester and nylon requires energy-intensive processes that emit volatile organic compounds such as nitrous oxide, a chemical substance known to contribute to ozone layer depletion, as well as acid gases such as hydrogen chloride, known to cause respiratory illness in humans. Other chemicals and volatile substances are emitted in the wastewater from polyester manufacturing plants (Chen and Burns, 2006; Claudio, 2007).

Production of natural fibres is often thought of as the lesser of two evils, however there are also environmental impacts associated with these. Cotton is the most widely produced natural fibre, with approximately 22.4 million tonnes of cotton produced in 2015 (International Cotton Advisory Committee, 2015). The benefits of cotton are that it is a renewable cellulose fibre that is biodegradable, and requires minimal amounts of farmland; cotton accounts for only three percent of global farmland (Chen and Burns, 2006; Zhang et al. 2015). Unfortunately the environmental costs of cotton production outweigh the benefits. Conventional methods of cotton production can result in serious environmental impacts in regards to water use, land degradation, and pollution. For example, it takes approximately 20,000 litres of water to produce just one kilogram of cotton, which is equivalent to one t-shirt and one pair of pants (Zhang et al., 2015; WWF, 2016). Cotton also accounts for one quarter of global pesticides use, and often requires heavy metals and toxic chemicals in the printing and dying process that leach into the environment and produce serious health consequences for human workers (Chen and Burns, 2006; Goworek, 2011; 
Zhang et al., 2015; WWF, 2016). Zhang et al. (2015) examined the lifecycle of conventional cotton t-shirts produced in China and found that pesticides and water-use in cotton cultivation, dyeing, and at home washing and maintenance were the main stages in the lifecycle that yielded adverse environmental impacts (Figure 1).

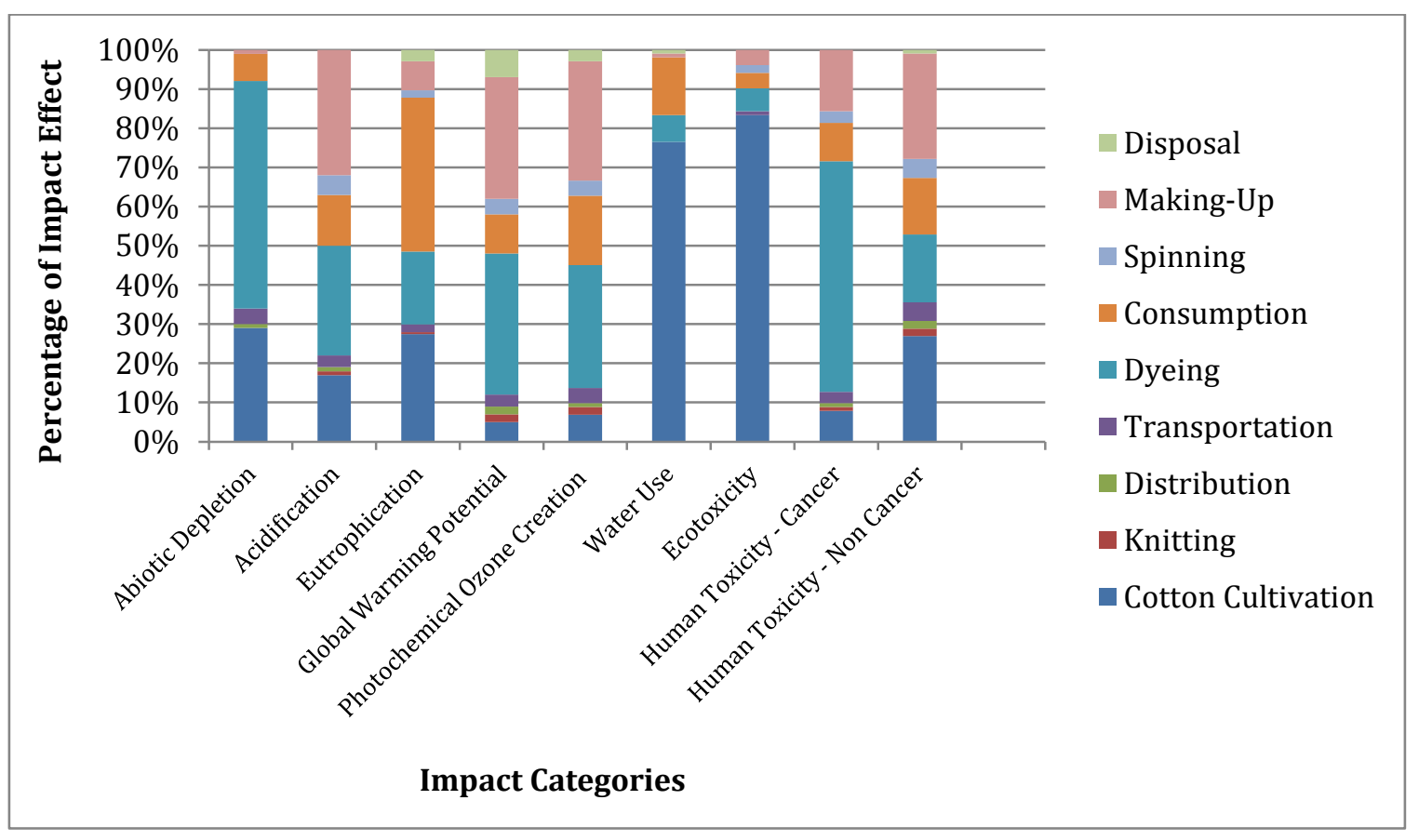

Figure 1: Relative environmental impacts associated with each stage in the lifecycle of cotton (Adapted from Zhang et al., 2015)

\subsubsection{Environmental Responsibility within the Clothing Industry}

One approach to alleviate some of the environmental pressure associated with cotton is by producing organic cotton over conventional cotton. Organic cotton farming may be a means of continuing the socio-economic development of this industry, while reducing negative environmental impacts. Certified organic cotton is defined as a process that is void of chemical fertilizers, pesticides, and genetically modified organisms (GMOs) (Ha-Brookshire and Norum, 2011). It should be noted however, that there is no reduction in water-use with 
organic cotton production. According to the Organic Trade Association (2015) the number of acres of organic cotton planted in the US has been growing on an upward trajectory since 2003. The number of acres planted increased by $6 \%$ from 2012 to 2013, and by $14 \%$ from 2013 to 2014 (OTA, 2015). These figures indicate that there is a growing market for this product, however organic cotton still only accounts for approximately $2 \%$ of global cotton production (Chen and Burns, 2006).

It should also be noted that there are other natural textiles options that are perhaps more environmentally sustainable than organic cotton. These include bamboo, hemp, and Tencel (®, all of which are made from less resource-intensive, renewable plant fibres. All three of these fibres are much less demanding in terms of land and water-use, and can be cultivated more efficiently (Cherrett et al., 2005; Chen and Burns, 2006; Waite, 2009). For example, Tencel $®$ is a fibre manufactured from wood pulp and harvested from trees grown specifically for this purpose (Chen and Burns, 2006). During the synthesis of the Tencel ${ }^{\circledR}$ polymer, the wood pulp is dissolved in a low-toxicity solvent where filaments are solidified. All the solvents used in the production of Tencel ${ }^{\circledR}$ filaments are then recovered and recycled for future use (Chen and Burns, 2006).

Regardless of the clothing textile being produced, perhaps the most important means of alleviating environmental pressures is to manufacture clothing using a 'slow design' approach (Niinimäki, and Hassi, 2011). Slow design is essentially the opposite of fast fashion, in which high quality garments are produced with textiles and designs aimed at prolonging the life of the clothing and ultimately resulting in high consumer satisfaction (Niinimäki and Hassi, 2011). Ozdamar and Atik (2015) emphasize three essential 
components of a slow design approach to clothing. The first is for companies to utilize local design and production, which includes local materials, resources, and skill. The second is to ensure a fully transparent production process between clothing retailers and consumers. This make certain that retailers place a greater emphasis on social and environmental responsibility and may also help to increase consumer knowledge of the production process and awareness of ethical clothing options. The third component is for clothing companies to create products that are high quality with greater longevity to prolong the lifecycle of the clothing and increase perceived value amongst consumers (Ozdamar and Atik, 2015). Information on slow fashion is valuable to study at hand, as it will aid the researcher in choosing the most suitable clothing products for the experiment.

\subsubsection{Social Issues Associated with the Clothing Industry}

Although some may argue that globalization has created a plethora of jobs for people in developing nations, the clothing industry employs 4.5 million people in China, the real issue to be addressed is the working conditions these employees must endure. Most developing countries have negligible labour laws that protect the well-being of workers in clothing manufacturing facilities (Cepolina, 2012). Some clothing companies that have received significant negative attention from the media regarding their labour practices include Nike, H\&M, The Gap, La Senza, Gildan ${ }^{\circledR}$, and Walmart (i.e. the world's largest retailer) (Dickson, 2001; Cheek and Moore, 2003; Donaldson, 2015). Controversies surrounding these companies and sweatshops in general pertain to violations against fair wages, health and safety, and child labour (Cheek and Moore, 2003). 
According to the International Labour Organization (2014) the minimum monthly wage in China for workers in the clothing industry is $\$ 650$ USD per month, however average number of hours worked per day, week, or month are not supplied. Despite this, some speculate that Chinese workers at clothing manufacturing facilities make as little as 18 cents (USD) per hour (Claudio, 2007). Monthly minimum wages are even lower in other developing countries. Garment workers in India, Bangladesh, Cambodia, and Vietnam earn less than $\$ 100$ USD per month (ILO, 2014). Many of these clothing manufacturing facilities have come to be referred to as sweatshops, characterized by long hours, low wages, and poor working conditions (Dickson, 2001).

Globalization and outsourcing also propagates inequity and unequal distribution of wealth among nations, by demanding increasingly lower production costs. Over the past two decades inequality has risen within and between most countries, and growth in consumption has been unequally distributed (Alsamawi et al., 2014). The United Nations 2013 report on global inequality stated that high income nations, representing only $16 \%$ of the global population, account for the vast majority of global consumption expenditures. Conversely, low income nations, representing $72 \%$ of the global population, account for just $1 \%$ of global consumption expenditures (United Nations, 2013).

\subsubsection{Social Responsibility within the Clothing Industry}

Over the past two decades government officials, labour boards, media personnel, and consumer activists have directed much attention to sweatshops and the unfair treatment of workers in these facilities (Dickson, 2001). This increased attention has put pressure on clothing manufacturers to develop better standards of working conditions and better 
monitor their facilities. Even with the increased pressure for companies to be more socially responsible, there is some disagreement about what constitutes appropriate working conditions in foreign countries and much work to be done still before sweatshops are completely abolished (Dickson, 2001).

One way retailers are engaging in corporate social responsibility is by manufacturing clothing products that are 'sweatshop free' or fair trade, and labelling them as such (Cheek and Moore, 2003). Fair trade products can be defined as items produced under a trading partnership that is based on transparency, equal opportunity, and greater equity in international trade (Jones and Williams, 2012). Social labels can help consumers identify products that are made by more socially responsible means than conventional alternatives (Dickson, 2001; Cheek and Moore, 2003). Depending on where a garment was produced, country of origin labels can also act as a social label if that country has a stringent set of labour laws and employment standards (i.e. Made in Canada). Clothing companies can also increase their social responsibility by partnering with ethical NGOs and foundations, and by being transparent with how their clothing is produced.

On a consumer level, the clothing industry can be made more socially and environmentally responsible through ethical consumption and increased consumer demands for ethical clothing and products. Dickson (2001) analyzed whether consumers making clothing purchases would be influenced by 'no sweat' labels by surveying 547 American consumers. The researcher found that only a small percentage (16\%) of respondents were influenced by the 'no sweat' label, but these respondents held a much stronger support for socially responsible businesses than their counterparts. The remaining majority of respondents 
indicated that quality, colour, and price were of more importance to them when making clothing purchases than the 'no sweat' label (Dickson, 2001). It is evident that clothing acquisition is a complex process and consumers' decisions are influenced by multiple variables. Research into theoretical approaches to ethical consumption is necessary to gain a better understanding of the decision-making process that drives consumers towards ethical consumption and ethical clothing acquisition.

\subsection{Theoretical Approaches to Ethical Consumption}

As was seen in Dickson's (2001) research, acquisition of ethical products and clothing in particular, is an extremely complex process affected by multiple motivations and barriers. Understanding the decision making process of consumers requires review of the theoretical approaches to ethical consumption that analyze different motivators and cognitive behavioural processes that underline the decision making process.

Amongst the relevant literature, there are two prominent theories that seek to explain the motivations behind engaging in environmentally responsible behaviours (ERBs) and ethical consumption: self-determination theory (SDT) and value-belief-norm theory (VBNT). Both of these theories help explain the social and psychological context behind environmental attitudes, ERBs, and in turn ethical consumption. Deci and Ryan (1985), Pelletier et al. (1998), Obaldiston and Sheldon (2003), and Ku and Zaroff (2014) are all theory-based studies that examine the pathway to ERBs and ethical consumption by means of using SDT. Stern et al. (1999), Kilbourne and Pickett (2008), and Fischer and Dam (2015) are all theory-based studies that examine the pathway to ERBs and ethical consumption through VBNT. 


\subsubsection{Self-determination Theory and Ethical Consumption}

The theory of self-determination was first put forth by Deci and Ryan in 1985, and defined as a means of examining one's innate psychological needs in regards to the internal motivation behind the choices they make (Deci and Ryan, 1985). In SDT, external motivations such as incentives or punishments (e.g. money, status, and validation from peers) are not considered effective mechanisms for instilling permanent behavioural changes. The reason external motivations are ineffective is because they are not permanent. Rewards and punishments are temporary, therefore the subsequent behaviour is also temporary (Pelletier et al., 1998; Obaldiston and Sheldon, 2003). Conversely, intrinsic motivations drives behaviour through internal values and rewards (e.g. feeling good about one's self), are considered to be more effective mechanisms that produce permanent behavioural changes (Deci and Ryan, 1985; Pelletier et al., 1998; Obaldiston and Sheldon, 2003). Thus, SDT examines the internal variables that motivate an individuals' decision, without external influence and interference.

One of the earliest studies that examined SDT and ethical behaviours was conducted by Pelletier et al. (1998). The research assessed motivations behind various environmental behaviours by means of distributing written surveys to 310 university students. Respondents answered based on a seven point Likert scale, and the results were found to support SDT, in that positive intrinsic variables (e.g. self-esteem) were positively correlated with the prolonged engagement in ERBs. Moreover, environmental attitudes, perceived environmental competence, and perceived importance of environmental issues were also positively correlated to self-determined, intrinsic motivations (Pelletier et al., 1998). 
Osbaldiston and Sheldon (2003) also used SDT as a means of examining motivations that result in permanent ERBs. The researchers employed a qualitative research method by means of conducting semi-structured interviews with 162 participants in the USA. The researchers questioned participants on their environmental values, goals, and behaviours. Participants were then asked to go home and record which of the listed pro-environmental behaviours they engaged in. To measure perceived autonomy of their ERB goals Osbaldiston and Sheldon (2003) had to ensure participants' motivations were intrinsic. Thus an 'internalized motivation' score was formed by subtracting the extrinsic responses from the intrinsic responses, a five point Likert scale was then used to measure success of goal performance and future intentions. Similarly to Pelletier et al. (1998), the results of this study supported the assumptions of SDT, that intrinsic (self-determined) motivation can promote sustained pro-environmental behaviours. The results of this study also provide evidence that perceived supportiveness, internalized motivation, goal performance, and future intentions are all positively correlated (Osbaldiston and Sheldon 2003).

One of the most recent studies on SDT was conducted by Ku and Zaroff in 2014. The researchers surveyed 169 university students and 347 adults of Chinese ethnicity to assess whether individuals who placed greater importance on intrinsic values opposed to extrinsic values, engaged in more self-reported pro-environmental behaviours. The results of this study are reflective of all previous SDT research, demonstrating that the assumptions of SDT are correct. One interesting finding was that 'material re-use and recycling' was found to be a much more prevalent ERB compared to 'purchasing ethical products', the latter was only reported amongst participants with higher socioeconomic 
status. Interestingly, while intrinsic values proved to be an indicator or ERBs, general environmental attitudes were not. This finding suggests that further research into the motivations behind ethical consumption is necessary. Another interesting finding was evidence of an attitude-behaviour gap, where pro-environmental attitudes are not reflected in consumer behaviours. Positive attitudes about the environment were observed in roughly $70 \%$ of participants, but only a fraction of these individuals reported to engage in ERBs (Ku and Zaroff, 2014).

\subsubsection{Value-Belief-Norm Theory and Ethical Consumption}

The second theoretical approach to ERBs and ethical consumption is VBNT, first coined by Paul Stern and colleagues in 1999. VBNT is defined as a psychological theory that examines the process that drives social movements in the form of environmental activism, environmental citizenship, policy support, and personal ethical behaviors (Stern et al., 1999). The proposed pathway to ERBs starts with an individual's personal values, whether altruistic or egotistic. Altruism is the act of valuing the welfare of others above one's self, where egoism is the inverse of this concept (Kilbourne and Pickett, 2008; Fischer and Dam, 2015). Based on one's personal values, individuals can process the potential consequences of their behaviour and their ascription of responsibility to behave in a certain way. During ascription of responsibility, societal norms play a role in influencing an individuals' decision to engage in an ERB (Figure 2). 


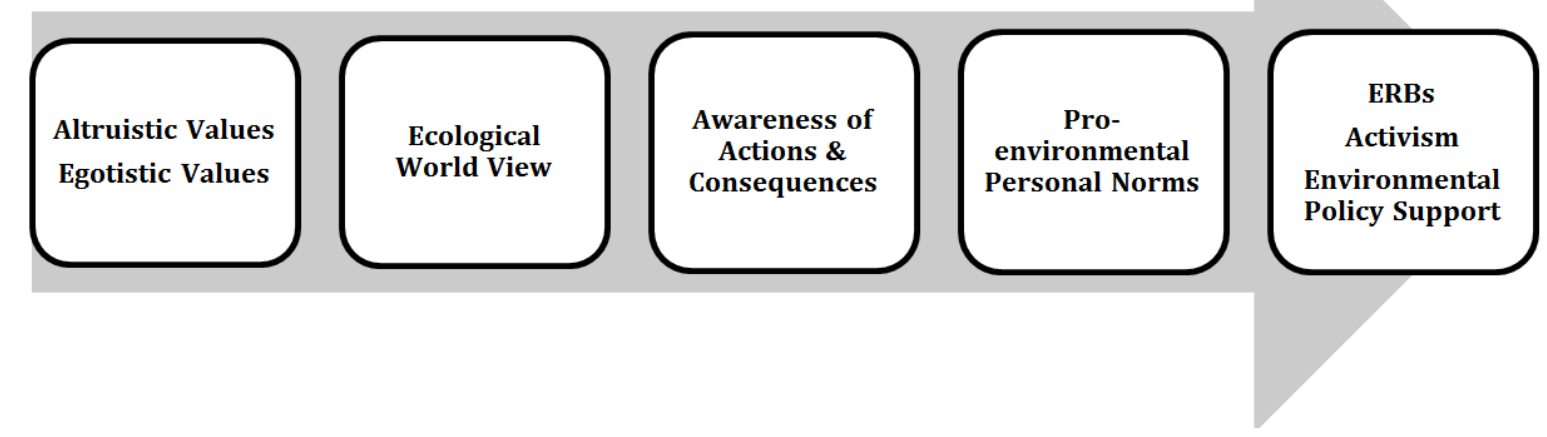

Figure 2: Schematic model of the value-belief-norm theory (Adapted from Stern et al., 1999).

VBNT can also be described as the ways in which individuals perceive and interpret the world and the actions of others (Fischer and Dam, 2015). While SDT looks only at intrinsic motivations behind actions, VBNT analyzes both intrinsic and extrinsic motivations. VBNT posits that consumers' ethical behaviours can be driven by societal norms (i.e. one's sense of obligation to behave in accordance with societal beliefs). As ethical consumption is an incredibly complex social dilemma that involves a multitude of motivations and influences, studies of VBNT often employ construal level theory (i.e. how the psychological distance of objects and events influences individuals' thoughts and behaviours). In this regards lowlevel construal is represented by near events and concrete details, while high-level construal is represented in abstract by distant events (Fischer and Dam, 2015). VBNT and construal levels are used help to explain the social context underlying conflicts between pro-environmental attitudes and actions.

Stern et al. (1999) conducted a national telephone survey of 420 American respondents to examine how altruistic and egoistic values lead to the four resulting social movements put forth in Figure 2. In accordance with the research on SDT, the results of this study indicated 
that each of these dependent variables (the four social movements/ outcomes) was directly affected by altruistic values, as was expected, while the other value types provided no direct correlation with the social movements. The results also provide evidence that social variables and value-norms affect the ways in which ethical behaviours are expressed. In particular, environmental citizenship behavior was significantly influenced by one's beliefs about how society should be organized, reflective of an individual's access to resources (e.g. household income).

Kilbourne and Pickett (2008) used VBNT to measure the relationship between an individual's environmental values, attitudes, and concerns against their behaviours. The researchers surveyed 303 respondents in the USA on their general environmental values, attitudes, concerns, and behaviours to assess the potential motives behind ethical consumption. The results of this study indicated that high materialistic, or extrinsic, values were negatively correlated with strong environmental values. Conversely, strong environmental values were positively correlated with ERBs and ethical consumption. Unlike Ku and Zaroff (2014) who found evidence an attitude-behaviour gap, this study found that the entire pathway from environmental values to behaviours were all positively linked (Kilbourne and Pickett, 2008).

Recent studies also reflect previous findings surrounding VBNT research. Similarly to Kilbourne and Pickett (2008), Fischer and Dam (2015) applied the concepts of VBNT to examine the pathway to ethical consumption by means of distributing an online survey to 229 in the Netherlands. Participants were asked to choose between ethical and non-ethical clothing products, and seven point Likert scales measured respondents' environmental 
values, motives, and identities. The results of this research demonstrated that environmental identify and values take ethical consumption to a low construal level, or a near psychological distance. The low construal level allows consumers to more easily identify with and carry out a given behaviour, and in turn rewards one's self-esteem. The results confirm that ethical consumer identities and intrinsic motives are activated by social dilemmas, and indicated that the strength of intrinsic motivation is positively correlated with the strength of the ethical consumer identity regardless of price of the clothing. A different effect was seen when ethical consumption was driven by extrinsic motives; the strength of motivation was still positively correlated with the strength of the ethical consumer identity, but only when the individual was not faced with a price premium on the ethical clothing (Fischer and Dam, 2015). The researchers also found that while intrinsic values resulted in ethical consumption.

All of the research on theoretical approaches to ethical consumption demonstrate that intrinsic values are the most powerful and substantial motivators that drive ethical consumption and other ERBs (Deci and Ryan, 1985; Pelletier et al., 1998; Stern et al., 1999; Obaldiston and Sheldon, 2003; Kilbourne and Pickett, 2008; Ku and Zaroff, 2014; Fischer and Dam, 2015). While intrinsic values consistently determined ethical behaviours, proenvironmental concerns and attitudes did not (Ku and Zaroff, 2014). This suggests that further research that examines the existence of an attitude-behaviour gap is required to better understand the conceptual pathway that leads to ethical consumption. While theoretical approaches for examining the pathway that leads to consumers' decisions, they are only the first step in studying ERBs and ethical consumption. Empirical studies help 
build on theories such as SDT and VBNT by observing and measuring consumer behaviours and tendencies towards ethical consumption.

\subsection{Willingness to Pay for Ethical Products}

In addition to the theoretical methods previously discussed, a common empirical approach to examining ethical consumption is willingness to pay (WTP) studies. WTP can be defined as the maximum amount a consumer will spend to procure an ethical good or service, or to avoid an undesirable outcome (Arnot, Boxall, and Cash, 2006). These studies place monetary values on non-market goods and services, such as protecting the environment (Andorfer and Liebe 2012).

There are both indirect and direct approaches used to measure WTP for environmental products. Indirect approaches include open-ended questions and contingent valuation, in which individuals self-report their hypothetical WTP for a particular environmental product or service (Arnot, Boxall, and Cash 2006; Hustvedt and Bernard, 2010). The downside to using an indirect approach is that consumers' state a hypothetical WTP that may not necessarily be reflective of their behaviour in actuality. This tendency is referred to as hypothetical bias, and results in consumers' overstating their WTP due to a lack of real incentive (Michaud and Llerena, 2011).

Conversely the Becker, DeGroot, Marschak (BDM) method was developed in 1964 and has since been a widely used direct approach to measure WTP (Arnot, Boxall, and Cash, 2006). The BDM method requires participants to formulate a bid on a product put up for auction. The participants bids are then compared with a bid from a known distribution or determined by s random number generator, if the participant's bid, or stated WTP, is equal 
to or greater than the generated value than the participant must pay their bid price and actually purchase the item (Becker, Degroot, Marschak, 1964; Wertenbroch and Skiera, 2002; Michaud and Llerena, 2011). Incorporating actual economic incentives participants may help to generate better results and overcome hypothetical bias. Still WTP studies that use the BDM method may not always be accurate because in some cases an individuals' WTP within a controlled study may differ from their purchase behaviour in actuality (Wertenbroch and Skiera, 2002; Michaud and Llerena, 2011).

\subsubsection{Indirect Approaches to Measure Willingness to Pay}

There are many studies that use an indirect approach to examine WTP, but upon review of the relevant literature only three WTP were found to measure consumers' WTP within the context of ethical clothing products: Ha-Brookshire and Norum (2011), Ellis et al. (2012), and Dodds et al. (2016). These studies used contingent valuation to survey individuals on their WTP for t-shirts that varied in regards to social and environmental responsibility.

Ha-Brookshire and Norum (2011) assessed respondents' WTP for three different types of tshirts; organic cotton, sustainable cotton, and shirts grown locally in the USA. The researchers differentiated between organic and sustainable cotton by clearly defining each. The researchers define organic cotton farming as a process that is void of chemical fertilizers, pesticides, and genetically modified organisms (GMOs). Sustainable cotton farming is defined as a process that reduces the use of water, energy, and pesticides compared to conventional farming practices. Sustainable cotton farming may or may not use genetically modified cotton seeds (Ha-Brookshire and Norum, 2011). The researchers used random-dialing to survey 500 consumers in the USA and found that more than half of the respondents were willing to pay a premium for each of the three types of $t$-shirts, over 
the conventional cotton one; $57.0 \%$ of respondents were willing to pay more for a cotton shirt grown locally, 55.1\% were willing to pay a premium for organic cotton, and $54.9 \%$ were willing to pay for sustainable cotton (Ha-Brookshire and Norum, 2011). The researchers also found that contradictory to their assumptions, there was a negative correlation between respondents' environmental attitudes and their WTP. The researchers infer that this may have occurred in part from consumers who are very concerned for the environment and wish to engage in very minimal amounts of clothing acquisition in general (Ha-Brookshire and Norum, 2011).

Similarly, Ellis et al. (2012) measured consumers' WTP for organic versus conventional cotton t-shirts by means of surveying 128 consumers in Washington, USA. Respondents reported they were willing to pay a $25 \%$ premium for the organic cotton $\mathrm{t}$-shirts compared to the conventional t-shirts of the same design. The average price participants were willing to pay for conventional and organic cotton t-shirts were \$11.09 and \$14.21 USD, respectively. Other factors that were seen to influence WTP and consumer purchasing behaviour included product quality, previous history of buying organic products, and fit (Ellis et al., 2012). It should be noted that a potential limitation of this study is that the researchers only surveyed university students, meaning that the entire sample were similar in age and financial status which may have biased the results.

Dodds et al. (2016) is the first study to examine WTP for ethical clothing within a festival setting. The researchers used quantitative sampling methods by means of surveying 427 attendees at the 2015 Mariposa Folk Festival in Orillia, Canada. The survey was administered via iPad, allowing the researchers to help guide the participants through the 
questions so there would be no misinterpretation. Respondents were presented with four fictitious festival t-shirts that varied in terms of fair trade certification and printed environmental messages, and asked how much they would be willing to pay for each; with a maximum value of $\$ 40.00$ CAN (Dodds et al., 2016). The survey also asked questions regarding respondents' general environmental attitudes, concerns, and behaviours. Results of this study indicated that respondents were willing to pay the most (\$16.59 CAN) for the festival t-shirt that possessed both the environmental message and the fair-trade certification. The lowest reported WTP ( $\$ 11.89$ CAN) was for the festival t-shirt with no environmental message or fair trade certification. There was a positive correlation between the level of importance placed on purchasing environmentally friendly products and WTP for a festival t-shirts that possessed an environmental message. Researchers also found a positive correlation between self-reported level of environmental awareness and WTP for festival t-shirts that possessed a fair trade certification (Dodds et al., 2016).

Consistent across all studies is that consumers indicated a willingness to pay a premium for ethical t-shirts over conventional cotton t-shirts (Ha-Brookshire and Norum, 2011; Ellis et al., 2012; Dodds et al., 2016). There is also some discrepancy regarding the connection between environmental awareness and attitudes and WTP for ethical clothing, suggesting that further research into this topic is necessary.

\subsubsection{Direct Approaches to Measure Willingness to Pay}

Didier and Lucie (2008) and Hustvedt and Bernard (2010) were two studies that used the direct approach of the BDM method to assess consumers' WTP for ethical products. While Didier and Lucie (2008), did not assess WTP within the context of clothing consumption, they did examine fair trade and organic products which is still relatable to ethical 
consumption and the study at hand. Didier and Lucie (2008) asked 102 European consumers to place anonymous bids on four different chocolate products that varied in terms of fair trade and organic certification and taste. The results indicated that participants were willing to pay more for both the certified organic and fair trade chocolate over the conventional chocolate, and willing to pay slightly more for the fair trade chocolate over the organic chocolate. The researchers also surveyed participants on their values and motivations for paying more for one product over another. In this respect, this study also ties back to the theoretical concept of VBNT. Didier and Lucie (2008) found evidence to suggest that some individuals purchase organic foods because of egocentric values (e.g. personal health and pleasure), while all individuals who were willing to pay a premium for fair trade chocolate did so based on altruistic values (i.e. primary concerns are the wellbeing of workers in developing countries associated with the product). This helps clarify why more consumers were willing to pay a higher premium for fair trade chocolate compared to organic (Didier and Lucie, 2008).

Hustvedt and Bernard (2010) used three rounds of BDM auctions to assess WTP for socially responsible clothing amongst 120 students in the USA. Five t-shirts from three brands were put up for bid that differed in regards to brand, social labels, and availability of information on the conditions of the company's manufacturing facility. For the first round, participants were presented with and allowed to examine five different shirts, but were given no label or brand information. The first round of bids represented WTP in the absence of any knowledge regarding the ethical attributes of the shirts. In the second round the five shirts were presented in random order with different label treatments that ranged from providing ambiguous to explicit information about the company's social responsibility. The final 
round of auctions provided both brand name and information about the company's manufacturing facilities and social responsibility. The results demonstrated that positive attitudes towards social responsibility and fair trade were positively correlated with the amount of money participants were willing to pay for labelled products. While brand was seen to be a significant motivation to purchase, consumers were willing to pay more for apparel that possessed labels detailing the manufacturing facility conditions and the social responsibility of the company. Hustvedt and Bernard (2010) observed WTP and purchase behaviour within a laboratory setting which allowed the researchers to control the variables and potentially collect more data, but the lack of realism limited the results. Most WTP research examines consumers WTP for environmentally responsible products in hypothetical or controlled situations. Only two studies were found that assessed WTP by examining actual purchase behaviour (Andorfer and Liebe, 2015; Reynolds et al., 2015).

\subsubsection{Measuring Actual Purchase Behaviour in WTP Studies}

It is important to note that while both of the studies assess consumption of ethical products by examining actual purchase behaviour, neither of the studies pertain to ethical clothing purchases. To date no studies have examined actual purchase behaviour in the context of ethical clothing consumption. Andorfer and Liebe (2015) examined consumers' actual WTP for certified organic and fair trade coffee by conducting a field experiment at a supermarket in Hanover, Germany. The researchers assessed consumers' actual purchase behaviours by selling six different coffee products that differed in terms of price, ethical certification, and available information on the fair trade and organic products. Comparable to Didier and Lucie (2008), they found that consumers paid more for fair trade coffee over organic coffee. The researchers also found that price reduction of the certified fair trade and organic 
products significantly increased purchases, while providing additional information on the certified products did not.

Reynolds et al. (2015) examined the relationship between self-reported WTP and actual purchase behaviour in regards to compact fluorescent light bulbs (CFLs). They surveyed 535 respondents, on the island of Saint Lucia, on their environmental concerns and WTP for CFLs. Upon completion of the survey respondents were then offered a chance to purchase said CFLs at a discounted rate, well below the average self-reported WTP. The researchers found that while $94 \%$ of respondents reported they were willing to pay a premium for a high quality CFL, only one-third of the consumers actually purchased the product. The disconnect between hypothetical WTP and actual purchase behaviour that was found in this study is analogous to the attitude-behaviour gap found in previous studies (Reynolds et al., 2015).

Review of WTP studies illuminated a research gap in regards to examining WTP versus actual purchase behaviour, and actual purchase behaviour in regards to ethical clothing purchases. This provides opportunity for the current study to further examine these topics.

\subsection{Influencing Willingness to Pay by Promoting Ethical Consumption}

Much of the existing literature on ethical consumption and WTP for ethical clothing indicates that marketing, labelling, and branding all play an important role in determining whether a product has perceived value to consumers' and if said consumers are in turn willing to pay for it (Yan et al., 2012; Ellis et al., 2012). Before exploring how marketing treatments such as these influence the clothing selection and acquisition process, it is important to first review any research that elucidates some of the main barriers to ethical 
clothing consumption. This way the current study can more effectively utilize marketing techniques to help overcome any applicable barriers. Joergens (2006), Hiller-Connell (2010), Ozdamar and Atik (2015) and Lundblad and Davies (2015) all provide research into the barriers to ethical clothing acquisition. Yan et al. (2012) and Pickett-Baker and Ozaki (2008) both investigate how branding and clothing messages influence ethical clothing purchases.

\subsubsection{Barriers to Ethical Clothing Consumption}

To determine effective marketing strategies for ethical clothing, one must first assess the potential merchandising barriers. Joergens (2006) conducted in-depth interviews with two focus groups, one in England and one in Germany, with a total of nine subjects to assess motivations and barriers to ethical clothing consumption. The results indicated that ethical issues have minimal effect on consumers' clothing purchases, while the main motivators were cost, personal needs, and aesthetics. The participants revealed that though they were aware of the social issues surrounding clothing production, it was not their main priority when purchasing clothing. Environmental issues surrounding clothing production were of even less interest to participants. All participants stated they would buy clothing made by an unethical retailer if they liked the style and design. Some participants noted that they purchase organic foods because they directly affect their health, while they do not purchase ethical clothing because clothing made from organic or sustainable materials does not (Joergens, 2006). This research highlights style and aesthetics, rather than lack of information, is the main barrier to ethical clothing consumption. This indicates that more mainstream ethical clothing options and modern aesthetics are required to push consumers towards ethical clothing. 
Contrary to Joergens (2006) research, Hiller-Connell (2010) interviewed ten participants in the USA and found that lack of available information and awareness regarding clothing production issues was a main barrier to ethical clothing consumption. She noted that consumers had many misconceptions about the environmental impacts of clothing textile production. For example, several participants stated they bought conventional cotton products over polyester because it is a natural fibre with little environmental impacts. In accordance with Joergens (2006) the researcher also found significant barriers to be financial constraints and a general perception that ethical clothing was less stylish than mainstream clothing.

Lundblad and Davies (2015) interviewed 39 individuals who frequently purchased ethical clothing and found that the main barriers to ethical consumption were lack of available styles and designs and the existence of price premiums on ethical clothing. This finding supports the results of Joergens (2006) and Hiller-Connel (2010), and demonstrates that consumers' tend to perceive ethical clothing as less stylish regardless of the time period. One interesting finding from Lundblad and Davies (2015) was that participants felt ethical clothing products were of higher quality than conventional alternatives. This finding has strong marketing implications as retailers can strategically promote the quality and longevity of their products to increase the purchase of ethical clothing.

Ozdamar and Atik (2015) also researched barriers and marketing strategies for ethical clothing consumption. The researchers divided their finding into two categories; macrooriented barriers and micro-oriented barriers. Macro-barriers focus on the large scale systems at work, while micro-barriers focus on personal obstacles at the consumer level. 
Two main macro-oriented barriers were identified. The first was the predominant economic system that emphasizes growth, development, and a global market. The second macro-barrier was the lack of adequate public policies in most nations to help regulate the availability, quality, and affordability of ethical products. The following four main microbarriers were identified: lack of consumer awareness amongst consumers, aesthetics and perception that ethical clothing is unattractive, the existence of an attitude-behaviour gap, and ambiguous or misleading labels that can cause confusion or mistrust amongst consumers (Ozdamar and Atik, 2015). Ambiguous labelling is also commonly referred to as 'greenwashing'. Dahl (2010) defines greenwashing as the practice of retailers making untrue or exaggerated claims regarding the sustainability or environmental responsibility of their products in an attempt to gain market share. Ozdamar and Atik (2015) also identified the following strategies as effective means of marketing ethical clothing: retailers partnering with powerful institutional actors or well-known ethical organizations, publicizing innovations in ethical clothing production, and transparent labelling and marketing schemes. This research indicates that perhaps more explicit labelling and advertising is necessary to incite consumer awareness and support.

\subsubsection{Marketing Ethical Clothing}

Yan et al. (2012) investigated the influence of message explicitness and brand name on consumer attitudes towards ethical clothing. The researchers used a quantitative survey to collect responses from 343 university students in Colorado, USA. Likert scales were used to assess consumers' environmental attitude and motivation behind clothing preferences. Participants were also presented with images of different shirts that varied in regards to message explicitness, branding, and advertising techniques. Results revealed that when the 
advertising message contained explicit information about the environmental benefits of a product, respondents formed positive attitudes toward the associated clothing brand. Message explicitness, however, did not positively influence consumer attitudes in regards to advertisements. This result may be explained by the notion that clothing advertisements are meant to be concise and eye-catching; inclusion of too much information in a limited space can cause disinterest amongst consumers (Yan et al., 2012). This finding corresponds with to other studies that imply implicit or simple advertising messages are more effective for influencing purchasing behaviour (Didier and Lucie, 2008). Furthermore, consumer attitudes towards environmental commitment, brand, advertisement, and environmental involvement of the clothing manufacturer were all significant predictors of intention to purchase from an ethical apparel brand. This study has practical applications for marketers, as it demonstrates that clothing companies can influence more positive attitudes toward brands by providing explicit information about the socially and environmentally responsible aspects of their products within their marketing claims (Yan et al., 2102).

Pickett-Baker and Ozaki (2008) also examined whether marketing and branding techniques can help establish more environmentally responsible clothing acquisition by surveying 52 individuals at retail stores in London, England. Consumers were asked three sets of questions on their general environmental concerns, their past environmental behaviours, and their attitudes towards purchasing ethical products. The results demonstrated that there is a positive correlation between consumers' environmental concerns and their confidence in the quality of ethical clothing products. This finding contradicts the attitude-behaviour gap found in previous research on ethical consumption 
(Ku and Zaroff, 2014; Reynolds, 2015; Ozdamar and Atik, 2015). Similarly to Yan et al. (2012), respondents stated that they were more likely to choose brands that were the most well-known and reputable for manufacturing ethical clothing. Respondents also replied positively to feeling good about buying brands which are less damaging to the environment. This finding relates back to the assumptions of SDT, in which intrinsic motivations lead to ERBs. However, consumers indicated that a barrier to purchasing ethical clothing was that could not identify which retailers carried ethical clothing and whether or not they were legitimate. Participants also stated that current marketing strategies for ethical clothing were irrelevant to their lifestyle and unengaging (PickettBaker and Ozaki, 2008). This implies that ethical clothing companies are currently inadequate in marketing and advertising their products in a way that engages consumers. Overall, further research into environmental branding, messaging, and advertising is required to determine the most effective means of engaging consumers.

While this review assessed various marketing and branding strategies and barriers to ethical clothing consumption, it is also important to consider how a venue may be used to promote ethical clothing and influence consumers' purchase decisions. While there is no research to date that explores the relationship between a venue and ethical clothing consumption, research examining the use of venues to promote ERBs in general does exist. All of the research on this topic explores how festivals and environmentally-linked events can be used to encourage ethical consumer behaviours.

\subsection{Using Festivals as Venues to Promote Ethical Consumption}

Although all of the research to date that examines the relationship between festivals and ERBs does not specifically pertain to ethical clothing consumption, research on this topic is 
still useful to the current study as techniques used to encourage ERBs may be applicable to encouraging ethical clothing consumption. Exploration of festivals as venues to promote ethical behaviour also provides further background and context for the current study.

Festivals can be defined as any event that promotes interrelated activities in one geographical area to stimulate the local economy (O’Sullivan \& Jackson, 2002). By that definition the potential socio-economic benefits of festivals is evident, however it is important to address the environmental implications of running a festival. Without sufficient environmental management festivals have the potential to cause numerous adverse environmental effects. If left unchecked, festivals can produce enormous carbon footprints by means of energy consumption, carbon emissions, water usage, noise pollution, waste production, waste water production, land degradation, vehicle traffic, etc. (Laing and Frost, 2010; Mair and Laing, 2013). According to the United Nations World Tourism Organization (UNWTO), the global tourism industry contributes to roughly five percent of carbon emissions. Only in the last five years has events literature begun to address the relationship between festivals and the environment. As environmental concerns increase and festivals continue to grow in popularity this topic will become a more prominent research topic.

Dodds and Graci (2012) conducted field research between 2008 and 2011 at Pride Festival in Toronto, Canada to examine the potential barriers to environmental sustainability. Pride Festival set goals in 2008 to become environmentally sustainable festival through achieving zero waste and becoming carbon neutral. Despite setting these goals the festival remained unsuccessful in its efforts. By means of performing annual carbon and waste audits and measuring festival environmental goals against its actual performance, Dodds 
and Graci (2012) directly observed the obstacles that impeded Pride Festival from achieving its greening goals. The researchers observed the following barriers to reaching Pride Festival's environmental goals: lack of communication, lack of understanding about sustainability, goal prioritization, corporate culture and values, and politics. Moreover, the researchers felt that even though the festival staff were consulted and excited about the environmental initiatives, the festival organizers did not make these a priority. This may be partially explained by the fact that environmental goals were initially proposed by an external government agency and not by the festival organizers themselves (Dodds \& Graci, 2012). This finding relates to theoretical research on SDT, VBNT, and ethical behaviours, as it demonstrates that intrinsic motivations more often determine ERBs on an institutional level as well as a personal level.

Recent studies have also begun to evaluate the environmental impacts of festivals by measuring their ecological footprint. Collins and Cooper (2017) used the Footprint Reporter $^{\mathrm{TM}}$ software to measure the outputs of the 2012 Hay Festival in the United Kingdom. The researchers evaluated the environmental outputs associated with travel to and from the festival, energy use, and food and drink consumption, and found that the festival's overall footprint was 3,300 global hectares (gha) or 0.011 gha per attendee over the eleven day festival. The researchers also found that travel to and from the festival produced the greatest impacts, at 2000 gha. It is important to note that the duration of the festival and its proximity to urban areas play an important role in the size of a festivals' carbon footprint, and these variables must be considered when comparing the environmental impacts of one festival with another. This study also discusses some developments towards more environmentally sustainable festivals that have taken place in 
recent years. This includes the International Organization for Standardization's (ISO) guide to sustainable event management (i.e. ISO 20121 series), which includes economic, social, and environmental considerations (Collins and Cooper, 2017). There has also been an increasing amount of non-government organizations (NGOs) aimed at providing festival organizers with best practice environmental management strategies.

Adding an environmental focus to an event is not only important for minimizing the environmental impacts of a festival, but also for encouraging ethical behaviour and spreading environmental awareness (Laing \& Frost, 2010; Laing \& Mair, 2012). Festivals provide a unique setting for researchers to explore ethical consumer behaviour, as they can act as a platform to communicate messages of environmental responsibility to large groups of individuals simultaneously.

Mair and Laing (2013) demonstrate that festivals with an environmental focus can actually encourage pro-environmental behaviours in individuals, and do so using the case study of Nelson Ecofest in Australia. The Ecofest is a community event in which the primary focus and central theme is environmental sustainability, meaning all of the vendors are either selling environmentally responsible products or promoting environmental groups and organizations (Mair and Laing, 2013). The researchers surveyed 196 attendees and interviewed an additional 42 to examine festival attendees' ERBs, their perceptions of event itself, and their general environmental attitudes. Mair and Laing also used SDT to support their hypothesis that environmental festivals can promote intrinsic motivations towards ERB by means of self-evaluation. The results indicated a positive correlation between pro-environmental values and attitudes and the number of ERBs an individual 
engages in. These events can also show consumers that ERBs are not only possible, but beneficial to one's lifestyle and sense of self. Another significant finding was that this event attracted attendees who were already committed to environmental sustainability and engaged in ERBs in their everyday lives. This finding implies that environmental festivals need to market themselves in a way that attracts a broader range of individuals with varying levels of environmental commitment. Festival organisers could potentially offer incentives to encourage attendance, such as contest prizes and showcasing high profile celebrities and musicians. Mair and Laing (2013) also propose that environmentally focused events consider naming themselves something that invokes a greater sense of fun to appeal to a wider audience, rather than including 'eco' or 'environment' in the name of the festival.

The most recent study on ERBs in a festival context was the WTP study conducted by Dodds, Pitts, and Smith (2016). This research was outlined in section 2.6.1, but to reiterate is the only study to examine WTP for ethical clothing within a festival setting. Results of this study demonstrated that participants were willing to pay the highest premium for festival t-shirts that were both fair trade and possessed an environmental message. This WTP study provides practical implications for event coordinators and clothing retailers, as it demonstrates that inclusion of an environmental message and socially responsible labels on festival merchandise may be a cost effective way to increase festival profits while simultaneously encouraging ethical behaviour within and outside of an event. Individuals' purchasing behaviour is particularly important for festivals, as the sale of festival merchandise can generate a substantial amount of revenue and act as advertisements to help increase traffic in the future (Dodds et al, 2016). This research provides opportunity 
for the current study to further examine ethical clothing consumption in a festival context through examining attendees actual purchase behaviour.

It is important to note that similarly to Mair and Laing (2013), Dodds et al. (2016) conducted their research at a festival that had already established its commitment to the environment; Nelson Ecofest and Mariposa Folk Festival respectively. As the current study will be building on the research by Dodds et al. (2016) within the same venue it is important to provide insight into why Mariposa Folk Festival was chosen as an ideal setting to study ethical consumption and behaviour. Additional information on the rationale for selecting Mariposa Folk Festival as the venue to conduct the current study is provided in the subsequent chapter.

\subsubsection{Mariposa Folk Festival}

Mariposa Folk Festival was established in 1961 in Orillia, Ontario. It is a three-day gated event, where attendees must have a ticket in order to gain entry to the festival grounds. In recent years Mariposa Folk Festival attracted 20,000-25,000 attendees annually (Mariposa Folk Foundation, 2016). This festival is an ideal venue to promote environmental responsibility and ethical consumption because this event has established itself as an environmentally focused event with best practice environmental management. Mariposa Folk Festival was the recipient of the 2015 Award of Excellence for Sustainable Tourism, by the Tourism Industry Association of Ontario (TIAO), due to their efforts to reduce the festival's carbon footprint and introduce new environmental initiatives (Tourism Industry Association of Ontario, 2016). For example, at Mariposa Folk Festival all food and beverage containers are $100 \%$ compostable, and instead of selling plastic water bottles the festival brings in mobile water refill stations. Efforts such as these allowed Mariposa to achieve an 
88\% landfill diversion rate in 2015 (Mariposa Folk Foundation, 2016). The festival also uses solar powered stages, bicycle-powered cell phone charging stations, and partners with printing companies that are Forest Stewardship Council (FSC) certified. In addition to openly communicating their environmental efforts on their website, the festival also has a new environmental education booth to help inform attendees on the environmental impacts typically associated with festivals, and inform them of the various environmental initiatives the festival is currently engaging in (Mariposa Folk Foundation, 2016).

\subsection{Conclusions \& Need for the Current Study}

Upon review of the relevant literature it is evident that there are a number of social and environmental issues surrounding the clothing industry, and while there has been some pressure from governments, consumers, and labour boards for retailers to adopt more ethical practices there is still much progress to be made. Ethical clothing consumption of more sustainable clothing products may help to alleviate some of social and environmental pressures caused by the industry. Ethical clothing options include products that are made from renewable cellulose textiles or organic cotton, made locally, possess fair trade certification or sweatshop free labels, or are made with a slow design approach (Cheek and Moore, 2003; Chen and Burns, 2006; Claudio, 2007; Ozdamar and Atik, 2015. Review of theoretical studies that explored the pathways between personal values and ethical consumption revealed that intrinsic motivations often drive ethical behaviours. These studies also determined the existence of an attitude-behaviour gap, where respondents expressed pro-environmental attitudes but did not reflect these attitudes in their behaviours (Didier and Lucie, 2008; Hiller-Connell, 2011; Ku and Zaroff, 2014; Reynolds, 
2015). There is much discrepancy amongst research on attitude-behaviour gaps, indicating that additional research is required to better identify trends and patterns.

Only two WTP examined the actual purchase behaviour of consumers in field experiments (Andorfer and Liebe, 2015; Reynolds et al., 2015), and currently no research has been done on actual purchase behaviour in regards to ethical clothing. Similarly, results from Dodds et al. (2016) indicated that attendees of Mariposa Folk Festival were willing to pay a premium on ethical festival t-shirts; however they did not test actual behaviour. This provides the current study the opportunity to examine the actual purchase behaviour of attendees of Mariposa Folk Festival. As such, this study intends to build on the research conducted by Dodds et al. (2016), by examining whether festival attendees will, in actuality, pay more for t-shirts that are socially and environmentally responsible.

Review of the relevant literature on marketing ethical clothing revealed several strategies and barriers to purchasing these products. The most predominant barriers to merchandising ethical clothing found across the literature were aesthetics, affordability, ambiguous labelling, and a lack of consumer awareness (Joergens, 2006; Hiller-Connell, 2010; Ozdamar and Atik (2015; Lundblad and Davies, 2015). Research on marketing ethical clothing also revealed that consumer attitudes towards brand, advertisement, and environmental involvement of the clothing manufacturer were all significant predictors of intention to purchase from an ethical apparel brand (Pickett-Baker and Ozaki, 2008; Yan et al., 2012). It was also determined that clothing companies can influence more positive attitudes toward brands by providing explicit information about the environmental and 
social responsibility of their products, which has significant practical implications for clothing marketers.

Finally, the literature review revealed that the sale of ethical clothing can have important implications for festivals, in terms of merchandising, revenue, advertising, and demonstrating social and environmental commitment. The sale of ethical festival clothing is a way for both attendees and event organizers alike to demonstrate environmentally responsible behaviour, and may help increase consumers' awareness of the social and environmental issues associated with the clothing industry. Buying ethical festival apparel may help to show attendees that their individual actions can make a difference and that there are ERBs they can easily engage in. If festival attendees receive internal rewards such as 'feeling good about one's self' from purchasing ethical festival apparel, this feeling may manifest as an intrinsic motivation that can be perpetuated in future clothing acquisition. Evidence for this has been seen throughout the relevant literature on SDT and VBNT (Osbaldiston and Sheldon, 2003; Kilbourne and Pickett, 2008; Ku and Zaroff; 2014; Fischer and Dam, 2015). 


\subsection{Methods}

\subsection{Introduction}

The purpose of this section is to outline the sequential process used to investigate whether attendees of Mariposa Folk Festival will pay a premium for socially and environmentally responsible festival t-shirts, as well as the variables that influenced their purchase decision. The section outlines the research questions and hypotheses, details how the research will be conducted, explains the rationale behind the chosen data collection and analysis methods, and addresses limitations and research biases.

\subsubsection{Research Questions and Hypotheses}

The current study seeks to answer the following research question; will individuals at Mariposa Folk Festival pay a premium for ethical festival t-shirts, and will certain variables influence their purchase decision? For the context of this study, ethical festival t-shirts refer to either festival t-shirts that are produced locally from a socially responsible company, or festival t-shirts produced locally that are certified fair trade and organic cotton. To answer the research questions, the following four hypotheses were tested:

H1: Individuals will pay a premium to purchase the ethical festival $t$-shirts over the conventional alternative.

H2: Employing marketing treatments that promote the ethical festival t-shirts will increase the number of ethical festival $t$-shirts sold in a given time period.

H3: The visibility of the fair trade/ organic certification label will influence individuals' willingness to purchase the fair trade/ organic festival t-shirts.

H4: Survey participants who express greater environmental awareness will be more likely to purchase an ethical festival $t$-shirt. 


\subsection{Research Process}

Primary research, in the form of a field experiment and online survey, was used to conduct this study. The sequential process by which the current study was carried out is illustrated Figure 3 and discussed in further detail in the subsequent sections.

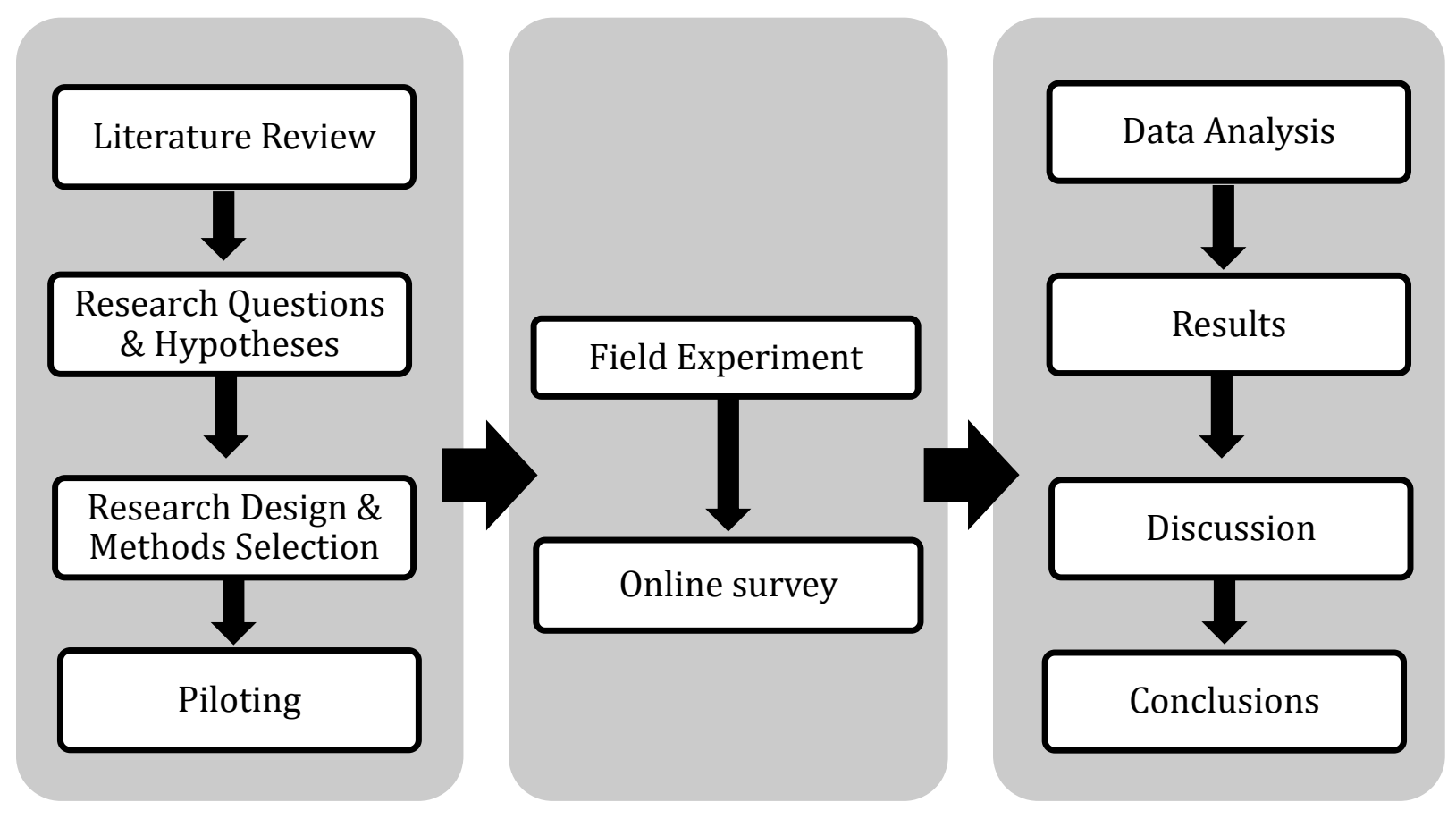

Figure 3: Sequential research process.

\subsection{Literature Review}

The first step in the research process was to conduct a thorough review of all available academic literature that may be relevant to the research questions presented in this study. Randolph (2009) emphasize that is it impossible to conduct competent and meaningful research without first having a complete understanding of the research that currently exists in relatable fields. Cooper (1984) compare the stages of conducting a literature review to that of conducting a scientific experiment, in that you must first formulate a problem, collect and evaluate the data, and then analyze and interpret said data. Both Webster and Watson (2002) and Randolph (2009) ascertain several key objectives of 
conducting a literature review. One objective is to determine the scope and boundaries of your research. Another is to determine where the study fits within existing research by identifying patterns and gaps in the relevant literature. Other objectives listed by Randolph (2009) include gaining methodological insights and avoiding research approaches that were unsuccessful in past endeavours.

The literature review for the current study examined dozens of scholarly and peerreviewed journal articles from credible sources on the topics of the social and environmental impacts of the clothing industry, socially and environmentally responsible purchasing behaviour amongst consumers, theoretical and empirical methods of measuring environmentally responsible consumer behaviour, marketing socially and environmentally responsible clothing, and using festivals as a setting to explore environmentally responsible consumer behaviour. The literature review identified that a knowledge gap exists in regards to studying actual clothing purchase behaviour of consumers in comparison to hypothetical WTP.

\subsection{Primary Research}

The primary research was collected using a quantitative approach in the form of a natural field experiment and a supplementary online survey administered via iPad. A quantitative research design was deemed the most appropriate for the study as it allows for statistical analysis of the data, in which relationships between variables can be examined to generalize findings (Neuman, 2002).

A field experiment was determined to be the most suitable means of determining whether attendees of Mariposa Folk Festival would pay a premium for ethical festival t-shirts over 
the conventional alternative. A field experiment can be defined as a scientific means of examining an intervention in a natural environment, opposed to in a laboratory or controlled setting (Paluck, 2010; Andorfer and Liebe, 2015). The natural setting allowed the researcher to collect data on actual purchase behaviour, while eliminating the risk of participants overstating their WTP, because they chose to purchase (or not to purchase) a festival t-shirt with their own money. Field experiments have also proven to yield stronger validity in their results than lab experiments (Andorfer and Liebe, 2015). Integrating quantitative data within field experiments allows researchers to not only explore treatment effects, but provides the ability to examine mechanisms of the causal effects as well (Paluck, 2010).

A quantitative survey was also deemed more appropriate than conducting qualitative interviews because it allows for statistical analysis of the data, in which relationships between variables can be examined to generalize findings. Although qualitative survey questions can sometimes allow for more diverse and detailed responses (Arcidiacono et al., 2009), often one cannot establish a set of variables and transform the data collected from qualitative to quantitative for statistical analysis. Quantitative survey questions allow for more direct responses that are easier to analyze (Leech and Onwuegbuzie, 2009).

\subsection{Data Collection}

The current quantitative study was conducted in two phases, a field experiment and an online survey. The research was conducted at the annual Mariposa Folk Festival, in Orillia, ON, from July 8-10, 2016. As Dodds et al. (2016) had already established a relationship with the coordinators of Mariposa Folk Festival, Pam Carter and Carrie-Anne Lauder; they were willing to have the current study take place at their festival. Mariposa Folk Festival's 
existing environmental focus also provided good sampling for the current research project, as it was assumed that an event with strong environmental management practices will attract attendees with higher levels of environmental awareness. The research team consisted of the primary researcher and five volunteers from Ryerson University that assisted with the data collection. The data collection for each phase of the study is described below.

\subsubsection{Field Experiment}

The first part of the field experiment was to sell three different types of festival t-shirts to the attendees of Mariposa Folk Festival (Table 2), and record the numbers sold for each.

Table 2

Description of the three festival $t$-shirts sold during the field experiment.

\begin{tabular}{|ccccccc|}
\hline $\begin{array}{c}\text { T-shirt } \\
\text { Manufacturer }\end{array}$ & $\begin{array}{c}\text { Company's } \\
\text { Social } \\
\text { Responsibility }\end{array}$ & Material & $\begin{array}{c}\text { Country } \\
\text { of Origin }\end{array}$ & $\begin{array}{c}\text { Visibility of } \\
\text { Certification }\end{array}$ & $\begin{array}{c}\text { Price } \\
\text { Per Unit } \\
\text { (CAN) }\end{array}$ & $\begin{array}{c}\text { Premium } \\
\text { (CAN) }\end{array}$ \\
\hline Gildan & N/A & Cotton & $\begin{array}{c}\text { China } \\
\text { Nicaragua } \\
\text { Honduras }\end{array}$ & N/A & $\$ 20.00$ & $\$ 0.00$ \\
\hline $\begin{array}{c}\text { Redwood } \\
\text { Classics }\end{array}$ & $\begin{array}{c}\text { Sweatshop free } \\
\text { and partners } \\
\text { with CAMSC }\end{array}$ & Cotton & Canada & N/A & $\$ 25.00$ & $\$ 5.00$ \\
\hline $\begin{array}{c}\text { Canadian } \\
\text { Union Apparel }\end{array}$ & $\begin{array}{c}\text { Unionized, fair } \\
\text { trade, and } \\
\text { sweatshop free }\end{array}$ & $\begin{array}{c}\text { Certified } \\
\text { organic } \\
\text { cotton }\end{array}$ & Canada & $\begin{array}{c}\text { External } \\
\text { certification } \\
\text { printed on } \\
\text { sleeve }\end{array}$ & $\$ 30.00$ & $\$ 10.00$ \\
\hline
\end{tabular}

All t-shirts displayed the same festival logo and graphics, but differed in regards to country of origin, social responsibility of the manufacturing company, ethical certification, and visibility of said environmental certification. In the context of this study ethical certifications refer to organic cotton and fair trade certification; only the \$30.00 CAN festival t-shirt possessed ethical certifications. The $\$ 25.00$ CAN and $\$ 30.00$ CAN festival tshirts were sold at premium prices based on the country of origin, ethical claims and 
certifications (i.e. socially responsible, fair trade, and/or organic cotton), and the visibility of the certification (i.e. internal or external). These premiums have been estimated based on previous WTP studies (Dodds et al., 2016; Habel et al., 2016; Ellis, et al., 2012). Retailers for the $\$ 25.00$ CAN and $\$ 30.00$ CAN festival t-shirts (i.e. Redwood Classics and Canadian Union Apparel) were chosen with the concept of a slow design approach in mind (Claudio, 2007; Niinimäki, and Hassi, 2011; Ozdamar and Atik, 2015). It is important to note that all three of the festival t-shirts were available in the same sizes and colours (i.e. black, white, gray, and navy); with the exception of the $\$ 20.00$ CAN t-shirts that were available in an additional two colours (i.e. purple and blue).

All three types of festival t-shirts were sold at the festival's t-shirt emporium (Figure 4). The emporium is the location within the festival where all festival merchandise is sold. Approximately half of the emporiums space was reserved for the festival t-shirts being sold during this field experiment. The remainder of the space was used to sell other festival merchandise such, as posters and CDs. The purple circle in Figure 4 denotes the location of the t-shirt emporium within the festival grounds. The three t-shirts being sold in this experiment were the only adult festival t-shirts available at Mariposa. It is also important to note that this entire experiment was directed towards those festival attendees with the intent to purchase a festival t-shirt and not festival attendees in general. 


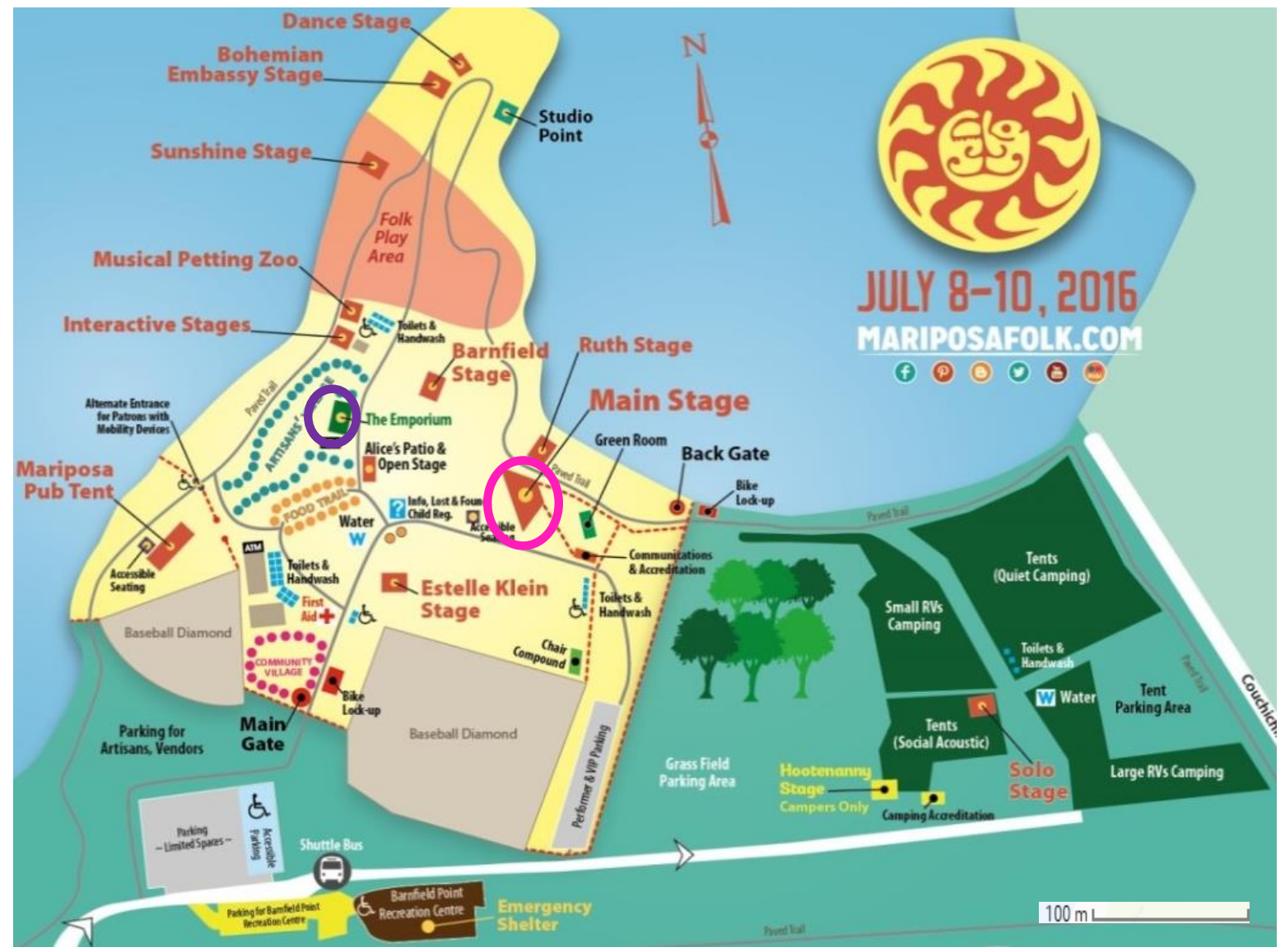

Figure 4: Map of Mariposa Folk Festival grounds. (Source: Mariposa Folk Foundation, 2016)

The coordinators of Mariposa Folk Festival gave the researcher full control of t-shirt sales at the t-shirt emporium in order to run the field experiment. It should be noted that although the researcher was in control of the festival's t-shirt sales, the festival coordinators were in charge of purchasing the three types of t-shirts and collecting the proceeds.

The number of each type of festival t-shirt sold was recorded over the course of the weekend to determine whether individuals would pay a premium to purchase the ethical festival t-shirts ( $\$ 25.00$ and $\$ 30.00 \mathrm{CAN}$ ). This data was used to test $H 1$, 'individuals will pay a premium to purchase the ethical festival $t$-shirts over the conventional alternative'. In this 
portion of the field experiment the total number of t-shirts sold represented the independent variable and the number of each type of festival t-shirt sold represented the dependent variables. The total number of t-shirts sold was the independent variable because it was controlled. The number of each type of festival t-shirt sold is the dependent variable because it was the variable being tested and measured. In 2015 Mariposa Folk Festival sold roughly 350 festival t-shirts; all t-shirts were conventional cotton priced at $\$ 20.00$ CAN. Based on last year's sales, a similar number of t-shirt sales were expected in 2016, with some variance due to the application of the field experiment.

\subsubsection{Description of the $\$ \mathbf{2 0 . 0 0}$ CAN Festival T-shirt}

The first type of festival t-shirt, priced at $\$ 20.00$ CAN, were conventional cotton t-shirts purchased from Gildan ${ }^{\circledR}$ (Figures 5 and 6). These t-shirts were produced in developing countries such as China, Honduras, and Nicaragua. Gildan ${ }^{\circledR}$ has been the subject of much controversy and media coverage regarding the conditions of their manufacturing facilities and the treatment of their workers (Turcotte et al. 2007; Livesey, 2014).

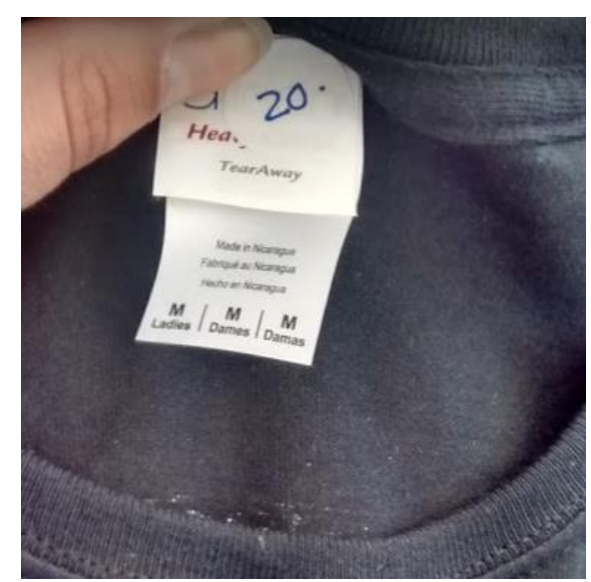

Figure 5: Label of the $\$ 20.00$ CAN festival t-shirt produced by Gildan ${ }^{\circledR}$. 


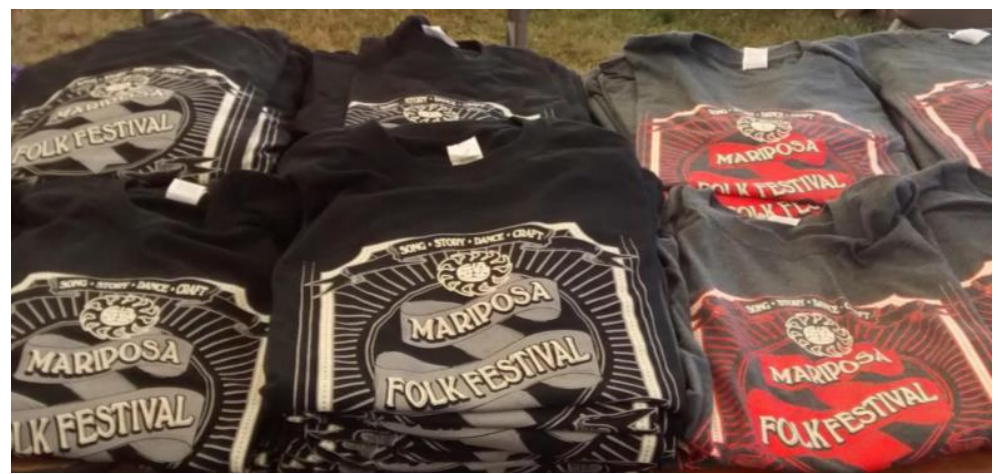

Figure 6: Display of the $\$ 20.00$ CAN festival t-shirts produced by Gildan $®$.

These t-shirts represent the baseline product for this experiment as they are not certified organic cotton and their manufacturing company has a lack of social responsibility.

\subsubsection{Description of the $\$ \mathbf{2 5 . 0 0}$ CAN Festival T-shirt}

The second type of festival t-shirt, priced at $\$ 25.00$ CAN, was purchased from Redwood Classics (Figures 7 and 8). These festival t-shirts are produced by a reputable Canadian company that is sweatshop-free and advocates corporate social responsibility, even though there are no certification labels.

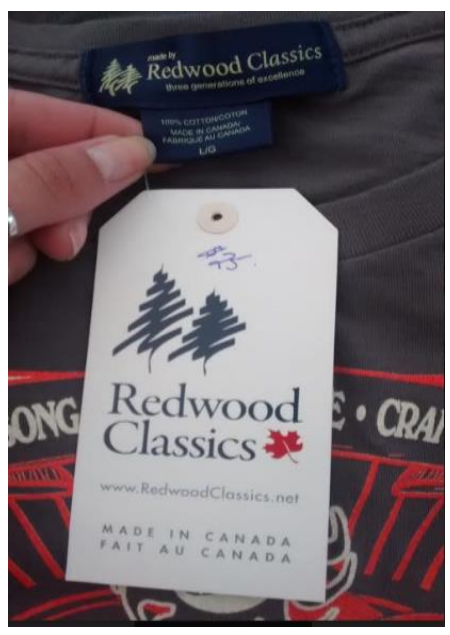

Figure 7: Label of the $\$ 25.00$ CAN festival t-shirt produced by Redwood Classics. 


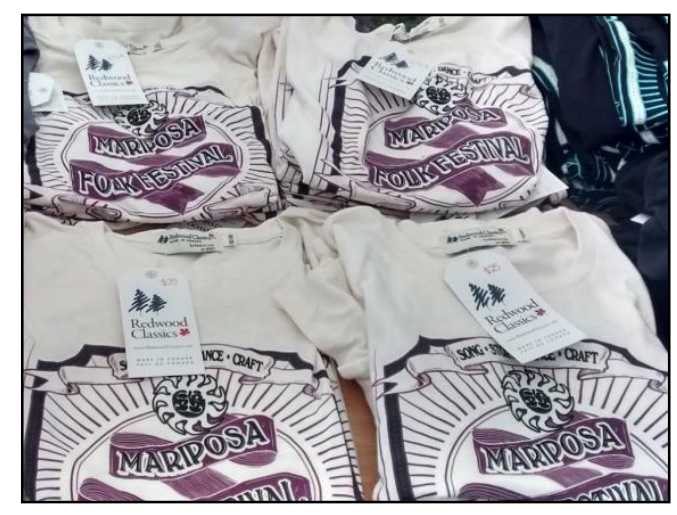

Figure 8: Display of the $\$ 25.00$ CAN festival t-shirts produced by Redwood Classics.

Redwood Classics uses a Toronto-based clothing manufacturing facility and partners with the Canadian Aboriginal and Minority Supplier Council (CAMSC) to provide 'minorityowned businesses better purchasing opportunities at major clothing companies across North America. This ensures the equitable distribution of wealth and equal employment opportunities within the North American clothing market (Redwood Classic, 2016).

\subsubsection{Description of the $\$ \mathbf{3 0 . 0 0}$ CAN Festival T-shirt}

The third type of festival t-shirt, priced at $\$ 30.00$ CAN, was purchased from Canadian Union Apparel. These t-shirts were made in Canada, certified organic cotton, and fair trade (Figures 9 and 10).

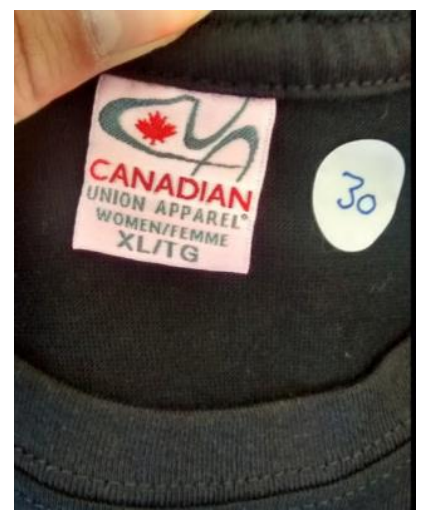

Figure 9: Label of the $\$ 30.00$ CAN festival t-shirt produced by Canadian Union Apparel. 


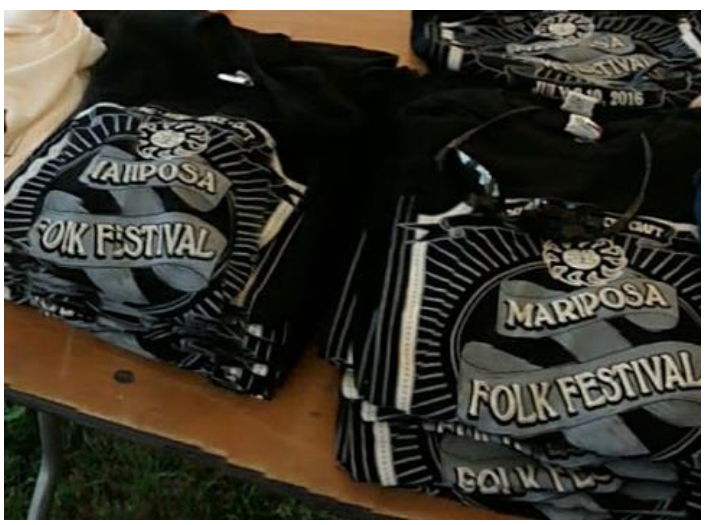

Figure 10: Display of the \$30.00 CAN festival t-shirts produced by Canadian Union Apparel.

Canadian Union Apparel ensures equal job opportunities and promotes an inclusive and diverse work environment (Canadian Union Apparel, 2016). The company is also a member of the Canada Organic Trade Association (COTA). For COTA clothing manufacturers, the cotton is grown on certified organic cotton farms in the USA that prohibit the use of GMOs and pesticides, and manufacturers produce clothing that is free from harsh chemicals and dyes (Organic Trade Association, 2016). The $\$ 30.00$ CAN festival t-shirts have the organic cotton and fair trade certifications printed externally on the sleeve of the shirt (Figure 11).

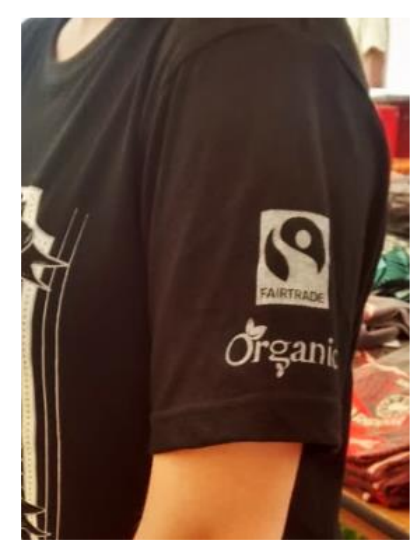

Figure 11: External certifications printed on the $\$ 30.00$ CAN festival $t$-shirt, produced by Canadian Union Apparel 


\subsubsection{Marketing Treatments}

This study also incorporated two marketing treatments throughout the three day festival, at regularly scheduled two hour time intervals (Table 3 ). This part of the experiment had a three by two experimental design, in that two marketing treatments were applied to the three t-shirt options.

Table 3

Schedule for marketing treatments and control groups.

\begin{tabular}{|cccc|}
\hline TIME (PM) & FRIDAY & SATURDAY & SUNDAY \\
\hline 12:00-2:00 & $*$ & Control & Control \\
\hline $2: 00-4: 00$ & $*$ & Treatment 1 & Treatment 2 \\
\hline 4:00-6:00 & Control & Control & Control \\
\hline 6:00-8:00 & Treatment 1 & Treatment 1 & Treatment 2 \\
\hline 8:00-10:00 & Control & Control & $*$ \\
\hline
\end{tabular}

*Note: these time frames fell outside of the festival's operating hours.

In treatment one, the researcher and volunteers promoted the ethical festival shirts at the t-shirt emporium by means of wearing the $\$ 30.00$ CAN fair trade and organic cotton festival t-shirt. In treatment one the researcher and volunteers also educated individuals on the following topics: the environmental impacts of traditional cotton production, the social impacts of cotton production, environmental benefits of organic cotton, and social benefits of buying fair trade clothing. Before any marketing treatments were applied the volunteers were verbally briefed with what facts to communicate to individuals looking to purchase a t-shirt (Appendix A). Individuals were educated on the above matters through verbal communication by the researcher and volunteers, and through the use of visual aids (Figure 12). 


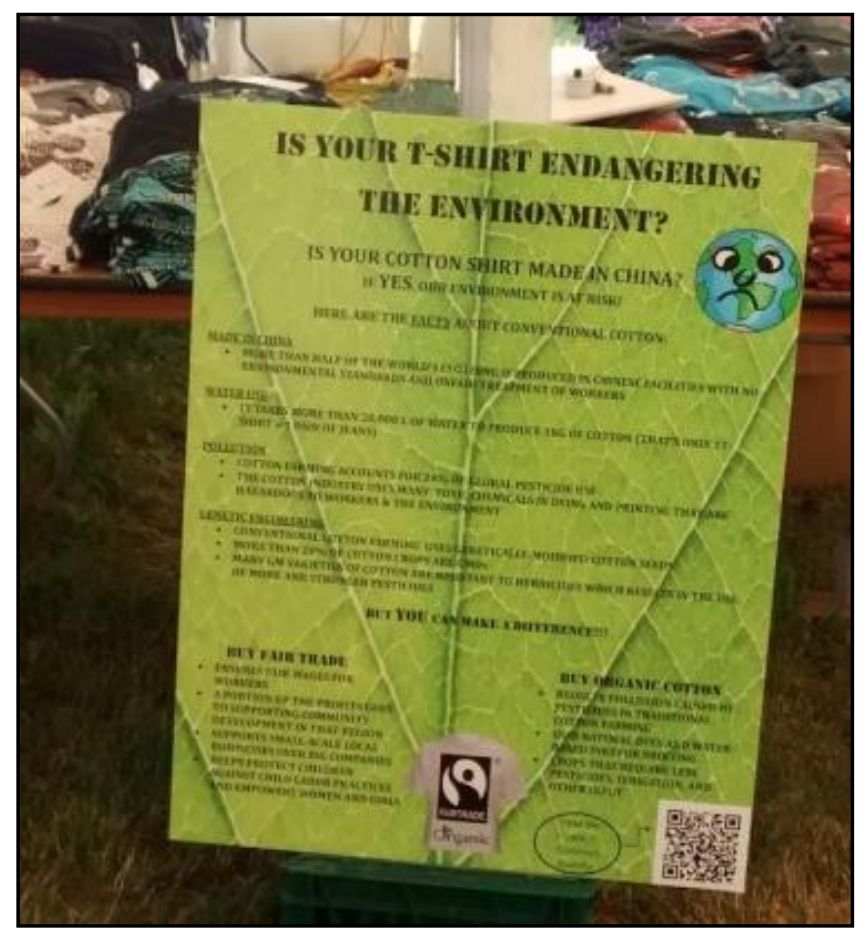

Figure 12: Visual aid used during marketing treatment one.

Treatment two was identical to treatment one with the addition on promoting the $\$ 30.00$ CAN fair trade and organic cotton festival t-shirts on the jumbotron. The jumbotron is a large television screen that broadcasts the musical performances as well as advertisements from sponsors. The jumbortron communicated the following message to promote the ethical festival t-shirts during marketing treatment two: 'support Mariposa's greening efforts; buy an organic, fair trade, Canadian-made festival t-shirt'.

Treatment two was only employed on Sunday as both treatment one and treatment two each required a full day with an equal number of marketing treatment, so there would be grounds for comparison. Rationale for adding the jumbotron message to treatment two was to see if t-shirt sales would increase significantly compared to treatment one, as the jumbotron was thought to be able to reach maximal numbers of attendees simultaneously. 
This is due to the fact that the jumbotron was located next to the main stage, circled in pink in Figure 4. The time segments in which the marketing treatment is not employed act as the control. The blank time segments in Table 3 represent time periods outside of the festival's scheduled operation.

Examining the number of each type of festival t-shirt sold during the treatment and control segments, will provide insight into whether strategic promotion and educating individuals on the benefits of ethical consumption would increase the number of socially and environmentally responsible t-shirts ( $\$ 25.00$ and $\$ 20.00 \mathrm{CAN}$ ) sold in a given time period. In this portion of the field experiment the marketing treatments acted as the independent variables and the number of each type of festival t-shirt sold were the dependent variables. The marketing treatments were the independent variables because they were being changed and controlled to test their effect on the dependent variables. The number of each type of festival t-shirt sold were the dependent variables because it was variable being tested and measured. The data collected from this portion of the field experiment was used to test $H 2$, 'employing marketing treatments that promote the ethical festival $t$-shirts will increase the number of ethical festival t-shirts sold in a given time period'. The number of each type of shirt sold will act as the dependent variables and the marketing treatment will act as the independent variable.

\subsubsection{Online Survey}

For the second phase of this research project, covariates were collected via an online survey administered via iPad. Individuals who purchased a festival t-shirt were then asked to complete an online survey asking them five short questions regarding which type of festival t-shirt they purchased, the rationale behind their purchase decision, general 
purchase behaviours, and their environmental awareness. Respondents were also asked an additional two questions on demographics at the end of the survey. Respondents' age was collected, as previous research by Dodds et al. (2016) indicated that Mariposas' attendees were of an older demographic compared to other music festivals in the area. The current study sought to examine whether Mariposa's 2016 demographics (i.e. age and sex) would be comparable to Dodds et al. (2016), and whether an older age demographic would influence the type of festival t-shirt purchased. Demographic information is often collected in quantitative research as it informs readers on the sample of participants and indicates whether the sample of participants is representative of larger populations (Arcidiacono et al., 2009). See Appendix D for a copy of the survey questionnaire.

Individuals were surveyed by the researcher and volunteers, within the t-shirt emporium after purchasing a festival t-shirt, throughout the entire three days of the festival. Surveys took approximately three minutes to complete. The surveys were administered via iPad to ensure ease of use and consistency amongst responses. The iPads also allowed the researcher to guide the participants through the survey to avoid any misunderstanding. Potential sampling bias can occur if questions are asked or explained differently to the respondents. To minimize the potential for bias all volunteers administering surveys were briefed and given specific instructions on what to say to respondents and how to explain the survey questions. Initially respondents were to use QR codes, or 2-D barcodes scanned by their phones, to pull up and fill out the online survey. After some consideration this was determined to be a potentially problematic means of distributing the surveys, as respondents would be completing surveys without the assistance of the researcher or volunteers and answers would be subject to potential bias depending on the respondents' 
interpretation of the question. The survey questions were formulated based on well-

established survey methods that have been used in studies of a similar nature (Table 4).

Table 4

List of survey questions and the corresponding studies that helped establish each question.

\begin{tabular}{|c|c|c|}
\hline Survey Question & Possible Responses & References \\
\hline $\begin{array}{l}\text { Which Mariposa } \\
\text { festival t-shirt did you } \\
\text { purchase this } \\
\text { weekend? }\end{array}$ & $\begin{array}{l}\text { Conventional t-shirt ( } \$ 20.00 \text { CAN) } \\
\text { Socially responsible t-shirt }(\$ 25.00 \mathrm{CAN}) \\
\text { Certified fair trade/ organic cotton t-shirt }(\$ 30.00 \\
\text { CAN) }\end{array}$ & $\mathrm{N} / \mathrm{A}$ \\
\hline $\begin{array}{l}\text { What influenced you } \\
\text { to buy the festival t- } \\
\text { shirt you purchased, } \\
\text { over the other two } \\
\text { choices? }\end{array}$ & $\begin{array}{l}\text { I always buy products that are fair trade and/or } \\
\text { organic } \\
\text { Promotion of the fair trade and/or organic t-shirts at } \\
\text { the t-shirt emporium } \\
\text { The visibility of the environmental certification } \\
\text { Cost } \\
\text { Promotion of the fair trade and/or organic t-shirts } \\
\text { on the jumbotron } \\
\text { Promotion of the fair trade and/or organic t-shirts at } \\
\text { the environmental education booth }\end{array}$ & $\begin{array}{l}\text { Dickson (2001) } \\
\text { Ha-Brookshire and } \\
\text { Norum (2011) } \\
\text { Andorfer and Liebe } \\
\text { (2012) } \\
\text { Ellis et al. (2012) } \\
\text { Dodds et al. (2016) }\end{array}$ \\
\hline $\begin{array}{l}\text { How often do you } \\
\text { make clothing } \\
\text { purchases based on } \\
\text { the following factors? }\end{array}$ & $\begin{array}{l}\text { Cost } \\
\text { Brand } \\
\text { Environmental Certification } \\
\text { Company's Social Responsibility } \\
\text { Country of Origin } \\
\text { Design (colour \& graphics) } \\
\text { Media advertisements } \\
\text { Peer influence }\end{array}$ & $\begin{array}{l}\text { Dickson (2001) } \\
\text { Hiller-Connell (2011) } \\
\text { Ellis et al. (2012) } \\
\text { Yan et al. (2012) } \\
\text { Habel et al. (2016) }\end{array}$ \\
\hline $\begin{array}{l}\text { I find that most } \\
\text { environmentally } \\
\text { friendly products are } \\
\text { often marketed in a } \\
\text { way that. }\end{array}$ & $\begin{array}{l}\text { Stands out amongst name brand competitors } \\
100 \% \text { credible with their claims } \\
\text { Provide useful information about its environmental } \\
\text { value } \\
\text { Marketed in a way that is engaging and relevant }\end{array}$ & $\begin{array}{l}\text { Pickett-Baker and Ozaki } \\
\text { (2008) } \\
\text { Tucker et al. (2012) } \\
\text { Yan et al. (2012) } \\
\text { Ozdamar and Atik (2015) }\end{array}$ \\
\hline $\begin{array}{l}\text { How environmentally } \\
\text { aware are you? }\end{array}$ & $\begin{array}{l}\text { Significant awareness } \\
\text { Awareness } \\
\text { Some awareness } \\
\text { Minimal awareness } \\
\text { No awareness }\end{array}$ & Dodds et al. (2016) \\
\hline
\end{tabular}

Multiple choice and five-point Likert scales were chosen as the most appropriate question format, opposed to rank order and open-ended questions, to achieve the level of data required for statistical analysis. 


\subsection{Survey Sample Size}

Cochran's formula for categorical data was used to determine the appropriate survey sample size (Bartlett, Kotrlik, \& Higgins, 2001). See Appendix B for depiction of Cochran's formula. For this calculation the total number of t-shirts sold in 2015 (i.e. $350 \mathrm{t}$-shirts) was used to represent sample size. Applying a 95\% confidence level, an alpha level of 0.5 , and a 5\% margin of error, Cochran's formula indicated that 384 surveys is required. This value, however, is only applicable if it is amounts to less than $5 \%$ of the sample size (Bartlett, Kotrlik, \& Higgins, 2001). Since 384 surveys greatly exceeds $5 \%$ of the sample size of $350 \mathrm{t}$ shirts, this value cannot be applied. For all calculations that exceed $5 \%$ of the given sample size, Cochran's correction formula must be used to calculate the true sample size (Appendix B). Using Cochran's correction formula, the ideal survey sample size necessary to obtain significant results was determined to be 183 .

\subsection{Piloting Survey Questions}

Online survey questions were piloted to ensure that they will be interpreted and understood correctly, and that they are in line with the study's research questions and objectives. Survey questions were piloted on June 14, 2016 by a sample of six university students from Ryerson University in Toronto, Canada, and on June 22, 2016 by Dr. Wayne Smith and Dr. Robert Pitts; two statisticians from the College of Charleston in South Carolina, and Dr. Rachel Dodds; graduate supervisor and faculty of Ted Rogers School of Management. Appendix C contains the initial online survey questions, and Appendix D contains the final survey questions, post-piloting. The changes made to the initial survey questions are outlined in detail below. 
All of the questions were either five-point Likert scales or multiple choice questions to ensure that the responses would be comparable during statistical analyses. The wording of the questions were changed and simplified to ensure that respondents would be able to understand all the terms and know what was being asked of them. The formatting of question number two was changed from multiple-choice to ranking order, to gain a better understanding of the greatest influence on purchase decision. The length of the survey was kept concise so that respondents would be more likely to stay engaged throughout the duration of the survey and complete the survey in a timely manner. Question five was also changed from ranking environmental concern based on potential environmental impacts of festivals to ranking one's level of environmental awareness. The initial question was deemed to be too convoluted and not directly relatable to the study at hand.

\subsection{Data Analysis}

The data collected in this study was analyzed using SPSS (Statistical Package for Social Science) software version 24. In SPSS data was scrubbed to remove any incomplete or inaccurate entries. Of the 183 online survey responses, two were incomplete and thus removed during the scrubbing stage, resulting in 181 useable survey responses. See Appendix E for a copy of the survey data in SPSS. Two types of data were collected in this experiment; categorical and ordinal. The categorical data pertains to which of the three festival t-shirts the respondent purchased, and whether the festival t-shirt was purchased during a marketing treatment or a control. The ordinal data pertains to survey responses in the form of five-point Likert scales. Data analysis required comparison between categorical data, or between categorical and ordinal data. 
To test the four hypotheses, chi-square tests were selected as the most appropriate method of statistical analysis. Chi-square tests are best for comparing sets of categorical variables because they determine whether there is independence, or association, between variables in the rows and columns of a contingency table (Parab and Bhalerao, 2010; Franke, 2012). In chi-square testing the null hypothesis, that there is no difference between expected and observed values, is rejected if the p value is less than the significance, or alpha $(\alpha)$ value. Performing a chi-square test requires determining the significance level, or alpha $(\alpha)$ value, the chi-square value, and the $\mathrm{p}$ value. The first step was to determine the significance level, or alpha $(\alpha)$ value, to test the data sample on. For this study chi-square tests were conducted using a significance level, or alpha $(\alpha)$ value, of 0.05 . The next step was to calculate the chi-square value. The formula for calculating the chi-square value is as follows:

$$
x^{2}=\sum \frac{\left(O_{i}-E_{i}\right)^{2}}{E_{i}}
$$

Where $\mathrm{O}_{\mathrm{i}}$ represents the observed values and $\mathrm{E}_{\mathrm{i}}$ represents the expected or theoretical values. Each observed value is subtracted by its respective expected value, this difference is then squared, and this squared value is then divided by the sum of expected values. The final step was to determine the $\mathrm{p}$ value based on the chi-square value. In chi-square testing, the p-value is the probability that the chi square value will be greater than the empirical value of your sample data (Parab and Bhalerao, 2010). The $\mathrm{p}$ values were found using a chisquare distribution table found online (Pennsylvania State University, 2017). A p value that is less than the significance value $(\alpha)$ of 0.05 indicates statistically significant results. In chisquare testing, a $\mathrm{p}$ value of less than the alpha level indicates that a significant difference 
exist between the observed and expected values, or that one variable of interest is associated, or dependent, on another (Franke, 2012). All chi-square test results are reported with degrees of freedom (df) and sample size (N) in parentheses, followed by the chi-square value, and the significance level (p). An asterisk beside the chi-square value denoted a significant p-value; less than the alpha level of 0.05 .

To test H1, 'individuals will pay a premium to purchase the ethical festival $t$-shirts over the conventional alternative', comparison of the outcomes, or proportions, of the number of each type of festival t-shirt purchased. Since there was only a single categorical variable (i.e. t-shirt sales) being examined, a chi-square goodness of fit test was determined to be the most appropriate (Franke, 2012). A chi-square goodness of fit test is used to compare the observed sample distribution with the expected distribution.

To prove or disprove $\mathrm{H2}$, 'employing marketing treatments that promote the ethical festival $t$-shirts will increase the number of ethical festival t-shirts sold in a given time period', a chisquare test of independence was performed to analyze the number of each type of festival t-shirt sold during marketing treatments against the number of each type of festival t-shirt sold during the controls. A chi-square test of independence is used when comparing two or more categorical variables within a given sample (Franke, 2012). This test determined whether the marketing treatments significantly increased the number of ethical t-shirts sold.

To test $H 3$, 'the visibility of the fair trade/ organic certification label will influence individuals' willingness to purchase the fair trade/ organic festival $t$-shirts', another chisquare test of independence was used to compare the number of $\$ 30.00$ CAN fair 
trade/organic festival t-shirts sold against respondents' answer to statement two in question two of the survey, 'did the visibility of the certification influence which festival tshirt you purchased' (Appendix D).Only the \$30.00 CAN festival t-shirts were considered for this test, as the other two t-shirt options did not possess any fair trade or organic cotton certifications.

To test H4, 'survey participants who express greater environmental awareness will be more likely to purchase an ethical festival t-shirt', a chi-square test of independence was conducted to examine the association between the number of each type of festival t-shirt sold and respondents' answer to question five of the survey that asked them to report their level of environmental awareness (Appendix D).

For additional validation of each chi-square test result, Cramer's V value was also computed using SPSS. Cramer's V test is statistical test used post chi-square test to measure the strength of association between variables after the chi-square has determined significance (Franke, 2012). Where chi-square tests only tell you whether or not two variables are associated, Cramer's V measures the strength of association between ordinal variables (Franker, 2012). Cramer's V is measured on a scale of 0 to 1 , where 0 indicates no association and 1 indicates a perfect relationship. Any Cramer's V value between 0.3 and 0.5 denotes a strong association between variables. A Cramer's V value between 0.5 and 1 , although high, may be worrisome as it may indicate that the variables are too similar or are measuring the same concept (Franker, 2012). 


\subsection{Ethics}

Approval for the current study was obtained on March 22, 2016, by Ryerson University's Research and Ethics Board. The Research and Ethics Board approved the consent form, recruitment form, and online survey questions. The consent form detailed the purpose of the project, potential risks for participants, how the data would be stored and used, the anonymity of the participants, and the contact information of the researcher and graduate supervisor (Appendix F). Upon request by the Research and Ethics Board, it should be noted that Mariposa's festival coordinators agreed to the procurement, market, and sale of multiple types of festival t-shirts. Mariposa's festival coordinators also purchased all of the t-shirts and received all of the profits from the t-shirt sales.

\subsection{Limitations}

There were several limitations research, some of which were methodological and some were environmental. The first environmental limitation was that there were certain days, and certain times of day, during the festival that yielded a higher volume of festival attendees. This fluctuation in traffic was based on when the most popular musicians were performing and may have impacted the number of festival t-shirts sold in a given time segment. To help overcome this potential limitation the researcher alternated between employing the control and the marketing treatment at two-hour time intervals each day.

Since Mariposa Folk Festival was outdoors, another environmental limitation was weather variability. On Friday July 8, 2016, a severe storm and hurricane warning forced the festival to shut down at approximately 7:50pm. As such, the experiment was halted before 
completion of the treatment phase and impacted both the number of festival t-shirts sold and the number of individuals surveyed.

The third environmental limitation was that the festival layout was difficult to conceptualize without having been there prior to conducting the experiment. This particularly affected the jumbotron message in marketing treatment two, as it was assumed that the jumbotron would be a large screen on the main stage. The main stage was also assumed to be a high traffic area. In actuality, the jumbotron was beside the stage behind a chain-link fence, and was much smaller in size than originally anticipated (Figure 13).

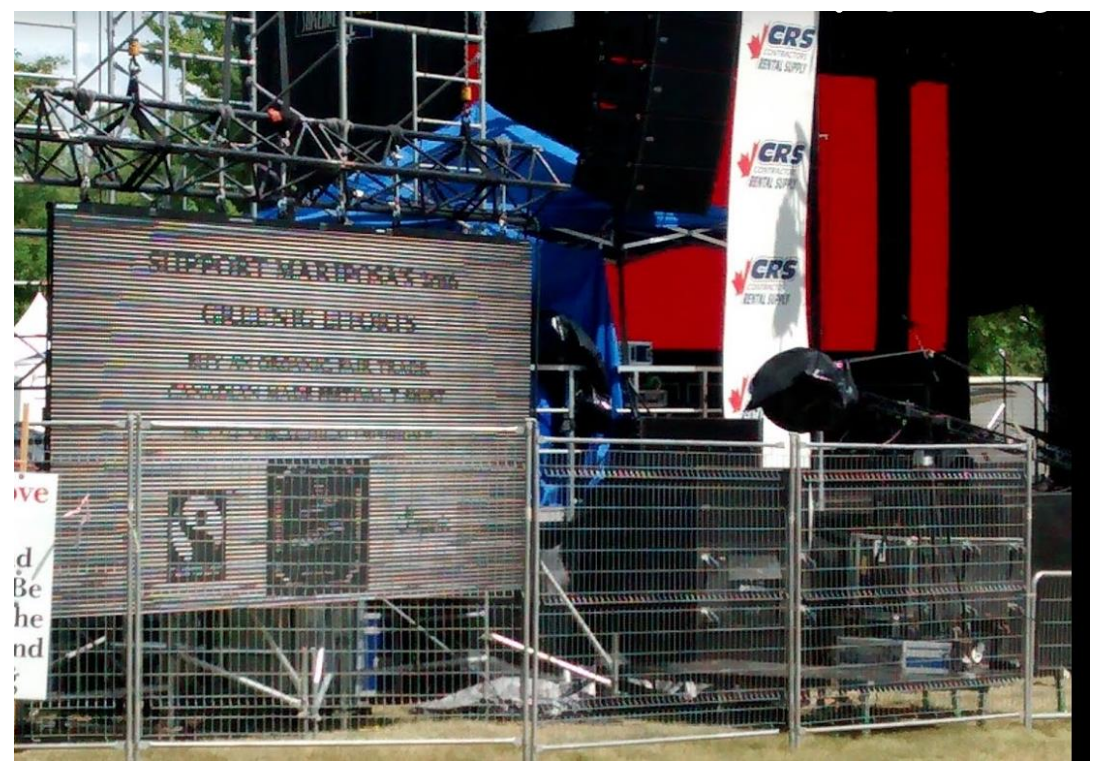

Figure 13: Location of the jumbotron displaying promotional messages of the fair trade/organic festival $t$-shirts for treatment two of the experiment.

The main stage was also not the high traffic area it was thought to be, and was unoccupied for the majority of the day. Very few attendees were able to see the jumbotron messages, 
which impacted the number of each type of festival t-shirt sold and the total number of festival t-shirts sold during treatment two.

The first methodological limitation to this research was that the three types of festival tshirts for sale were supposed to be a $\$ 20.00$ CAN conventional cotton t-shirt that was made in China, a $\$ 25.00$ CAN cotton $t-s h i r t$ that was certified fair trade and made in Canada, and a \$30.00 CAN locally made t-shirt that was certified organic cotton and certified fair trade. The $\$ 25.00$ CAN t-shirt was meant to have internal fair trade certification. These specifications were communicated to the festival coordinators, but due to an oversight or lack of availability amongst $t$-shirt suppliers that fit the criteria, the $\$ 25.00$ CAN $t$-shirt was not certified fair trade. Fortunately, the $\$ 25.00$ CAN festival t-shirt was produced by a reputable Canadian company that manufactures their products locally and engages in socially responsible operations and partnerships.

The second methodological limitation was that all three types of festival t-shirts were supposed to be identical in terms of colour and design, which was again communicated to the festival coordinators. In actuality, the festival t-shirts differed slightly in terms of colours available in each of the three t-shirt categories. While the $\$ 25.00$ and $\$ 30.00$ CAN festival t-shirts were available in the same colours (black, white, navy, and gray), the $\$ 20.00$ CAN t-shirts were available in an additional two colours (blue and purple). The intention was that all three types of festival t-shirts were supposed to be identical in design and colour, the only differences being the country of origin, certifications, and visibility of certifications. This discrepancy in colour may have caused sampling bias, as it acted as an 
additional variable that influenced which type of festival t-shirt is purchased. It should be noted that limitations two, three, and four were beyond the control of the researcher.

Another methodological limitation was that although the five volunteers were briefed on what to say to attendees during marketing treatment one, without a set hardcopy script there was still opportunity for inconsistencies in what and how messages were being communicated amongst the volunteers.

A fourth methodological limitation was that according to the survey responses, individuals who purchased the $\$ 30.00$ CAN fair trade/organic cotton t-shirt were the most willing to participate in the survey. This tendency may have somewhat biased the survey results.

It is important to note that the generalizability of the data is also limited as it only accounted for those individuals at Mariposa Folk Festival who had the intent to purchase a festival t-shirt. Therefore assumptions cannot be made about the entire population of festival attendees.

The final methodological limitation to this research was that there was a difference in the number of festival t-shirts sold according to the cash register tallies, and the number sold according to the hand tally performed by the researcher and volunteers. According to the register tallies, a total of 350 festival t-shirts were sold from July 8-10, 2016. According to the hand tally, a total of 254 festival t-shirts were sold during the experiment. This discrepancy may have been a result of the variable weather, during shift changes amongst the five volunteers, or t-shirts purchased outside of the field experiment. It is important to note, however, that the proportions of each type of festival t-shirt sold, according to both tallies, are not significantly different from one another according to statistical testing. The 
cash register tally $(\mathrm{N}=350)$ was used to test $H 1$ as this was the primary method of recording the t-shirt sales, but the hand tally $(\mathrm{N}=254)$ was used to test $H 2$ which involved the marketing treatments as the number of t-shirts sold during the marketing treatments and control periods were only recorded by hand. 


\subsection{Results}

\subsection{Introduction}

This section presents the findings of the primary research from both the field experiment and the online survey. The primary results of the field experiment, which details the number of each type of festival t-shirt sold at Mariposa Folk Festival, are presented first. The primary research results also include evaluation of the interdependence between the time-phased marketing treatments and the number of each type of festival t-shirt sold in a given time period. After the findings from the field experiment have been presented, the results of the online survey are analyzed. The demographics of survey respondents are presented next, followed by evaluation of the influence of certification visibility on the type of festival t-shirt purchased, and the influence of environmental awareness on the type of festival t-shirt purchased. This chapter also discusses all other significant findings from the survey results. The final chapter of this section will summarize the significant findings and highlight any discrepancies that were found.

\subsection{Field Experiment}

From July 8 to July 10, 2016, a total of 350 festival t-shirts were sold at Mariposa Folk festival. This count is based on the cash register tallies. A detailed analysis of the t-shirt sales and the influence of the time-phased marketing treatments on t-shirt sales is presented below.

\subsubsection{Results of T-shirt Sales}

Of the 350 t-shirts sold, $27 \%$ purchased the conventional $\$ 20.00$ CAN t-shirts, 37\% purchased the $\$ 25.00$ CAN socially responsible t-shirts, and 36\% purchased the $\$ 30.00$ CAN fair trade and organic cotton t-shirts with external certification labels (Table 5). These 
counts were tallied over the course of the festival weekend using the cash registers. A chisquare test for goodness of fit was then applied to these results to determine if there was any statistically significant difference among the number of each type of festival t-shirt sold. The a priori, or expected count, used for this chi-square test was an equal three-way distribution of the total number of festival t-shirts sold.

\section{Table 5}

Chi-square test results for the total number of each type of $t$-shirt sold.

\begin{tabular}{|ccc|}
\hline \multirow{2}{*}{ Type of Festival T-shirt } & \multicolumn{2}{c|}{ Number of Festival T-shirts Sold } \\
\cline { 2 - 3 } & $\mathbf{N}$ & $\mathbf{\%}$ \\
\hline Conventional (\$20 CAN) & 94 & 27 \\
\hline $\begin{array}{c}\text { Socially Responsible } \\
\text { (\$25 CAN) }\end{array}$ & 130 & 37 \\
\hline $\begin{array}{c}\text { Fair Trade/Organic Certification } \\
\text { (\$30 CAN) }\end{array}$ & 126 & 36 \\
\hline
\end{tabular}

Note: $\chi^{2}(2,350)=6.67^{*}, p=0.035$. Numbers in parentheses indicate column percentages.

Chi-square results show a statistically significant difference $(p=0.035)$ in $t$-shirt sales between each of the three types of festival t-shirts. Both the $\$ 25.00$ CAN socially responsible t-shirts and the $\$ 30.00$ CAN fair trade/ organic t-shirts outsold the conventional $\$ 20.00$ CAN t-shirts. The $\$ 25.00$ CAN t-shirts sold the most of the three types of festival t-shirts, but this lead was marginal over the $\$ 30.00$ CAN t-shirts.

To test H1, 'festival attendees will pay a premium for the ethical festival $t$-shirts over the conventional alternative', the counts for the $\$ 25.00$ CAN and $\$ 30.00$ CAN t-shirt sales were pooled to represent the number of ethical festival t-shirts sold (Table 6). A chi-square test for goodness of fit was applied to these results to determine if there was any statistically significant difference between the numbers of ethical t-shirts sold ( $\$ 25.00$ and $\$ 30.00$ 
CAN)and the number of conventional t-shirts sold ( $\$ 20.00 \mathrm{CAN})$. The a priori used was an equal two-way distribution of the total number of festival t-shirts sold.

Table 6

Chi-square test results for ethical and conventional festival t-shirt sales.

\begin{tabular}{|ccc|}
\hline \multirow{2}{*}{ Type of Festival T-shirt } & \multicolumn{2}{c|}{ Number of Festival T-shirts Sold } \\
\cline { 2 - 3 } & $\mathbf{N}$ & $\boldsymbol{\%}$ \\
\hline Conventional $(\$ 20 \mathrm{CAN})$ & 94 & 27 \\
\hline Ethical $(\$ 25 \&$ \&30 CAN) & 256 & 73 \\
\hline
\end{tabular}

Note: $\chi^{2}(1,350)=74.98^{*}, p=0.0001$. Numbers in parentheses indicate column percentages.

Chi-square results indicate a statistically significant difference $(p=0.0001)$ between the number of conventional t-shirts sold and the number of ethical t-shirts sold. The combined sale of the $\$ 25.00$ CAN and $\$ 30.00$ CAN festival t-shirts (i.e. the ethical festival t-shirts) represent $73 \%$ of total t-shirt sales, versus $27 \%$ for the conventional $\$ 20.00$ CAN festival tshirt. Therefore, $H 1$ 'individuals will pay a premium for the ethical festival $t$-shirts over the conventional alternative', is accepted.

\subsubsection{Influence of the Marketing Treatments}

The total number of festival t-shirts sold throughout the time-phase portion of the field experiment, where marketing and control periods were applied, was 254. It is important to note that Friday yielded no t-shirt sales during the control period, as inclement weather caused the festival to shut down early, resulting in incomplete marketing and control treatments. Therefore, Friday's results are excluded from statistical testing because they are not comparable. Excluding Friday's results, the number of festival t-shirts sold throughout the time-phase portion of the field experiment was 227. Both Saturday and Sunday had the same number of marketing treatments and controls, therefore only the 
proportions of t-shirt sold during these two days were put through statistical analysis.

Saturday's t-shirt sales are used to represent treatment one and Sunday's t-shirt sales are used to represent treatment two. The number of each type of festival t-shirt sold during the controls and both the treatment phases was collected during each of the three days of the festival (Table 7). A chi-square test of independence was used to determine if there was a statistically significant difference in the number of each type of festival t-shirt sold during marketing treatment one and marketing treatment two. A total of 59 festival t-shirts were sold during Saturday's marketing treatments (treatment one), compared to a total of 44 festival t-shirts sold during Sunday's marketing treatments (treatment two). The results of this test will elucidate if one treatment was more effective than the other. The a priori, or expected counts, used for this chi-square test were the number of each type of festival tshirt sold during the control periods on Saturday and Sunday.

Table 7

Chi-square test results for the number of each type of t-shirt sold during treatment one and two.

\begin{tabular}{|c|c|c|c|c|c|c|c|c|}
\hline \multirow{3}{*}{$\begin{array}{c}\text { Type of Festival } \\
\text { T-shirt }\end{array}$} & \multicolumn{4}{|c|}{ Saturday } & \multicolumn{4}{|c|}{ Sunday } \\
\hline & \multicolumn{2}{|c|}{ Treatment 1} & \multicolumn{2}{|c|}{ Control } & \multicolumn{2}{|c|}{ Treatment 2} & \multicolumn{2}{|c|}{ Control } \\
\hline & $\mathbf{N}$ & $\%$ & $\mathbf{N}$ & $\%$ & $\mathbf{N}$ & $\%$ & $\mathbf{N}$ & $\%$ \\
\hline Conventional ( $\$ 20$ CAN) & 15 & 25 & 17 & 25 & 8 & 18 & 12 & 22 \\
\hline $\begin{array}{c}\text { Socially Responsible } \\
\text { (\$25 CAN) }\end{array}$ & 26 & 44 & 26 & 38 & 21 & 48 & 22 & 39 \\
\hline $\begin{array}{c}\text { Fair Trade/Organic Certification } \\
\text { (\$30 CAN) }\end{array}$ & 18 & 31 & 25 & 37 & 15 & 34 & 22 & 39 \\
\hline
\end{tabular}

Note: $\chi^{2}(2,103)=0.38, p=0.536$. Numbers in parentheses indicate column percentages.

Chi-square results show that there was no statistically significant difference $(\mathrm{p}=0.536)$ between the number of each type of festival t-shirt sold during marketing treatment one and marketing treatment two. Therefore, neither of the marketing treatments was more 
effective than the other. Saturday yielded a greater number of total t-shirts sold than Sunday, 127 and 100 respectively. Sunday yielded a higher proportion of sales for the ethical festival t-shirts ( $\$ 25.00 \mathrm{CAN}$ and $\$ 30.00 \mathrm{CAN}$ ) than Saturday, $82 \%$ and $75 \%$ respectively. On both Saturday and Sunday the $\$ 25.00$ CAN socially responsible festival tshirts yielded the highest sales over the other two t-shirts, $44 \%$ and $48 \%$ respectively. Similarly the $\$ 20.00$ CAN conventional festival t-shirts produced the least sales on both Saturday and Sunday, $25 \%$ and $18 \%$ respectively.

The counts for the $\$ 25.00 \mathrm{CAN}$ and $\$ 30.00 \mathrm{CAN}$ t-shirt sales were then pooled to represent the number of ethical festival t-shirts sold. A chi-square test of independence was conducted to compare the number of ethical t-shirts sold on Saturday (treatment 1) versus Sunday (treatment 2), and determine whether the pooled counts led to a more significant result than the individual counts for each of the three types of festival t-shirts (Table 8). The a priori was the number of each type of festival t-shirt sold during the control periods on Saturday and Sunday.

Table 8 Chi-square test results for the number of ethical and conventional $t$-shirts sold during treatment one and two.

\begin{tabular}{|cccccccccc|}
\hline \multirow{2}{*}{$\begin{array}{c}\text { Type of Festival } \\
\text { T-shirt }\end{array}$} & \multicolumn{4}{c}{ Saturday } & \multicolumn{4}{c|}{ Sunday } \\
\cline { 2 - 10 } & \multicolumn{2}{c}{ Treatment 1 } & Control & \multicolumn{1}{c|}{ Treatment 2 } & \multicolumn{2}{c|}{ Control } \\
\cline { 2 - 10 } & $\mathbf{N}$ & $\mathbf{0}$ & $\mathbf{N}$ & $\mathbf{\%}$ & $\mathbf{N}$ & $\mathbf{\%}$ & $\mathbf{N}$ & $\mathbf{\%}$ \\
\hline Conventional (\$20 CAN) & 15 & 25 & 17 & 25 & 8 & 18 & 12 & 22 \\
\hline Ethical (\$25 \& \$30 CAN) & 44 & 75 & 51 & 75 & 36 & 82 & 44 & 78 \\
\hline
\end{tabular}

Note: $\chi^{2}(1,103)=0.39, p=0.536$. Numbers in parentheses indicate column percentages. 
Chi-square results demonstrate that the pooled results also show no statistically significant difference $(p=0.536)$ between the number ethical t-shirts sold and conventional t-shirts sold during Saturday's marketing treatments (treatment one) compared with Sunday's marketing treatments (treatment two). Based on these results it can be concluded that marketing treatment one was not more effective than marketing treatment two, and vice versa.

The number of each type of festival t-shirt sold during Saturday's marketing treatments (treatment one) were then compared with the number of each type of festival t-shirt sold during Saturday's control periods using a chi-square test of independence (Table 9). The results will demonstrate whether or not treatment one was effective in general. The a priori used for this test was an equal three-way distribution of the total number of festival t-shirts sold.

Table 9

Chi-square test results for the effectiveness of marketing treatment one (Saturday).

\begin{tabular}{|cccccc|}
\hline & \multicolumn{4}{c|}{ Saturday } \\
\cline { 2 - 6 } $\begin{array}{c}\text { Type of Festival } \\
\text { T-shirt }\end{array}$ & $\mathbf{N}$ & $\mathbf{0}$ & $\mathbf{N}$ & $\boldsymbol{\%}$ \\
\cline { 2 - 6 } & 15 & 25 & 17 & 25 \\
\hline Conventional (\$20 CAN) & 26 & 44 & 26 & 38 \\
\hline Socially Responsible (\$25 CAN) & 18 & 31 & 25 & 37 \\
\hline Fair Trade/Organic Certification \\
$(\$ 30$ CAN)
\end{tabular}

Note: $\chi^{2}(2,127)=0.630, p=0.73$. Numbers in parentheses indicate column percentages.

Chi-square test results indicate that there was no statistically significant difference $(\mathrm{p}=$ 0.730 ) between the number of each type of festival t-shirt sold during marketing treatment one and the controls. Therefore marketing treatment one was ineffective. 
The number of each type of festival t-shirt sold during Sunday's marketing treatments (treatment two) were also compared with the number of each type of festival t-shirt sold during Sunday's control periods using a chi-square test of independence (Table 10). The results will demonstrate whether or not treatment two was effective in general. The a prior used for this test was an equal three-way distribution of the total number of festival t-shirts sold.

Table 10 Chi-square test results for the effectiveness of marketing treatment two (Sunday).

\begin{tabular}{|ccccc|}
\hline \multirow{2}{*}{$\begin{array}{c}\text { Type of Festival } \\
\text { T-shirt }\end{array}$} & \multicolumn{4}{c|}{ Sunday } \\
\cline { 2 - 6 } & Treatment 2 & Control \\
\hline Conventional (\$20 CAN) & $\mathbf{N}$ & $\boldsymbol{\%}$ & $\mathbf{N}$ & $\boldsymbol{\%}$ \\
\hline Socially Responsible (\$25 CAN) & 21 & 48 & 22 & 39 \\
\hline Fair Trade/Organic Certification \\
(\$30 CAN)
\end{tabular}

Note: $\chi^{2}(2,100)=0.72, p=0.698$. Numbers in parentheses indicate column percentages.

Chi-square test results indicate that there was no statistically significant difference $(p=$ 0.698) between the number of each type of festival t-shirt sold during marketing treatment two and the controls. Therefore marketing treatment two was ineffective.

The number of each type of festival t-shirt sold during Saturday's marketing treatments (treatment one) and Sunday's marketing treatments (treatment two) were pooled and compared against the pooled t-shirt sales from both Saturday and Sunday's control periods. A chi-square test of independence was conducted to determine whether the pooled marketing treatments (treatment one and two) were effective (Table 11). The a priori, or 
expected count, for this test was an equal three-way distribution of the total number of each type of festival t-shirts sold.

Table 11

Chi-square test results for the number of each type of festival $t$-shirt sold during the control and pooled treatment phases.

\begin{tabular}{|ccccc|}
\hline \multirow{2}{*}{ Type of Festival T-shirt } & \multicolumn{2}{c}{ Treatments (1 \& 2) } & \multicolumn{2}{c|}{ Control } \\
\cline { 2 - 5 } & $\mathbf{N}$ & $\mathbf{\%}$ & $\mathbf{N}$ & $\boldsymbol{\%}$ \\
\hline Conventional (\$20 CAN) & 29 & 22 & 29 & 23 \\
\hline Socially Responsible (\$25 CAN) & 60 & 46 & 48 & 39 \\
\hline $\begin{array}{c}\text { Fair Trade/Organic Cotton Certification } \\
(\$ 30 \text { CAN) }\end{array}$ & 41 & 32 & 47 & 38 \\
\hline
\end{tabular}

Note: $\chi^{2}(2,227)=2.94, p=0.229$. Numbers in parentheses indicate column percentages.

Results of the chi-square test show that there was no statistically significant difference $(\mathrm{p}=$ 0.229) between the number of festival t-shirts sold during the pooled marketing treatments and the number sold during the control periods. Both the chi-square test results that examined the individual t-shirt categories, and the chi-square test results that examined the pooled data, indicated that there was no significant difference between tshirt sales during the marketing treatments and the controls. Therefore $H 2$, 'Employing marketing treatments by means of promoting the benefits of the fair trade/organic festival tshirt will increase the number of fair trade/organic festival t-shirts sold in a given time period' must be rejected.

\subsection{Online Survey}

Of the 350 festival attendees that purchased a t-shirt, 181 of these individuals completed a subsequent survey. This section first compares the number of each type of festival t-shirt sold according to the survey responses against the tallied results from the field experiment 
to ensure proportions are comparable. This section also includes analysis of the survey respondents' demographic profiles, the influence of certification visibility on the type of festival t-shirt purchased, and the influence of environmental awareness on the type of festival t-shirt purchased.

\subsubsection{Comparison of T-shirt Sales}

Proportions of t-shirt sales according to the survey results $(\mathrm{N}=181)$ were compared with the tallied results from the field experiment $(\mathrm{N}=350)$ (Table 12). The proportions of each type of festival t-shirt sold according to the survey responses differed slightly from the tallied results collected during the field experiment. It is important to note that there were more individuals who purchased a t-shirt than who answered a survey, as the survey participants only represent a sample of the t-shirt buyers. The survey responses show that the $\$ 30.00$ CAN t-shirts sold the most, while the tallied results from the field experiment indicate the $\$ 25.00$ CAN t-shirts did. A chi-square test of independence was conducted to compare t-shirt sales according to survey responses with t-shirt sales from field experiment to discern whether or not the survey responses were reflective of the t-shirt sales in the field experiment. The a priori for this test was an equal three-way distribution of the total number of festival t-shirts sold. 
Table 12

Results of chi-square test comparing t-shirt sales from the field experiment with the survey responses.

\begin{tabular}{|ccccc|}
\hline \multirow{2}{*}{ Type of Festival T-shirt } & \multicolumn{4}{c|}{ Number of Festival T-shirts Sold } \\
\cline { 2 - 5 } & \multicolumn{3}{c|}{ Online Survey } & \multicolumn{3}{c|}{ Field Experiment } \\
\cline { 2 - 5 } & $\mathbf{N}$ & $\mathbf{\%}$ & $\mathbf{N}$ & $\mathbf{\%}$ \\
\hline Conventional $(\$ 20 \mathrm{CAN})$ & 36 & 20 & 94 & 27 \\
\hline $\begin{array}{c}\text { Socially Responsible }(\$ 25 \mathrm{CAN}) \\
\text { Fair Trade/Organic Cotton Certification } \\
(\$ 30 \text { CAN) }\end{array}$ & 70 & 39 & 130 & 37 \\
\hline
\end{tabular}

Note: $\chi^{2}(2,531)=0.18, p=0.911$. Numbers in parentheses indicate column percentages.

Chi-square test results indicate that there was no statistically significant difference $(p=$ 0.911) between the proportions of t-shirts sold during the field experiment and according to the survey responses. This demonstrates that survey responses are an accurate representation of the tallied results collected during the field experiment. This ensures that further statistical testing can be performed on the survey questions using the proportions of t-shirt sales according to the survey results.

\subsubsection{Demographics of Survey Respondents}

Upon completion of the survey questions, the respondents were then asked to provide demographic information on their age and gender. In regards to gender, $57 \%$ of respondents were female, $39 \%$ were male, and $4 \%$ preferred not to disclose this information (Table 13).

Table 13

Gender demographics of survey respondents.

\begin{tabular}{|ccc|}
\hline \multirow{2}{*}{ Gender } & \multicolumn{2}{c|}{ Response Rate } \\
\cline { 2 - 3 } & $\mathbf{N}$ & $\mathbf{\%}$ \\
\hline Female & 104 & 57 \\
\hline Male & 70 & 39 \\
\hline Prefer Not to Say & 7 & 4 \\
\hline
\end{tabular}

$N=181$. Numbers in parentheses indicate column percentages. 
A chi-square test of independence comparing gender to the number of each type of festival t-shirt sold was conducted to determine if gender had any influence on which festival tshirt respondents' purchased (Table 14).

Table 14

Chi-square test results for $t$-shirt sales by gender, $(N=181)$.

\begin{tabular}{|c|c|c|c|c|c|c|}
\hline \multirow{2}{*}{ Type of Festival T-shirt } & \multicolumn{2}{|c|}{ Male } & \multicolumn{2}{|c|}{ Female } & \multicolumn{2}{|c|}{ Prefer Not to Say } \\
\hline & $\mathbf{N}$ & $\%$ & $\mathbf{N}$ & $\%$ & $\mathbf{N}$ & $\%$ \\
\hline Conventional (\$20 CAN) & 14 & 38 & 22 & 59 & 1 & 3 \\
\hline Socially Responsible (\$25 CAN) & 29 & 41 & 39 & 55 & 3 & 4 \\
\hline $\begin{array}{c}\text { Fair Trade/Organic Cotton Certification } \\
(\$ 30 \text { CAN })\end{array}$ & 27 & 37 & 43 & 59 & 3 & 4 \\
\hline
\end{tabular}

Note: $\chi^{2}(4,181)=0.443, p=0.979$. Numbers in parentheses indicate column percentages.

Chi-square test results from indicate that there is no statistically significant association $(\mathrm{p}=$ 0.979) between gender and the type of festival t-shirt purchased. A Cramer's V value of 0.04 was also obtained, demonstrating a weak association between the two variables.

In regards to age, the highest survey response rate was from the age category of $60+$ (Table 15). Although there was some variation in age, the age bracket with the highest response rate (345) was from the 60+ age category. More than half of the respondents (64\%) were 50 years of age or older.

Table 15 Age demographics of survey respondents.

\begin{tabular}{|ccc|}
\hline Age Bracket & \multicolumn{2}{c|}{ Response Rate } \\
\cline { 2 - 3 } & $\mathbf{N}$ & $\boldsymbol{\%}$ \\
\hline $18-29$ & 18 & 10 \\
\hline $30-39$ & 13 & 7 \\
\hline $40-49$ & 34 & 19 \\
\hline $50-59$ & 55 & 30 \\
\hline $60+$ & 61 & 34 \\
\hline
\end{tabular}

$N=181$. Numbers in parentheses indicate column percentages. 
A chi-square test of independence comparing age to the number of each type of festival tshirt sold was conducted to determine if age had any influence on which festival t-shirt respondents' purchased (Table 16).

Table 16

Chi-square test results for t-shirt sales by age.

\begin{tabular}{|ccc|cc|cc|cc|cc|}
\hline $\begin{array}{c}\text { Type of Festival T- } \\
\text { shirt }\end{array}$ & \multicolumn{2}{c}{$\mathbf{1 8 - 2 9}$} & $\mathbf{3 0 - 3 9}$ & \multicolumn{2}{c}{$\mathbf{4 0 - 4 9}$} & \multicolumn{2}{c|}{$\mathbf{5 0 - 5 9}$} & $\mathbf{6 0 +}$ \\
\hline $\begin{array}{c}\text { Conventional } \\
(\$ 20 \text { CAN) }\end{array}$ & 2 & 5 & 1 & 3 & 8 & 22 & 11 & 31 & 14 & 39 \\
\hline $\begin{array}{c}\text { Socially Responsible } \\
\text { (\$25 CAN) }\end{array}$ & 9 & 13 & 6 & 9 & 13 & 18 & 22 & 31 & 20 & 29 \\
\hline $\begin{array}{c}\text { Fair Trade/Organic } \\
\text { Cotton Certification } \\
(\$ 30 \text { CAN) }\end{array}$ & 7 & 9 & 6 & 8 & 13 & 17 & 22 & 29 & 27 & 36 \\
\hline
\end{tabular}

Note: $\chi^{2}(8,181)=3.87, p=0.869$. Numbers in parentheses indicate column percentages.

Chi-square test results show that there is no statistically significant association $(\mathrm{p}=0.869)$ between age and the type of festival t-shirt purchased. A weak Cramer's V value (0.103) was also obtained, affirming a weak association between the two variables.

\subsubsection{Variables that Influenced the Type of Festival T-shirt Purchased}

Respondents were asked which variables, from the list provided, influenced their decision to purchase the festival t-shirt they chose (Table 17). 
Table 17

Variables that may have influenced the type of festival t-shirt purchased.

\begin{tabular}{|c|c|c|c|c|c|c|}
\hline \multirow[b]{2}{*}{ Survey Response } & \multicolumn{5}{|c|}{ Likert Score } & \multirow[b]{2}{*}{ Mean } \\
\hline & $\begin{array}{c}5 \\
\text { Significant } \\
\text { influence }\end{array}$ & $\begin{array}{c}4 \\
\text { Influence }\end{array}$ & $\begin{array}{c}3 \\
\text { Some } \\
\text { influence }\end{array}$ & $\begin{array}{c}2 \\
\text { Minimal } \\
\text { influence }\end{array}$ & $\begin{array}{c}1 \\
\text { No } \\
\text { influence }\end{array}$ & \\
\hline I always buy ethical products & $14 \%$ & $28 \%$ & $29 \%$ & $9 \%$ & $20 \%$ & 3.31 \\
\hline $\begin{array}{l}\text { Promotion of the fair } \\
\text { trade/organic } t \text {-shirts at the } \\
\text { t-shirt emporium }\end{array}$ & $25 \%$ & $21 \%$ & $10 \%$ & $3 \%$ & $41 \%$ & 3.11 \\
\hline $\begin{array}{l}\text { The visibility of the fair } \\
\text { trade/organic certification }\end{array}$ & $19 \%$ & $21 \%$ & $12 \%$ & $3 \%$ & $45 \%$ & 2.98 \\
\hline Cost & $5 \%$ & $9 \%$ & $22 \%$ & $7 \%$ & $57 \%$ & 2.31 \\
\hline $\begin{array}{l}\text { Promotion of the fair } \\
\text { trade/organic t-shirts on the } \\
\text { jumbotron }\end{array}$ & $4 \%$ & $1 \%$ & $2 \%$ & $2 \%$ & $91 \%$ & 1.35 \\
\hline $\begin{array}{l}\text { Promotion of the fair } \\
\text { trade/organic } t \text {-shirts at the } \\
\text { education booth }\end{array}$ & $2 \%$ & $2 \%$ & $2 \%$ & $1 \%$ & $93 \%$ & 1.23 \\
\hline
\end{tabular}

Note: $N=181 /$ statement.

Based on the information presented in Table 17, the visibility of the environmental certification and the promotion of the fair trade/organic cotton festival t-shirts at the tshirt emporium had much influence on respondents' purchase decisions. Conversely, the promotion of the fair trade/organic cotton festival t-shirts at the education booth and on the jumbotron did not have much influence on respondents' purchase decision; respectively, $93 \%$ and $91 \%$ of respondents ranked the influence a one on the Likert scale.

To test the influence each variable had on the type of festival t-shirt purchased, a chisquare test was conducted comparing each of the statement responses with the type of tshirt purchased. Of the six statements outlined in Table 17, the following three variables were found to have statistically significant influence on the type of festival t-shirt purchased: cost, visibility of the fair trade/organic certification, and promotion of the fair 
trade/organic cotton festival t-shirts at the t-shirt emporium. The chi-square results for each of the statistically significant statements are outlined in the subsequent sections.

\subsubsection{Influence of Cost}

Chi-square test results indicated that there is statistically significant association $(p=0.001)$ between cost and the type of festival t-shirt purchased (Table 18). A Cramer's V value of 0.327 also verifies a strong association. This means that the type of festival t-shirt respondents' purchased was dependent on cost. The majority of respondents who indicated that cost was a significant influence on their purchase decision bought a conventional festival t-shirt ( $\$ 20.00 \mathrm{CAN}$ ). Conversely, most of the respondents who indicated cost was not an influential factor purchased either the $\$ 25.00$ or $\$ 30.00$ CAN festival t-shirt.

Table 18

Chi-square results for the influence of cost on type of festival t-shirt purchased.

\begin{tabular}{|c|c|c|c|c|c|c|c|c|c|c|}
\hline \multirow{3}{*}{ Type of Festival T-shirt } & \multicolumn{10}{|c|}{ Likert Score } \\
\hline & \multicolumn{2}{|c|}{$\begin{array}{c}5 \\
\text { Significant } \\
\text { influence }\end{array}$} & \multicolumn{2}{|c|}{$\begin{array}{c}4 \\
\text { Influence }\end{array}$} & \multicolumn{2}{|c|}{$\begin{array}{c}3 \\
\text { Some } \\
\text { influence }\end{array}$} & \multicolumn{2}{|c|}{$\begin{array}{c}2 \\
\text { Minimal } \\
\text { influence }\end{array}$} & \multicolumn{2}{|c|}{$\begin{array}{c}1 \\
\text { No } \\
\text { influence }\end{array}$} \\
\hline & $\mathbf{N}$ & $\%$ & $\mathbf{N}$ & $\%$ & $\mathbf{N}$ & $\%$ & $\mathbf{N}$ & $\%$ & $\mathbf{N}$ & $\%$ \\
\hline Conventional (\$20 CAN) & 8 & 22 & 6 & 17 & 10 & 28 & 2 & 5 & 10 & 28 \\
\hline $\begin{array}{l}\text { Socially Responsible } \\
\text { (\$25 CAN) }\end{array}$ & 0 & 0 & 5 & 7 & 17 & 25 & 5 & 7 & 43 & 61 \\
\hline $\begin{array}{l}\text { Fair Trade/Organic } \\
\text { Cotton Certification } \\
(\$ 30 \text { CAN })\end{array}$ & 1 & 1 & 5 & 7 & 13 & 17 & 6 & 8 & 50 & 67 \\
\hline
\end{tabular}

Note: $\chi^{2}(8,181)=38.67^{*}, p=0.0001$. Numbers in parentheses indicate column percentages.

\subsubsection{Influence of Certification Visibility}

Chi-square test results indicated that there is statistically significant association $(p=0.001)$ between the visibility of the fair trade/organic certification and the type of festival t-shirt purchased (Table 19). Only the results of the $\$ 30.00$ CAN fair trade/organic t-shirts were 
included in the statistical testing, as they were the only festival t-shirt that bore social and environmental certifications. A Cramer's V value of 0.323 affirms a strong association between the two variables. This means that respondents the visibility of the fair trade/organic certifications contributed significantly to the reason why they purchased the $\$ 30.00$ fair trade/organic t-shirt over the other two options. These results support $H 3$, 'the visibility of the fair trade/ organic certification label will influence individuals' willingness to purchase the fair trade/ organic l festival t-shirts'.

Table 19

Chi-square test results for the influence of certification visibility on the sale of the $\$ 30.00$ CAN festival t-shirts.

\begin{tabular}{|c|c|c|c|c|c|c|c|c|c|c|}
\hline \multirow{3}{*}{$\begin{array}{c}\text { Type of Festival T- } \\
\text { shirt }\end{array}$} & \multicolumn{10}{|c|}{ Likert Score } \\
\hline & \multicolumn{2}{|c|}{$\begin{array}{c}5 \\
\text { Significant } \\
\text { influence }\end{array}$} & \multicolumn{2}{|c|}{$\begin{array}{c}4 \\
\text { Influence }\end{array}$} & \multicolumn{2}{|c|}{$\begin{array}{c}3 \\
\text { Some } \\
\text { influence }\end{array}$} & \multicolumn{2}{|c|}{$\begin{array}{c}2 \\
\text { Minimal } \\
\text { influence }\end{array}$} & \multicolumn{2}{|c|}{$\begin{array}{c}1 \\
\text { No } \\
\text { influence }\end{array}$} \\
\hline & $\mathbf{N}$ & $\%$ & $\mathbf{N}$ & $\%$ & $\mathbf{N}$ & $\%$ & $\mathbf{N}$ & $\%$ & $\mathbf{N}$ & $\%$ \\
\hline $\begin{array}{c}\text { Fair Trade/Organic } \\
\text { Cotton Certification } \\
\text { (\$30 CAN) }\end{array}$ & 20 & 27 & 26 & 35 & 7 & 9 & 2 & 2 & 20 & 27 \\
\hline
\end{tabular}

Note: $\chi^{2}(4,181)=26.93^{*}, p=0.001$. Numbers in parentheses indicate column percentages.

\subsubsection{Influence of Marketing Promotions at the T-shirt Emporium}

Chi-square test results show that there was a statistically significant association $(p=0.001)$ between the promotion of the fair trade/organic cotton t-shirts at the t-shirt emporium and the type of festival t-shirt purchased (Table 20). The Cramer's V value of 0.323 confirms a strong association. This means the type of festival t-shirt purchased was dependent on the promotion of the fair trade/organic cotton $\mathrm{t}$-shirts at the t-shirt emporium. It is evident that the majority of respondents who purchased a fair trade/organic cotton festival t-shirt ( $\$ 30.00 \mathrm{CAN}$ ) indicated that promotion at the t-shirt emporium had significant influence on their purchase decision. 
Table 20

Chi-square test results comparing the promotion of the fair trade/organic cotton $t$-shirts at the $t$-shirt emporium and the type of festival $t$-shirt purchased.

\begin{tabular}{|c|c|c|c|c|c|c|c|c|c|c|}
\hline \multirow{3}{*}{$\begin{array}{c}\text { Type of Festival T- } \\
\text { shirt }\end{array}$} & \multicolumn{10}{|c|}{ Likert Score } \\
\hline & \multicolumn{2}{|c|}{$\begin{array}{c}5 \\
\text { Significant } \\
\text { influence }\end{array}$} & \multicolumn{2}{|c|}{$\begin{array}{c}4 \\
\text { Influence }\end{array}$} & \multicolumn{2}{|c|}{$\begin{array}{c}3 \\
\text { Some } \\
\text { influence }\end{array}$} & \multicolumn{2}{|c|}{$\begin{array}{c}2 \\
\text { Minimal } \\
\text { influence }\end{array}$} & \multicolumn{2}{|c|}{$\begin{array}{c}1 \\
\text { No } \\
\text { influence }\end{array}$} \\
\hline & $\mathbf{N}$ & $\%$ & $\mathbf{N}$ & $\%$ & $\mathbf{N}$ & $\%$ & $\mathbf{N}$ & $\%$ & $\mathbf{N}$ & $\%$ \\
\hline $\begin{array}{c}\text { Conventional (\$20 } \\
\text { CAN) }\end{array}$ & 3 & 8 & 1 & 3 & 3 & 8 & 0 & 0 & 29 & 81 \\
\hline $\begin{array}{c}\text { Socially } \\
\text { Responsible } \\
(\$ 25 \mathrm{CAN})\end{array}$ & 17 & 25 & 14 & 20 & 8 & 11 & 3 & 4 & 28 & 40 \\
\hline $\begin{array}{c}\text { Fair Trade/Organic } \\
\text { Cotton Certification } \\
(\$ 30 \mathrm{CAN})\end{array}$ & 25 & 33 & 24 & 32 & 7 & 9 & 2 & 3 & 17 & 23 \\
\hline
\end{tabular}

Note: $\chi^{2}(8,181)=37.72^{*}, p=0.001$. Numbers in parentheses indicate column percentages.

\subsubsection{Influence of Environmental Awareness}

Respondents were asked to evaluate their level of environmental awareness on a five-point Likert-scale (Table 21). A mean rating of environmental awareness was 4.05 was found, insinuating that the majority of respondents thought themselves to be environmentally conscious. This assumption is further validated by the fact that $43 \%$ of respondents ranked themselves a four on the Likert scale, and $30 \%$ of respondents ranked themselves a five on the Likert scale.

Table 21

Survey responses self-reported level of environmental awareness.

\begin{tabular}{|c|c|c|c|c|c|c|c|c|c|c|c|}
\hline \multirow{3}{*}{ Variable } & \multicolumn{10}{|c|}{ Likert Score } & \multirow{3}{*}{$\begin{array}{c}\text { Mean } \\
\mathbf{N} \\
\end{array}$} \\
\hline & \multicolumn{2}{|c|}{$\begin{array}{c}5 \\
\text { Significant } \\
\text { awareness }\end{array}$} & \multicolumn{2}{|c|}{$\begin{array}{c}4 \\
\text { Awareness }\end{array}$} & \multicolumn{2}{|c|}{$\begin{array}{c}3 \\
\text { Some } \\
\text { awareness }\end{array}$} & \multicolumn{2}{|c|}{$\begin{array}{c}2 \\
\text { Minimal } \\
\text { awareness }\end{array}$} & \multicolumn{2}{|c|}{$\begin{array}{c}1 \\
\text { No } \\
\text { awareness }\end{array}$} & \\
\hline & $\mathbf{N}$ & $\%$ & $\mathbf{N}$ & $\%$ & $\mathbf{N}$ & $\%$ & $\mathbf{N}$ & $\%$ & $\mathbf{N}$ & $\%$ & \\
\hline $\begin{array}{c}\text { Environmental } \\
\text { Awareness }\end{array}$ & 54 & 30 & 78 & 43 & 41 & 23 & 2 & 1 & 6 & 3 & 4.05 \\
\hline
\end{tabular}

Note: $N=181$. Numbers in parentheses indicate column percentages. 
A chi-square test of independence was conducted to examine the influence of self-reported environmental awareness on the type of festival t-shirt purchased (Table 22). The results were used to test H4; 'survey participants who express greater environmental awareness will be more likely to purchase an ethical festival $t$-shirt'.

Table 22

Contingency table comparing the level of environmental awareness and the type of festival tshirt purchased.

\begin{tabular}{|c|c|c|c|c|c|c|c|c|c|c|}
\hline \multirow{3}{*}{$\begin{array}{c}\text { Type of Festival T- } \\
\text { shirt }\end{array}$} & \multicolumn{10}{|c|}{ Likert Score } \\
\hline & \multicolumn{2}{|c|}{$\begin{array}{c}5 \\
\text { Significant } \\
\text { awareness } \\
\end{array}$} & \multicolumn{2}{|c|}{$\begin{array}{c}4 \\
\text { Awareness }\end{array}$} & \multicolumn{2}{|c|}{$\begin{array}{c}3 \\
\text { Some } \\
\text { awareness }\end{array}$} & \multicolumn{2}{|c|}{$\begin{array}{c}2 \\
\text { Minimal } \\
\text { awareness }\end{array}$} & \multicolumn{2}{|c|}{$\begin{array}{c}1 \\
\text { No } \\
\text { awareness } \\
\end{array}$} \\
\hline & $\mathbf{N}$ & $\%$ & $\mathrm{~N}$ & $\%$ & $\mathrm{~N}$ & $\%$ & $\mathbf{N}$ & $\%$ & $\mathbf{N}$ & $\%$ \\
\hline $\begin{array}{c}\text { Conventional (\$20 } \\
\text { CAN) }\end{array}$ & 6 & 17 & 19 & 53 & 9 & 25 & 0 & 0 & 2 & 5 \\
\hline $\begin{array}{c}\text { Socially Responsible } \\
\text { (\$25 CAN) }\end{array}$ & 19 & 27 & 29 & 42 & 19 & 27 & 1 & 1 & 2 & 3 \\
\hline $\begin{array}{c}\text { Fair Trade/Organic } \\
\text { Cotton Certification } \\
(\$ 30 \text { CAN })\end{array}$ & 29 & 39 & 30 & 40 & 13 & 17 & 1 & 1 & 2 & 3 \\
\hline
\end{tabular}

Note: $\chi^{2}(8,181)=8.05, p=0.429$. Numbers in parentheses indicate column percentages.

Chi-square test results show that there is no statistical significance $(p=0.429)$ between level of environmental awareness and the type of festival t-shirt purchased. A Cramer's V value of 0.149 affirms a weak association between the two variables. Based on these results H4, 'survey participants who express greater environmental awareness will be more likely to purchase an ethical festival $t$-shirt' is rejected. Although nearly all of the respondents who purchased a $\$ 25.00$ CAN socially responsible t-shirt or $\$ 30.00$ fair trade/organic t-shirt reported a very high level of environmental awareness, the majority of respondents who purchased a conventional $\$ 20.00$ CAN t-shirt reported the same. 


\subsubsection{Variables that Influence General Clothing Purchases}

Respondents were asked which variables, from the list provided, influenced their general clothing purchases on a regular basis. Responses were based on a 5-point Likert scale, where $5=$ significant influence and $1=$ no influence (Table 23).

The statement found to have the most influence on general clothing purchases was design (i.e. colour, style, and graphics), with a mean Likert score of 4.09. The second most influential variable was country of origin (i.e. where the clothing was made), with a mean Likert score of 3.46. Conversely, 89\% of respondents indicated that media and advertisements had no influence on their general clothing purchases, giving this variable the lowest mean Likert score (1.20). Peer influence was also found to have no influence on general clothing purchases, $82 \%$ of respondents indicated this. The results of Table 23 were not put through chi-square testing because there is no direct connection between what influences respondents' general clothing purchases and the type of festival t-shirt they purchased at Mariposa Folk Festival. 
Table 23

Variables that may influence respondents' general clothing purchases.

\begin{tabular}{|lccccccc|}
\hline \multicolumn{1}{c}{ Variable } & \multicolumn{7}{c}{ Likert Score } \\
\cline { 2 - 7 } & $\begin{array}{c}\text { Significant } \\
\text { influence }\end{array}$ & $\begin{array}{c}\mathbf{4} \\
\text { Influence }\end{array}$ & $\begin{array}{c}\mathbf{3} \\
\text { Some } \\
\text { influence }\end{array}$ & $\begin{array}{c}\mathbf{2} \\
\text { Minimal } \\
\text { influence }\end{array}$ & $\begin{array}{c}\mathbf{1} \\
\text { No } \\
\text { influence }\end{array}$ & Mean & SD \\
\hline $\begin{array}{l}\text { Design (colour, } \\
\text { style, graphics) }\end{array}$ & $47 \%$ & $31 \%$ & $13 \%$ & $2 \%$ & $6 \%$ & 4.09 & 1.13 \\
\hline $\begin{array}{l}\text { Country the } \\
\text { clothing is made in }\end{array}$ & $26 \%$ & $30 \%$ & $25 \%$ & $3 \%$ & $16 \%$ & 3.46 & 1.35 \\
\hline Cost & $13 \%$ & $39 \%$ & $29 \%$ & $2 \%$ & $17 \%$ & 3.30 & 1.23 \\
\hline $\begin{array}{l}\text { Supporting socially } \\
\text { responsible } \\
\text { clothing } \\
\text { manufacturers }\end{array}$ & $19 \%$ & $28 \%$ & $23 \%$ & $2 \%$ & $29 \%$ & 3.10 & 1.49 \\
\hline $\begin{array}{l}\text { Environmental } \\
\text { Certification }\end{array}$ & $7 \%$ & $25 \%$ & $31 \%$ & $5 \%$ & $32 \%$ & 2.71 & 1.32 \\
\hline Brand & $1 \%$ & $13 \%$ & $24 \%$ & $8 \%$ & $55 \%$ & 1.98 & 1.18 \\
\hline Peer Influence & $1 \%$ & $3 \%$ & $9 \%$ & $4 \%$ & $82 \%$ & 1.36 & 0.85 \\
\hline $\begin{array}{l}\text { Media \& } \\
\text { Advertisements }\end{array}$ & $1 \%$ & $1 \%$ & $6 \%$ & $3 \%$ & $89 \%$ & 1.20 & 0.63 \\
\hline
\end{tabular}

Note: $N=181 /$ statement.

\subsubsection{Consumers' Perception of Ethical Products}

Respondents were also asked to determine how they tend to perceive environmentally friendly products based on the 4 statements detailed in Table 24 .

These results demonstrate that there is much variation amongst responses for each of the statements. For each of the statements the majority of respondents answered with a 3 or 4 on the Likert-scale, or that they somewhat agree with the statements. The results of Table 24 were not put through chi-square testing because there is no direct connection between how respondents' perceive ethical or environmental products, and the type of festival tshirt they purchased at Mariposa Folk Festival. 
Table 24

Respondents' perception of how ethical products are marketed.

\begin{tabular}{|c|c|c|c|c|c|c|c|}
\hline \multirow[b]{2}{*}{ Variable } & \multicolumn{5}{|c|}{ Likert Score } & \multirow[b]{2}{*}{ Mean } & \multirow[b]{2}{*}{ SD } \\
\hline & $\begin{array}{c}5 \\
\text { Strongly } \\
\text { Agree } \\
\end{array}$ & $\begin{array}{c}4 \\
\text { Agree }\end{array}$ & $\begin{array}{c}3 \\
\text { Neutral }\end{array}$ & $\begin{array}{c}2 \\
\text { Disagree }\end{array}$ & $\begin{array}{c}1 \\
\text { Strongly } \\
\text { Disagree } \\
\end{array}$ & & \\
\hline $\begin{array}{l}\text { Ethical products are } \\
\text { marketed in a way that is } \\
\text { engaging and relevant }\end{array}$ & $13 \%$ & $34 \%$ & $23 \%$ & $4 \%$ & $25 \%$ & 3.06 & 1.39 \\
\hline $\begin{array}{l}\text { Ethical products stand } \\
\text { out amongst name brand } \\
\text { competitors }\end{array}$ & $12 \%$ & $29 \%$ & $32 \%$ & $4 \%$ & $23 \%$ & 3.02 & 1.32 \\
\hline $\begin{array}{l}\text { Ethical products provide } \\
\text { useful information about } \\
\text { its value }\end{array}$ & $8 \%$ & $33 \%$ & $29 \%$ & $4 \%$ & $25 \%$ & 3.00 & 1.31 \\
\hline $\begin{array}{l}\text { I find products with } \\
\text { ethical certifications to be } \\
100 \% \text { credible }\end{array}$ & $5 \%$ & $27 \%$ & $29 \%$ & $6 \%$ & $33 \%$ & 2.67 & 1.33 \\
\hline
\end{tabular}

Note: $N=181 /$ statement.

\subsection{Conclusion}

This section first detailed the primary research findings from the field experiment. It was found that the majority of attendees of Mariposa Folk Festival, who purchased a festival tshirt, were willing to pay the premium in order to purchase the certified fair trade or certified fair trade/organic cotton t-shirt. Based on these findings H1; 'individuals will pay a premium to purchase ethical festival $t$-shirts over the conventional alternative', was accepted.

The number of each type of festival t-shirt sold was then broken down into those sold during marketing treatments and those sold during the control periods. Upon further examination it was found that although more $\$ 25.00$ CAN festival t-shirts and $\$ 30.00$ CAN festival t-shirts were sold during the marketing treatments compared to the controls, the difference between the number of each type of festival t-shirt sold in the marketing treatments compared to the controls was not statistically significant. Based on these 
findings $\mathrm{H2}$; 'employing a marketing treatments that promote the ethical festival $t$-shirts will increase the number of ethical festival t-shirts sold in a given time period', was rejected.

This chapter then addressed the findings from the online survey, and looked at the variables that influenced respondents' purchase decision. Analysis of the survey data revealed that cost, visibility of the environmental certification, and promotion of the fair trade and fair trade/organic cotton t-shirts at the t-shirt emporium all had statistically significant associations in regards to the type of festival t-shirt respondents purchased. Chisquare testing revealed that the visible fair trade/organic certification on the $\$ 30.00$ CAN festival t-shirts influenced attendees to purchase that particular t-shirt. These results support H3; 'the visibility of the fair trade/ organic certification label will influence individuals' willingness to purchase the fair trade/ organic festival t-shirts.

Finally this chapter examined the relationship between respondents' level of environmental awareness and the type of festival t-shirt purchased. These two variables were not found to have a statistically significant association with one another. Therefore, H4; 'survey participants who express greater environmental awareness will be more likely to purchase an ethical festival t-shirt' was rejected. It was noted that the majority of respondents reported a high level of environmental awareness despite which of the three festival t-shirts they purchased. 


\subsection{Discussion}

This section will discuss the key findings and results of the research in relation to the existing literature. This section begins by interpreting the findings of the field experiment and discussing the novelty of studying actual purchase behaviour in the context of WTP research. Next, the influence of the marketing treatments on the type of festival t-shirt purchased is discussed. Key variables from the survey found to influence the type of festival t-shirt purchased, as well as individuals' general clothing purchases are analyzed. These findings are compared with similar WTP studies on the topic of ethical clothing acquisition. The relationship between environmental awareness and the purchase of ethical clothing products is also explored. This chapter concludes by addressing some of the potential barriers to buying ethical clothing by examining how consumers perceive ethical products.

\subsection{Actual Purchase Behaviour of Ethical Clothing}

Based on the results of this study it was concluded that attendees of Mariposa Folk Festival in 2016 paid a premium for ethical festival t-shirts (i.e. $\$ 25.00$ and $\$ 30.00$ CAN) over the conventional alternative ( $\$ 20.00 \mathrm{CAN})$. The majority of attendees purchased an ethical festival t-shirt (73\%), over the conventional alternative (27\%). This is synonymous with Andorfer and Liebe (2015), one of the only other studies to date that examined actual purchase behaviour in the context of ethical consumption. Andorfer and Liebe's (2015), field experiment examining actual purchase behaviour, also found that when given the choice between multiple types of coffee, consumers paid a premium for the ethical coffee (i.e. fair trade and/or organic) over the conventional alternative. 
It is also important to note that more individuals purchased festival t-shirts than completed surveys. Interestingly, the proportions of each type of t-shirt sold varied slightly between the field experiment and the survey responses. According to the survey responses a higher proportion of the $\$ 30.00$ CAN fair trade/ organic cotton t-shirts were reportedly sold compared to the field experiment tally. This implies that individuals who purchased the $\$ 30.00$ CAN t-shirt were the most willing to participate in the subsequent survey compared to individuals who purchased the $\$ 20.00$ and $\$ 25.00$ CAN t-shirts. This might have been due to the fact that purchasers of the $\$ 30.00$ CAN t-shirt were intrinsically motivated to participate because they felt good about their purchase decision.

One objective of the current study was to examine the relationship between hypothetical WTP and actual purchase behaviour, by building on the results of the WTP study conducted by Dodds et al. (2016). Dodds et al. (2016) found that attendees of Mariposa Folk Festival, in 2015 , reported they would be willing to pay more for festival t-shirts that were fair trade and/or possessed environmental messaging over the conventional alternative. In this regard the current study demonstrated that actual purchase behaviour corresponded with self-reported WTP, as both studies demonstrated that ethical festival t-shirts were preferable over conventional festival t-shirts. Reynolds et al. (2015) was the only study to date that directly compared hypothetical WTP and actual purchase behaviour in relation to ethical consumption. Reynolds et al. (2015) found that hypothetical WTP did not correspond with actual purchase behaviour, contrary to the results of the current study and the findings from Dodds et al. (2016). With so few studies comparing WTP to actual purchase behaviour it is not currently possible to detect a trend in the relationship between hypothetical WTP and corresponding purchase behaviour. 
When comparing the results of the current study with Reynolds et al. (2015), there are several variables that may have influenced the outcome of the relationship between hypothetical WTP and actual purchase behaviour. As Mariposa Folk Festival had already established strong environmental management strategies and initiatives, this event may have attracted attendees that also possessed strong environmental and ethical values, which may have influenced their purchase decision. Results of the Reynolds et al. (2015) study were based on an entirely random sample of participants on the island of St. Lucia. Comparatively, attendees of Mariposa Folk Festival were all attending an event with a strong environment focus.

Some form of social desirability bias, where individuals act in a manner that others would perceive as 'good behaviour' (Kilbourne and Pickett, 2008), may have also influenced the current study. Attendees of Mariposa Folk festival may have purchased one of the ethical festival t-shirts over the conventional one because they felt external pressure, or like it was the right thing to do. This phenomenon also relates back to theoretical research on VBNT which demonstrates that societal norms and ascription of responsibility play a role in influencing an individuals' decision to engage in ethical behaviour (Stern et al., 1999; Kilbourne and Pickett, 2008; Fischer and Dam, 2015).

\subsection{Influence of Marketing Treatments on Ethical Clothing Acquisition}

Another objective of the current study was to examine variables that may influence attendees' decision to purchase one type of festival t-shirt over another. One way influence was examined was through implementation of two types of marketing treatments that promoted the ethical festival t-shirts through various means. The key finding was that 
although more ethical festival t-shirts ( $\$ 25.00$ and $\$ 30.00$ CAN) were sold during the marketing treatments compared to the controls, $51 \%$ and $49 \%$ respectively, the difference in total t-shirt sales was marginal. Ultimately, the marketing treatments were found to have no statistically significant influence on the type of festival t-shirt purchased. This is an interesting finding because according the results of the survey, promotion of the ethical festival t-shirts at the t-shirt emporium had a statistically significant influence on the type of festival t-shirt respondents purchased. This provides evidence that consumer perceptions may not always correspond with their actual behaviour. This represents another type of behaviour gap, synonymous with the attitude-behaviour gap demonstrated in much of the relevant literature on ethical consumption (Pickett-Baker and Ozaki, 2008; Ku and Zaroff, 2014; Reynolds, 2015; Ozdamar and Atik, 2015). One reason for this may be that respondents would have purchased the festival t-shirt that they did regardless of marketing promotions, and only when they were presented with the question and had to think about what may have influenced their decision did they consider the marketing promotions.

Relevant literature on marketing environmental products indicates that strategic environmental messaging and advertising are essential in encouraging environmentally responsible purchasing in consumers. Strategic marketing can refer to marketing products at certain times of day, at specific locations to reach a maximal audience, or tailoring advertisements to cater to a target audience (Pickett-Baker and Ozaki, 2008; Yan et al., 2012). This proved to be true during the field experiment, as the influence of the marketing treatments varied based on whether the ethical festival t-shirts were being marketed in a high traffic or low traffic area of the festival. According to the survey results, promotion of 
the ethical festival t-shirts at the t-shirt emporium, a high traffic area, had a statistically significant influence on the type of festival t-shirt purchased. Conversely, promotion of the ethical festival t-shirts at the education booth and on the jumbotron had no significant influence of the type of t-shirt purchased; these turned out to be fairly low traffic areas within the festival. This may have resulted because the researcher was stationed at, and allocated the most resources to, the t-shirt emporium. Unlike the other locations, attendees had the opportunity to ask the researcher questions and clarify any misunderstandings they had about the t-shirts themselves and the social and environmental impacts of the clothing industry. This is consistent with existing literature on marketing ethical clothing, which expresses that explicitness of the message being conveyed, and the amount information provided on the product, impacts product sales (Pickett-Baker and Ozaki, 2008; Yan et al., 2012).

\subsection{Influence of Cost on Ethical Clothing Purchases}

Joergens (2006), Hiller-Connell (2010), Ha-Brookshire and Norum (2011), Ellis et al. (2012), and Ozdamar and Atik (2015) all found price to be one of the most important factors when making clothing purchases. The results of this study found that attendees who purchased a \$30.00 CAN festival t-shirt reported that price was of little influence on their purchase decision, while attendees who purchased a \$20.00 CAN festival t-shirt reported that price was of significant importance. This difference may again be due to the fact that attendees of Mariposa Folk Festival may have stronger ethical values than a more random population sample. This result may also be due to the fact that the majority of attendees were over the age of 50, meaning potentially higher income levels, compared to Joergens (2006) and Hiller-Connell (2010) whose participants were all under the age of 30. 
Andorfer and Liebe's (2015) study on WTP for certified fair trade and organic coffee found that reducing the cost of the certified fair trade and organic products significantly increased purchases, while providing additional information on buying certified fair trade and organic coffee did not. Andorfer and Liebe (2015), however, only provided a small visual sign to provide consumers with additional information on buying fair trade and organic, which may be why it had little influence over their purchase decisions. The current study used multiple methods of promoting the fair trade/organic cotton festival t-shirts, including both visual displays and verbal communication. Multiple communication pathways likely resulted in a more comprehensive promotion of the ethical festival t-shirts, which may be why promoting the ethical t-shirts at the t-shirt emporium had significant influence on the type of festival t-shirt purchased.

\subsection{Influence of Certification Visibility on Ethical Clothing Purchases}

The study by Dodds et al. (2016) was the only other to examine the influence of the visibility of an environmental certification on one's WTP for environmentally responsible clothing. The results of the current study parallel the findings from Dodds et al. (2016) in that both studies found certification visibility to have significant influence on one's WTP for ethical festival t-shirts. The findings from the current study indicated that there was a strong association between visibility and the type of $t$-shirt purchased, for the $\$ 30.00$ CAN fair trade/organic cotton t-shirts with external visibility. One possible reason for this outcome is that individuals whose purchase decision was influenced by certification visibility, like to advocate their concern for the environment and indirectly spread awareness to other members of society by providing visible evidence of their environmentally responsible behaviour. In some respect this could be considered both an 
intrinsic and extrinsic motivation. Intrinsic because advocating ethical purchases and ERB may make an individual feel good about themselves, and extrinsic because they may be motivated by the potential to receive praise for their actions. Previous research on ethical consumption also indicated that ambiguous labelling was a potential barrier to clothing purchases (Ozdamar and Atik, 2015), based on these results it appears that the current study overcame this obstacle by ensuring products were procured from credible sources and were properly marked.

\subsection{Influence of Design on Clothing Purchases}

Another prominent finding from the current study was that the majority of survey respondents indicated that design (i.e. colour, style, and graphics) had the greatest influence on their general clothing purchases. In terms of actual t-shirt purchases design may have been a non-issue in some respects, as all festival t-shirts possessed the same graphics, however there were two additional colour options for the conventional $(\$ 20.00$ CAN) t-shirts which some attendees reported to have swayed their purchase decision. This is consistent with previous literature that indicates design is a primary motive for making clothing purchases (Joergens, 2006; Hiller-Connell, 2010; Lundblad and Davies (2015; Ozdamar and Atik, 2015).

\subsection{Environmental Awareness and Ethical Consumption}

Much of the current WTP literature indicated that there was an attitude-behaviour gap between environmental awareness and purchase behaviour. Existing literature on this subject demonstrates that high levels of environmental awareness are not significant predictors of purchasing environmental products or engaging in environmentally responsible behaviours (Didier and Lucie, 2008; Ku and Zaroff, 2014; Reynolds, 2015). In 
accordance with the existing literature, the results of the current study indicated a high level of environmental awareness amongst respondents; however, high levels of environmental awareness were not a significant predictor of the type of festival t-shirt purchased. Although nearly all of the respondents who purchased a fair trade/organic cotton t-shirt ( $\$ 30.00 \mathrm{CAN}$ ) or a socially responsible t-shirt ( $\$ 25.00 \mathrm{CAN}$ ) reported a very high level of environmental awareness, the majority of respondents who purchased a conventional ( $\$ 20.00 \mathrm{CAN}$ ) t-shirt reported the same. A similar result was seen in the study by Dodds et al., (2016), who found that self-reported environmental awareness was not significantly associated with $\mathrm{t}$-shirt message treatment or fair trade certification. The reason for this disconnect is likely because without any incentives or consequences, individuals are likely to overstate their environmental concern or awareness (Michaud and Llerena, 2011; Barbarossa and Pastore, 2015). This finding also gives validation to the sample population, as the lack of correlation between environmental awareness and purchase decision suggests that Mariposa's existing environmental focus did not bias the survey results. It is also important to note that a possible reason as to why there is much inconsistency regarding whether an attitude-behaviour gap exists is because researchers are asking participants questions regarding their environmental attitudes that are too general or not directly related to the environmental behaviour being observed. With specific regards to this study, the lack of correlation between environmental awareness and purchase decision may have been due to the fact that general environmental awareness was not a specific enough to be directly associated with individuals' purchase decisions. 


\subsection{Consumers' Perception of Ethical Products}

Another interesting finding from the survey component of this study was that there was much variation and no clear patterns in regards to how consumers perceive ethical products. Respondents were asked if they thought most environmental products provide them with enough information about their value, whether they find environmental products to be credible, whether they are marketed in a way that is engaging, and whether environmental products stand out amongst name-brand alternatives. The lowest mean Likert score was concerning the credibility of ethical products. This is reflective of previous literature that found fear of 'greenwashing' to be a common obstacle preventing consumers from purchasing ethical products (Ozdamar and Atik, 2015). Although this finding does not affect the results of this study, it may have important implications for future research on marketing ethical products. Proper labelling and better communication of the socially and environmentally responsible product features may help consumers become more confident in a products' value and the retailers' credibility. 


\subsection{Conclusions}

The previous section discussed the prominent findings of the current research and how it fits in with relevant research on ethical clothing consumption. This section summarizes the key findings and addresses the broader implications the current research. In this respect, the academic implications and potential for future research is discussed. Overall, this research helped reduce the gap that existed in the literature on the subject of examining WTP versus actual purchase behaviour, and further explored motivations behind consumers' purchase decisions in regards to environmentally responsible clothing. The purpose of this study was to answer following research question; will individuals at Mariposa Folk Festival pay a premium for ethical festival t-shirts, and will certain variables influence their purchase decision? For the context of this study, ethical festival t-shirts refers to either festival t-shirts that are produced locally from a socially responsible company or festival t-shirts produced locally that are certified fair trade and organic cotton. To answer the research questions, the following four hypotheses were tested:

H1: Individuals will pay a premium to purchase the ethical festival $t$-shirts over the conventional alternative.

H2: Employing marketing treatments that promote the ethical festival t-shirts will increase the number of ethical festival $t$-shirts sold in a given time period.

H3: The visibility of the fair trade/ organic certification label will influence individuals' willingness to purchase the fair trade/ organic festival t-shirts.

H4: Survey participants who express greater environmental awareness will be more likely to purchase an ethical festival t-shirt.

\subsection{Summary of Key Findings}

In relation to the research objectives and subsequent hypotheses, there were five key findings from the current research. The first was that attendees of Mariposa Folk Festival, 
2016, paid a premium for socially responsible or fair trade/organic festival t-shirts over the conventional alternative. The second finding was that actual behaviour observed in this study corresponded with the hypothetical WTP from Dodds et al. (2016). The third conclusion drawn was that during the field experiment, marketing treatments were found to have no significant influence on the number of ethical festival t-shirts sold. Another finding was that the visibility of the fair trade/organic certification influenced attendees to purchase the \$30.00 CAN fair trade/organic cotton festival t-shirt. The fifth and final conclusion was that environmental awareness was not a significant predictor of which tshirt a festival attendee purchased. Each of these findings is discussed in further detail below.

\subsubsection{Paying a Premium for Ethical Festival T-shirts}

This research determined that attendees of Mariposa Folk Festival paid a premium to purchase certified fair trade/ organic festival t-shirts over conventional cotton t-shirts with no environmental certification. Results of this study indicated that the majority of attendees of Mariposa Folk Festival, who purchased a festival t-shirt, were willing to pay the premium in order to purchase the certified fair trade or certified fair trade/organic cotton t-shirt. Based on these findings H1; 'Individuals will pay a premium to purchase the ethical festival t-shirts over the conventional alternative', was accepted.

\subsubsection{Influencing Purchase Decisions}

$H 2, H 3$, and $H 4$ were tested to determine what variables had the greatest influence over purchase decisions. Through the field experiment it was determined that although more $\$ 25.00$ CAN festival t-shirts and \$30.00 CAN festival t-shirts were sold during the marketing treatments compared to the controls, the difference between the number of each 
type of festival t-shirt sold in the marketing treatments compared to the controls was not statistically significant. Based on these findings H2; 'employing marketing treatments that promote the ethical festival $t$-shirts will increase the number of ethical festival $t$-shirts sold in a given time period', was rejected. However, based on the online survey results promotion of the fair trade/ organic cotton festival t-shirts at the t-shirt emporium were found to significantly influence the type of festival t-shirt purchased, while promotion on the jumbotron and at the education booth had no effect on purchases.

Data collected from online survey was used in conjunction with the field experiment to test $H 3$ and $H 4$. Chi-square testing revealed that the visibility of the fair trade/organic certification on the $\$ 30.00$ CAN festival t-shirts influenced attendees to purchase that particular t-shirt. These results support $H 3$; 'the visibility of the fair trade/ organic certification label will influence individuals' willingness to purchase the fair trade/ organic festival t-shirts'. Chi-square testing also determined that environmental awareness was not related to the type of festival t-shirt purchased. Therefore, H4; 'survey participants who express greater environmental awareness will be more likely to purchase an ethical festival tshirt', was rejected. It was noted that the majority of respondents reported a high level of environmental awareness despite which of the three festival t-shirts they purchased. Analysis of the survey data also revealed that cost had statistically significant influence on the type of festival t-shirt respondents purchased.

\subsection{Contribution of the Research}

While a couple WTP exist that examine actual purchase behaviour of consumers, no previous research was done on actual purchase behaviour in regards to ethical clothing. Similarly, while several studies examine hypothetical WTP for ethical clothing products, 
only one study examined WTP for ethical clothing within a festival context (Dodds et al., 2016). This study filled the gap in existing literature and built on the results of Dodds et al.'s (2016) study by examining the relationship between hypothetical WTP and corresponding behaviour. Based on the limited amount of research that has been done in regards to actual purchase behaviour and ethical clothing consumption in a festival context, this research presents novel findings. This is one of the first studies to examine WTP versus actual purchase behaviour, and the first to do so in regards to ethical clothing consumption. Furthermore, the current study contributed to Mariposa Folk Festival by providing the necessary funding and resources to help them explore the potential merchandising capabilities at their event.

\subsection{Implications of the Research}

This information will provide festival organizers insight into how much consumers are willing to pay for clothing that is environmentally responsible, the factors that influence consumers' purchasing behaviours, and how consumers perceive and value festival clothing and merchandise. The sale of environmentally responsible apparel is important in festival settings, as festival merchandise is a way for both attendees and event organizers to demonstrate environmentally responsible behaviour. Engaging in the purchase of environmentally certified apparel at an event may help increase their environmental awareness and result in them engaging in more environmentally responsible behaviours outside of the event. The sale of environmentally certified and ethically sourced festival clothing will also help contribute to Mariposa's environmental management initiatives. Effectively communicating the social and environmental benefits of buying certified fair trade and organic clothing over conventional alternatives may also help encourage festival 
attendees to engage in more environmentally responsible purchasing in their everyday lives. While this research has many implications for the festival organizers of Mariposa, it is also applicable to the organizers of any festival or event. These findings are especially relevant for festival organizers who are looking to take on new environmental initiatives or reduce some of the social and environmental impacts of their festival. The results of this study also has tremendous merchandising implications for festival managers, as they can gain a better understanding of consumer preferences and merchandising capabilities. Understanding how much of a premium attendees will pay for socially and environmentally responsible t-shirts can help to increase profits in future years.

\subsection{Future Research}

The results of this study demonstrate that there is a market for fair trade and organic festival clothing, but whether or not that market exists outside Mariposa Folk Festival is unknown. This research is limited by the generalizability of the data and the sample of participants, as assumptions regarding the behaviour of attendees at other festivals cannot be inferred from the data. Future research of a similar nature should be conducted at other events and festivals that have a different central focus, not necessarily the environment, and that attract a diverse range of patrons. This would also require analysis of attendees' values and motivations so to better identify market segments.

The sample of participants used in this study was also limited by age. The majority of respondents at Mariposa Folk Festival were over the age of 50. While this age demographic may be reflective of the general age demographic for folk festivals, it is not necessarily an accurate reflection of the general population. Future research can replicate this study at events that have greater variation in age demographic. 
Another limitation of the current research was that only one of the three t-shirt options had ethical certifications (i.e. fair trade and organic cotton certifications). Future research can explore the influence of certification by selling multiple festival t-shirts that possess ethical certifications, but differ in terms of certification visibility. This provides an opportunity for future research to study the influence of internal versus external certification visibility on attendees' purchase decision.

The relationship between design and the type of festival t-shirt purchased was not examined during the field experiment, as the three types of festival t-shirts were meant to all be identical in terms of colour and graphics. Unfortunately due to a purchasing error made by the festival coordinators the colour options differed slightly between the conventional $\$ 20.00$ CAN festival t-shirts and the ethical ( $\$ 25.00$ and $\$ 30.00$ CAN) festival t-shirts. This presents the opportunity for future research to examine consumers' purchase decisions when given a choice on ethics as well as clothing design. This would help develop a better understanding of the variables that influence purchase decision.

With so few studies comparing WTP to actual purchase behaviour it is not currently possible to detect a trend in the relationship between hypothetical WTP and corresponding purchase behaviour. Future research that replicates or builds on the current study is needed in order to identify patterns in ethical consumption of festival clothing. Since this experiment was the first to examine actual purchase behaviour of ethical clothing in a festival setting, it provides an opportunity for future research to replicate this study in other festival settings to discern any patterns in purchase behaviour or the influence of marketing treatments. This research is also limited by the generalizability of the data in the 
sense that it only accounted for those individuals at Mariposa with the intent to purchase a festival t-shirt, so assumptions regarding all of Mariposa's attendees cannot be made. Future research could attempt to overcome the limitation of generalizability by surveying all individuals at Mariposa rather than just those who purchased a festival t-shirt, then compare the psychographics of those who purchased a festival t-shirt to those who did not. Future replications of this study at Mariposa Folk Festival should also look into employing different marketing treatments that may be more effective and suitable to Mariposa's layout. 


\section{Appendices}

\section{Appendix A: Script Used in Marketing Treatment One}

In marketing treatment one the five volunteers were instructed to communicate the

following information to festival attendees looking to purchase a festival t-shirt:

\section{Environmental impacts of cotton production}

Conventional cotton production accounts for one quarter of global pesticide use, often uses heavy metal and toxic chemicals in the printing and dying process, and uses genetically modified cotton seeds. To produce only one kilogram of cotton (i.e. one t-shirt and one pair of pants) approximately 20,000 litres of water is used (Chen and Burns, 2006; Goworek, 2011; Zhang et al., 2015; WWF, 2016)

\section{Social impacts of conventional t-shirt manufacturers}

Many manufacturers use clothing sweatshops (i.e. Gildan ${ }^{\circledR}$ ), which are known for unfair wages and abuse of the workers' human rights.

\section{Environmental benefits of organic cotton}

Organic cotton does not use pesticides, GMOs, or harsh chemical dyes (Ha-Brookshire and Norum, 2011).

\section{Social benefits of buying fair trade}

Fair trade clothing ensures that clothing is produced under a partnership based on transparency, equity, equal opportunity, and fair wages for everyone involved in the production process (Jones and Williams, 2012). 


\section{Appendix B: Calculating Sample Size for Online Survey}

To determine the appropriate sample size to collect survey data on consumer purchase behaviour and psychographics, Cochran's sample size formula for categorical data, as presented by Bartlett, Kotrlik \& Higgins (2001), was applied.

$$
\begin{aligned}
& \underline{\mathrm{n}}_{0}=\frac{(\underline{\mathrm{t}})^{2 *}(\mathrm{p})(\mathrm{q})}{(\underline{\mathrm{d}})^{2}} \\
& \underline{\mathrm{n}}_{0}=\frac{(1.96)^{2 *}(.5)(.5)}{(.05)^{2}}=384
\end{aligned}
$$

Where $\underline{t}=$ the value for the selected alpha level of .025 in each tail $=1.96$.

(the alpha level of 0.05 indicates the level of risk the researcher is willing to take that the true margin of error may exceed the acceptable margin of error).

Where $(p)(q)=$ the estimate of variance $=.25$. (maximum possible proportion (.5)*1 - maximum possible proportion (.5) produces maximum possible sample size).

Where $\underline{\mathrm{d}}=$ acceptable margin of error for proportion being estimated $=.05$

Since the population size is 350 , a sample size of 384 greatly exceeds $5 \%$ of the population. Therefore, Cochran's correction formula must be applied to calculate the final sample size. These calculations are as follows:

$$
\begin{aligned}
& \underline{\mathrm{n}} 1=\frac{\mathrm{n}_{0}}{1+\mathrm{n}_{0} / \text { Population }} \\
& \underline{\mathrm{n}} 1=\frac{384}{1+384 / 350}
\end{aligned}
$$

Where population size $=350$

Where $\mathrm{n}_{0}=$ required return sample size according to Cochran's formula (384)

Where $\mathrm{n} 1=$ required return sample size because sample $>5 \%$ of population 


\section{Appendix C: Online Survey Questions (Before Piloting)}

1. Which Mariposa Festival t-shirt did you purchase?

a. Conventional festival t-shirt with no fair trade/ organic certification (\$20.00 CAN)

b. Festival t-shirt with internal fair trade/ organic certification (\$25.00 CAN)

c. Festival t-shirt with external fair trade/ organic certification (\$30.00 CAN)

2. What influenced you to buy the festival t-shirt you purchased over the other two options? Please rank the following options in order from most to least influential.
a. Cost
b. Promotion of the fair trade and/or organic t-shirts on the jumbotron
c. Promotion of the fair trade and/or organic t-shirts at the t-shirt emporium
d. Promotion of the fair trade and/or organic t-shirts at the education booth
e. I saw someone wearing a festival t-shirt with fair trade and/or organic labels
f. I always try and buy products that are certified fair trade/ organic
g. Visibility of the fair trade and/or organic labels

3. How often do you make clothing purchases based on the following variables? $(1=$ never, 5 = always)

\begin{tabular}{|l|c|c|c|c|c|}
\hline \multicolumn{1}{|c|}{ Variable } & $\mathbf{1}$ & $\mathbf{2}$ & $\mathbf{3}$ & $\mathbf{4}$ & $\mathbf{5}$ \\
\hline Cost & & & & & \\
\hline Brand & & & & & \\
\hline Environmental certification & & & & & \\
\hline Supporting socially responsible clothing manufacturers & & & & & \\
\hline Country of origin & & & & & \\
\hline Design (colour and graphics) & & & & & \\
\hline Media advertisements (television, billboards, magazines) & & & & & \\
\hline Peer influence & & & & & \\
\hline
\end{tabular}


4. I find that most environmental products are... (1=completely disagree; $5=$ completely agree)

\begin{tabular}{|l|c|c|c|c|c|}
\hline \multicolumn{1}{|c|}{ Variable } & $\mathbf{1}$ & $\mathbf{2}$ & $\mathbf{3}$ & $\mathbf{4}$ & $\mathbf{5}$ \\
\hline $100 \%$ credible with their claims & & & & & \\
\hline Stand out amongst name brand competitors & & & & & \\
\hline Provide useful information about its environmental value & & & & & \\
\hline Marketed in a way that is engaging and relevant & & & & & \\
\hline
\end{tabular}

5. Below are environmental impacts typically associated with festivals. Please indicate your level of concern for each of following impacts you $(1=$ not concerned; $5=$ very concerned)

\begin{tabular}{|l|c|c|c|c|c|}
\hline \multicolumn{1}{|c|}{ Variable } & $\mathbf{1}$ & $\mathbf{2}$ & $\mathbf{3}$ & $\mathbf{4}$ & $\mathbf{5}$ \\
\hline Land Damage & & & & & \\
\hline Energy Use & & & & & \\
\hline Waste Production and Management & & & & & \\
\hline $\begin{array}{l}\text { Waste Water Production (i.e. black water from toilets and } \\
\text { grey water from sinks, showers, etc.) }\end{array}$ & & & & & \\
\hline Water Use & & & & & \\
\hline Transportation (to and from the festival) & & & & & \\
\hline Noise Pollution & & & & & \\
\hline
\end{tabular}

\section{Please identify which age bracket you fall into.}
a. $18-29$
b. $30-39$
c. $40-49$
d. $50-59$
e. $60+$

\section{Please indicate which gender you most associate with.}
a. male
b. female 


\section{Appendix D: Online Survey Questions (After Piloting)}

\section{Which Mariposa Festival t-shirt did you purchase?}

a. Conventional festival t-shirt with no fair trade/ organic certification (\$20.00 CAN)

b. Festival t-shirt with internal fair trade/ organic certification (\$25.00 CAN)

c. Festival t-shirt with external fair trade/ organic certification (\$30.00 CAN)

2. What influenced you to buy the festival t-shirt you purchased over the other two options? (1=not influential; 5=very influential)

\begin{tabular}{|l|l|l|l|l|l|}
\hline \multicolumn{1}{|c|}{ Variable } & $\mathbf{1}$ & $\mathbf{2}$ & $\mathbf{3}$ & $\mathbf{4}$ & $\mathbf{5}$ \\
\hline I always buy products that are fair trade and/or organic & & & & & \\
\hline $\begin{array}{l}\text { Promotion of the fair trade and/or organic t-shirts at the } \\
\text { t-shirt emporium }\end{array}$ & & & & & \\
\hline The visibility of the environmental certification & & & & & \\
\hline Cost & & & & & \\
\hline $\begin{array}{l}\text { Promotion of the fair trade and/or organic t-shirts on the } \\
\text { jumbotron }\end{array}$ & & & & & \\
\hline $\begin{array}{l}\text { Promotion of the fair trade and/or organic t-shirts at the } \\
\text { environmental education booth }\end{array}$ & & & & & \\
\hline
\end{tabular}

3. How often do you make clothing purchases based on the following variables? $(1=$ never, 5 = always)

\begin{tabular}{|l|c|c|c|c|c|}
\hline \multicolumn{1}{|c|}{ Variable } & $\mathbf{1}$ & $\mathbf{2}$ & $\mathbf{3}$ & $\mathbf{4}$ & $\mathbf{5}$ \\
\hline Cost & & & & & \\
\hline Brand & & & & & \\
\hline Environmental certification & & & & & \\
\hline Supporting socially responsible clothing manufacturers & & & & & \\
\hline Country of origin & & & & & \\
\hline Design (colour, style, graphics) & & & & & \\
\hline Media advertisements (television, billboards, magazines) & & & & & \\
\hline Peer influence & & & & & \\
\hline
\end{tabular}

4. I find that most ethical products are... (1=completely disagree; $5=$ completely agree)

\begin{tabular}{|l|c|c|c|c|c|}
\hline \multicolumn{1}{|c|}{ Variable } & $\mathbf{1}$ & $\mathbf{2}$ & $\mathbf{3}$ & $\mathbf{4}$ & $\mathbf{5}$ \\
\hline $100 \%$ credible with their claims & & & & & \\
\hline Stand out amongst name brand competitors & & & & & \\
\hline Provide useful information about its environmental value & & & & & \\
\hline Marketed in a way that is engaging and relevant & & & & & \\
\hline
\end{tabular}


5. How environmentally aware are you ( $1=$ not aware; $5=$ very aware)

\begin{tabular}{|c|c|c|c|c|c|}
\hline Variable & $\mathbf{1}$ & $\mathbf{2}$ & $\mathbf{3}$ & $\mathbf{4}$ & $\mathbf{5}$ \\
\hline Level of environmental awareness & & & & & \\
\hline
\end{tabular}

6. Please identify which age bracket you fall into.
a. $18-29$
b. $30-39$
c. $40-49$
d. $50-59$
e. $60+$
7. Please indicate which gender you most associate with.
a. male
b. female
c. prefer not to say 


\section{Appendix E: SPSS Survey Data}

\begin{tabular}{|c|c|c|c|c|c|c|c|c|c|c|c|c|c|}
\hline 1 & recordedDati Q1 & Q2_S1 & Q2_S2 & Q2_S3 & Q2_s4 & Q2_55 & Q2_S6 & Q3_S1 & Q3_s2 & Q3_S3 & Q3_S4 & Q3_55 & Q3_56 \\
\hline 2 & 2016-07-10 b. Festiv & 2.00 & 3.00 & 1.00 & 1.00 & 4.00 & 3.00 & 4.00 & 3.00 & 3.00 & 3.00 & 4.00 & 5.00 \\
\hline 3 & 2016-07-10 b. Festiv & 2.00 & 3.00 & 1.00 & 1.00 & 5.00 & 1.00 & 4.00 & 3.00 & 1.00 & 1.00 & 1.00 & 4.00 \\
\hline 4 & 2016-07-10 b. Festiv & 1.00 & 5.00 & 1.00 & 1.00 & 5.00 & 3.00 & 4.00 & 3.00 & 1.00 & 3.00 & 3.00 & 4.00 \\
\hline 5 & 2016-07-10 a. Festiv & 1.00 & 1.00 & 1.00 & 1.00 & 4.00 & 2.00 & 1.00 & 1.00 & 2.00 & 2.00 & 2.00 & 5.00 \\
\hline 6 & 2016-07-10 a. Festiv & 1.00 & 3.00 & 1.00 & 1.00 & 4.00 & 5.00 & 3.00 & 1.00 & 4.00 & 4.00 & 3.00 & 3.00 \\
\hline 7 & 2016-07-10 a. Festiv & 3.00 & 1.00 & 1.00 & 1.00 & 3.00 & 3.00 & 4.00 & 2.00 & 3.00 & 3.00 & 4.00 & 5.00 \\
\hline 8 & 2016-07-10 b. Festiv & 1.00 & 1.00 & 1.00 & 1.00 & 2.00 & 3.00 & 5.00 & 4.00 & 1.00 & 1.00 & 1.00 & 1.00 \\
\hline 9 & 2016-07-10 c. Festival & 1.00 & 1.00 & 1.00 & 1.00 & 1.00 & 3.00 & 3.00 & 3.00 & 3.00 & 5.00 & 5.00 & 3.00 \\
\hline 10 & 2016-07-10 b. Festiv & 3.00 & 4.00 & 1.00 & 1.00 & 5.00 & 5.00 & 4.00 & 3.00 & 5.00 & 5.00 & 5.00 & 3.00 \\
\hline 11 & 2016-07-10 b. Festiv & 4.00 & 4.00 & 1.00 & 3.00 & 5.00 & 4.00 & 5.00 & 4.00 & 3.00 & 5.00 & 4.00 & 3.00 \\
\hline 12 & 2016-07-10 a. Festiv & 1.00 & 4.00 & 1.00 & 1.00 & 4.00 & 4.00 & 3.00 & 1.00 & 4.00 & 5.00 & 5.00 & 5.00 \\
\hline 13 & 2016-07-10 c. Festival & 2.00 & 3.00 & 1.00 & 1.00 & 4.00 & 2.00 & 3.00 & 4.00 & 3.00 & 3.00 & 3.00 & 5.00 \\
\hline 14 & 2016-07-10 a. Festiv & 3.00 & 2.00 & 1.00 & 1.00 & 2.00 & 2.00 & 4.00 & 2.00 & 2.00 & 3.00 & 3.00 & 4.00 \\
\hline 15 & 2016-07-10 a. Festiv & 1.00 & 3.00 & 1.00 & 1.00 & 1.00 & 3.00 & 4.00 & 1.00 & 3.00 & 3.00 & 3.00 & 5.00 \\
\hline 16 & 2016-07-10 b. Festiv & 4.00 & 4.00 & 1.00 & 1.00 & 5.00 & 3.00 & 4.00 & 3.00 & 3.00 & 4.00 & 3.00 & 5.00 \\
\hline 17 & 2016-07-10 c. Festival & 3.00 & 1.00 & 1.00 & 1.00 & 1.00 & 2.00 & 3.00 & 3.00 & 1.00 & 2.00 & 3.00 & 5.00 \\
\hline 18 & 2016-07-10 a. Festiv & 3.00 & 3.00 & 1.00 & 1.00 & 1.00 & 3.00 & 4.00 & 4.00 & 3.00 & 3.00 & 5.00 & 5.00 \\
\hline 19 & 2016-07-10 c. Festival & 1.00 & 2.00 & 3.00 & 1.00 & 1.00 & 3.00 & 2.00 & 2.00 & 3.00 & 3.00 & 3.00 & 4.00 \\
\hline 20 & 2016-07-10 b. Festiv & 1.00 & 2.00 & 1.00 & 1.00 & 4.00 & 2.00 & 1.00 & 1.00 & 1.00 & 4.00 & 4.00 & 5.00 \\
\hline 21 & 2016-07-10 b. Festiv & 3.00 & 4.00 & 1.00 & 4.00 & 3.00 & 4.00 & 3.00 & 1.00 & 3.00 & 3.00 & 3.00 & 4.00 \\
\hline 22 & 2016-07-10 b. Festiv & 1.00 & 1.00 & 1.00 & 1.00 & 4.00 & 1.00 & 5.00 & 1.00 & 3.00 & 3.00 & 5.00 & 4.00 \\
\hline 23 & 2016-07-10 a. Festiv & 1.00 & 3.00 & 2.00 & 1.00 & 3.00 & 3.00 & 4.00 & 1.00 & 3.00 & 3.00 & 3.00 & 4.00 \\
\hline 24 & 2016-07-10 a. Festiv & 1.00 & 1.00 & 1.00 & 1.00 & 1.00 & 5.00 & 4.00 & 1.00 & 4.00 & 4.00 & 1.00 & 5.00 \\
\hline 25 & 2016-07-10 b. Festiv & 2.00 & 4.00 & 4.00 & 3.00 & 4.00 & 3.00 & 3.00 & 3.00 & 4.00 & 5.00 & 5.00 & 4.00 \\
\hline 26 & 2016-07-10 b. Festiv & 4.00 & 4.00 & 1.00 & 1.00 & 4.00 & 3.00 & 4.00 & 4.00 & 3.00 & 5.00 & 4.00 & 5.00 \\
\hline 27 & 2016-07-10 a. Festiv & 1.00 & 1.00 & 1.00 & 1.00 & 5.00 & 3.00 & 2.00 & 2.00 & 3.00 & 3.00 & 5.00 & 4.00 \\
\hline 28 & 2016-07-10 a. Festiv & 1.00 & 3.00 & 1.00 & 1.00 & 5.00 & 5.00 & 4.00 & 1.00 & 3.00 & 5.00 & 5.00 & 5.00 \\
\hline 29 & 2016-07-10 a. Festiv & 3.00 & 1.00 & 1.00 & 1.00 & 1.00 & 1.00 & 4.00 & 4.00 & 1.00 & 1.00 & 1.00 & 5.00 \\
\hline 30 & 2016-07-10 b. Festiv & 3.00 & 3.00 & 1.00 & 1.00 & 3.00 & 4.00 & 4.00 & 1.00 & 1.00 & 5.00 & 4.00 & 5.00 \\
\hline 31 & 2016-07-10 a. Festiv & 4.00 & 1.00 & 1.00 & 1.00 & 1.00 & 3.00 & 4.00 & 1.00 & 1.00 & 3.00 & 4.00 & 4.00 \\
\hline 32 & 2016-07-10 a. Festiv & 4.00 & 4.00 & 1.00 & 1.00 & 4.00 & 3.00 & 4.00 & 4.00 & 3.00 & 3.00 & 3.00 & 4.00 \\
\hline 33 & 2016-07-10 c. Festival & 1.00 & 1.00 & 1.00 & 1.00 & 1.00 & 5.00 & 1.00 & 1.00 & 1.00 & 1.00 & 1.00 & 3.00 \\
\hline 34 & 2016-07-10 b. Festiv & 1.00 & 5.00 & 1.00 & 4.00 & 5.00 & 4.00 & 3.00 & 1.00 & 4.00 & 4.00 & 4.00 & 2.00 \\
\hline 35 & 2016-07-10 b. Festiv & 1.00 & 4.00 & 1.00 & 1.00 & 5.00 & 5.00 & 3.00 & 3.00 & 4.00 & 5.00 & 4.00 & 5.00 \\
\hline 36 & 2016-07-10 b. Festiv & 1.00 & 5.00 & 1.00 & 5.00 & 1.00 & 5.00 & 3.00 & 3.00 & 5.00 & 5.00 & 5.00 & 4.00 \\
\hline 37 & 2016-07-10 b. Festiv & 1.00 & 1.00 & 1.00 & 1.00 & 4.00 & 3.00 & 3.00 & 3.00 & 3.00 & 3.00 & 3.00 & 4.00 \\
\hline 38 & 2016-07-10 a. Festiv & 1.00 & 3.00 & 1.00 & 1.00 & 3.00 & 3.00 & 1.00 & 1.00 & 1.00 & 1.00 & 3.00 & 4.00 \\
\hline 39 & 2016-07-10 b. Festiv & 1.00 & 1.00 & 1.00 & 1.00 & 4.00 & 2.00 & 2.00 & 3.00 & 1.00 & 1.00 & 1.00 & 4.00 \\
\hline 40 & 2016-07-09 a. Festiv & 3.00 & 1.00 & 2.00 & 2.00 & 2.00 & 2.00 & 5.00 & 1.00 & 4.00 & 1.00 & 5.00 & 4.00 \\
\hline 41 & 2016-07-10 a. Festiv & 1.00 & 5.00 & 1.00 & 1.00 & 4.00 & 4.00 & 3.00 & 1.00 & 4.00 & 4.00 & 5.00 & 1.00 \\
\hline 42 & 2016-07-10 b. Festiv & 1.00 & 1.00 & 1.00 & 1.00 & 4.00 & 4.00 & 3.00 & 3.00 & 1.00 & 4.00 & 3.00 & 4.00 \\
\hline 43 & 2016-07-10 b. Festiv & 1.00 & 3.00 & 1.00 & 1.00 & 5.00 & 3.00 & 4.00 & 3.00 & 3.00 & 3.00 & 3.00 & 3.00 \\
\hline 44 & 2016-07-10 a. Festiv & 3.00 & 1.00 & 1.00 & 1.00 & 1.00 & 4.00 & 4.00 & 1.00 & 3.00 & 4.00 & 2.00 & 5.00 \\
\hline 45 & 2016-07-10 a. Festiv & 1.00 & 5.00 & 1.00 & 1.00 & 5.00 & 4.00 & 3.00 & 2.00 & 4.00 & 5.00 & 4.00 & 2.00 \\
\hline 46 & 2016-07-10 a. Festiv & 3.00 & 5.00 & 1.00 & 1.00 & 5.00 & 4.00 & 4.00 & 4.00 & 4.00 & 5.00 & 5.00 & 4.00 \\
\hline 47 & 2016-07-10 a. Festiv & 1.00 & 1.00 & 1.00 & 1.00 & 4.00 & 4.00 & 4.00 & 3.00 & 1.00 & 4.00 & 4.00 & 5.00 \\
\hline 48 & 2016-07-10 b. Festiv & 1.00 & 4.00 & 1.00 & 1.00 & 1.00 & 4.00 & 4.00 & 1.00 & 3.00 & 4.00 & 4.00 & 5.00 \\
\hline 49 & 2016-07-10 a. Festiv & 4.00 & 1.00 & 2.00 & 1.00 & 3.00 & 4.00 & 4.00 & 3.00 & 3.00 & 4.00 & 5.00 & 3.00 \\
\hline 50 & 2016-07-10 a. Festiv & 2.00 & 1.00 & 1.00 & 1.00 & 5.00 & 5.00 & 4.00 & 2.00 & 4.00 & 4.00 & 2.00 & 4.00 \\
\hline 51 & 2016-07-10 a. Festiv & 3.00 & 3.00 & 1.00 & 1.00 & 5.00 & 3.00 & 4.00 & 1.00 & 1.00 & 1.00 & 2.00 & 3.00 \\
\hline 52 & 2016-07-10 b. Festiv & 1.00 & 5.00 & 1.00 & 1.00 & 3.00 & 5.00 & 5.00 & 2.00 & 5.00 & 5.00 & 5.00 & 5.00 \\
\hline 53 & 2016-07-10 c. Festival & 1.00 & 1.00 & 1.00 & 1.00 & 1.00 & 4.00 & 4.00 & 4.00 & 4.00 & 4.00 & 5.00 & 4.00 \\
\hline 54 & 2016-07-10 c. Festival & 5.00 & 5.00 & 1.00 & 1.00 & 5.00 & 4.00 & 5.00 & 1.00 & 3.00 & 4.00 & 4.00 & 5.00 \\
\hline 55 & 2016-07-10 c. Festival & 1.00 & 5.00 & 1.00 & 1.00 & 1.00 & 3.00 & 3.00 & 3.00 & 3.00 & 4.00 & 4.00 & 5.00 \\
\hline 56 & 2016-07-10 b. Festiv & 4.00 & 4.00 & 1.00 & 5.00 & 4.00 & 1.00 & 4.00 & 1.00 & 1.00 & 1.00 & 1.00 & 5.00 \\
\hline 57 & 2016-07-10 a. Festiv & 1.00 & 4.00 & 1.00 & 1.00 & 1.00 & 1.00 & 3.00 & 1.00 & 3.00 & 3.00 & 5.00 & 5.00 \\
\hline 58 & 2016-07-09 b. Festiv & 3.00 & 1.00 & 1.00 & 1.00 & 4.00 & 3.00 & 4.00 & 1.00 & 3.00 & 4.00 & 3.00 & 5.00 \\
\hline 59 & 2016-07-10 c. Festival & 1.00 & 00 & 1.00 & 00 & 1.00 & 3.00 & 5.00 & 1.00 & 1.00 & 4.00 & 1.00 & 5.00 \\
\hline 60 & 2016-07-10 b. Festiv & 1.00 & 5.00 & 1.00 & 1.00 & 1.00 & 3.00 & 3.00 & 1.00 & 1.00 & 1.00 & 3.00 & 3.00 \\
\hline 61 & 2016-07-10 c. Festival & 3.00 & 1.00 & 1.00 & 1.00 & 3.00 & 3.00 & 3.00 & 1.00 & 3.00 & 3.00 & 1.00 & 5.00 \\
\hline 62 & 2016-07-10 b. Festiv & 1.00 & 4.00 & 1.00 & 1.00 & 3.00 & 5.00 & 1.00 & 1.00 & 4.00 & 4.00 & 5.00 & 3.00 \\
\hline 63 & 2016-07-10 a. Festiv & 4.00 & 3.00 & 1.00 & 1.00 & 4.00 & 3.00 & 4.00 & 3.00 & 3.00 & 3.00 & 5.00 & 5.00 \\
\hline 64 & 2016-07-10 b. Festiv & 3.00 & 1.00 & 5.00 & 1.00 & 1.00 & 3.00 & 3.00 & 1.00 & 5.00 & 5.00 & 1.00 & 5.00 \\
\hline 65 & 2016-07-10 b. Festiv & 1.00 & 0 & 1.00 & 1.00 & 4.00 & 4.00 & 4.00 & 00 & 4.00 & 5.00 & 4.00 & 4.00 \\
\hline 66 & 2016-07-10 a. Festiv & 4.00 & 4.00 & 1.00 & 1.00 & 5.00 & 5.00 & 4.00 & 4.00 & 4.00 & 5.00 & 4.00 & 5.00 \\
\hline 67 & 2016-07-10 b. Festiv & 3.00 & 4.00 & 1.00 & 1.00 & 5.00 & 2.00 & 4.00 & 3.00 & 3.00 & 4.00 & 3.00 & 5.00 \\
\hline 68 & 2016-07-10 a. Festiv & 2.00 & 1.00 & 1.00 & 1.00 & 3.00 & 2.00 & 4.00 & 1.00 & 3.00 & 3.00 & 3.00 & 5.00 \\
\hline 69 & 2016-07-10 a. Festiv & 1.00 & 3.00 & 1.00 & 1.00 & 5.00 & 1.00 & 3.00 & 4.00 & 1.00 & 5.00 & 5.00 & 5.00 \\
\hline 70 & 2016-07-10 b. Festiv & 1.00 & 4.00 & 1.00 & 1.00 & 5.00 & 3.00 & 4.00 & 1.00 & 2.00 & 3.00 & 4.00 & 5.00 \\
\hline 71 & 2016-07-10 b. Festiv & 3.00 & 4.00 & 1.00 & 1.00 & 1.00 & 4.00 & 1.00 & 1.00 & 2.00 & 3.00 & 3.00 & 5.00 \\
\hline 72 & 2016-07-10 b. Festiv & 2.00 & 3.00 & 1.00 & 3.00 & 4.00 & 3.00 & 1. & 1.00 & 4.00 & 4.00 & 3.00 & 4.00 \\
\hline 73 & 2016-07-10 c. Festival & 1.00 & 1.00 & 1.00 & 1.00 & 1.00 & 4.00 & 4.00 & 1.00 & 4.00 & 5.00 & 1.00 & 5.00 \\
\hline 74 & 2016-07-10 a. Festiv & 1.00 & 1.00 & 1.00 & 1.00 & 0 & 1.00 & 5.00 & 4.00 & 2.0 & 1.00 & 0 & 3.00 \\
\hline 75 & 2016-07-10 a. Festiv & 3.00 & 00 & 1.00 & 0 & 1.00 & 00 & 3.00 & 1.00 & 4.00 & 1.00 & 1.00 & 3.00 \\
\hline 76 & 2016-07-10 a. Festiv & 3.00 & 3.00 & 1.00 & 1.00 & 1.00 & 00 & 3.00 & 3.00 & 3.00 & 4.00 & 4.00 & 5.00 \\
\hline 77 & 2016-07-09 c. Festival & 2.00 & 1. & 1.00 & 1. & 1.00 & 2.00 & 1. & 1.00 & 5. & 5.00 & 5 & 5.00 \\
\hline 78 & 2016-07-09 c. Festival & 3.00 & 3.00 & 1.00 & 0 & 1. & & 4. & 2.00 & 2.00 & 4.00 & 0 & 4.00 \\
\hline 79 & 2016-07-09 b. Festiv & 3.00 & 2.00 & 1.00 & 1.00 & 5.00 & 3.00 & 4.00 & 4.00 & 3.00 & 3.00 & 3.00 & 5.00 \\
\hline 80 & 2016-07-09 b. Festiv & 1.00 & 1.00 & 1.00 & 1 & 5.6 & 4.0. & 3 & 1.00 & 4 & 4.00 & 5 & 5.00 \\
\hline 81 & 2016-07-09 b. Festiv & v & 00 & 1.00 & 0 & 3.00 & 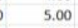 & 1. & 1.00 & $4 . c$ & 4.00 & 4.0 & 5.00 \\
\hline 82 & 2016-07-09 b. Festiv & 1.00 & 5.00 & 1.00 & 1.00 & 5.00 & 3.00 & 3.00 & 1.00 & 3.00 & 4.00 & 4.00 & 5.00 \\
\hline 83 & 2016-07-09 a. Festiv & 1.00 & 1.00 & 1.00 & 1.00 & 4.00 & 4.00 & 4.00 & 2.00 & 3.00 & 3.00 & 3.00 & 5.00 \\
\hline 84 & 2016-07-09 b. Festiv & 1.00 & 5.00 & 1.00 & 1.00 & 5.00 & 4.00 & 3.00 & 3.00 & 5.00 & 5.00 & 5.00 & 5.00 \\
\hline 85 & 2016-07-09 c. Festival & 5.00 & 1.00 & 1.00 & 1.00 & 1.00 & 1.00 & 5.00 & 1.00 & 1.00 & 1.00 & 1.00 & 4.00 \\
\hline
\end{tabular}




\begin{tabular}{|c|c|}
\hline 86 & 2016-07-09 c. Festival \\
\hline 87 & 2016-07-09 a. Festiv \\
\hline 88 & 2016-07-09 b. Festiv \\
\hline 89 & 2016-07-09 b. Festiv \\
\hline 90 & 2016-07-09 b. Festiv \\
\hline 91 & 2016-07-09 a. Festiv \\
\hline 92 & 2016-07-09 c. Festival \\
\hline 93 & 2016-07-09 b. Festiv \\
\hline 94 & 2016-07-09 b. Festiv \\
\hline 95 & 2016-07-09 b. Festiv \\
\hline 96 & 2016-07-09 b. Festiv \\
\hline 97 & 2016-07-09 b. Festiv \\
\hline 98 & 2016-07-09 c. Festival \\
\hline 99 & 2016-07-09 b. Festiv \\
\hline 100 & 2016-07-09 c. Festival \\
\hline 101 & 2016-07-09 a. Festiv \\
\hline 102 & 2016-07-09 b. Festiv \\
\hline 103 & 2016-07-09 a. Festiv \\
\hline 104 & 2016-07-09 b. Festiv \\
\hline 105 & 2016-07-09 b. Festiv \\
\hline 106 & 2016-07-09 b. Festiv \\
\hline 107 & 2016-07-09 b. Festiv \\
\hline 108 & 2016-07-09 a. Festiv \\
\hline 109 & 2016-07-09 a. Festiv \\
\hline 110 & 2016-07-09 b. Festiv \\
\hline 111 & 2016-07-09 b. Festiv \\
\hline 112 & 2016-07-09 a. Festiv \\
\hline 113 & 2016-07-09 c. Festival \\
\hline 114 & 2016-07-09 c. Festival \\
\hline 115 & 2016-07-09 c. Festival \\
\hline 116 & 2016-07-09 a. Festiv \\
\hline 117 & 2016-07-09 a. Festiv \\
\hline 118 & 2016-07-09 b. Festiv \\
\hline 119 & 2016-07-09 a. Festiv \\
\hline 120 & 2016-07-09 b. Festiv \\
\hline 121 & 2016-07-09 a. Festiv \\
\hline 122 & 2016-07-09 a. Festiv \\
\hline 123 & 2016-07-09 a. Festiv \\
\hline 124 & 2016-07-09 b. Festiv \\
\hline 125 & 2016-07-09 c. Festival \\
\hline 126 & 2016-07-09 a. Festiv \\
\hline 127 & 2016-07-09 b. Festiv \\
\hline 128 & 2016-07-09 c. Festival \\
\hline 129 & 2016-07-09 c. Festival \\
\hline 130 & 2016-07-09 a. Festiv \\
\hline 131 & 2016-07-09 b. Festiv \\
\hline 132 & 2016-07-09 b. Festiv \\
\hline 133 & 2016-07-09 b. Festiv \\
\hline 134 & 2016-07-09 b. Festiv \\
\hline 135 & 2016-07-09 c. Festival \\
\hline 136 & 2016-07-09 c. Festival \\
\hline 137 & 2016-07-09 a. Festiv \\
\hline 138 & 2016-07-09 b. Festiv \\
\hline 139 & 2016-07-09 a. Festiv \\
\hline 140 & 2016-07-09 b. Festiv \\
\hline 141 & 2016-07-09 a. Festiv \\
\hline 142 & 2016-07-09 a. Festiv \\
\hline 143 & 2016-07-09 b. Festiv \\
\hline 144 & 2016-07-09 a. Festiv \\
\hline 145 & 2016-07-09 a. Festiv \\
\hline 146 & 2016-07-09 c. Festival \\
\hline 147 & 2016-07-09 b. Festiv \\
\hline 148 & 2016-07-09 b. Festiv \\
\hline 149 & 2016-07-09 c. Festival \\
\hline 150 & 2016-07-09 b. Festiv \\
\hline 151 & 2016-07-09 a. Festiv \\
\hline 152 & 2016-07-09 a. Festiv \\
\hline 153 & 2016-07-09 b. Festiv \\
\hline 154 & 2016-07-09 b. Festiv \\
\hline 155 & 2016-07-09 a. Festiv \\
\hline 156 & 2016-07-09 c. Festival \\
\hline 157 & 2016-07-09 c. Festival \\
\hline 158 & 2016-07-09 a. Festiv \\
\hline 159 & 2016-07-09 a. Festiv \\
\hline 160 & 2016-07-09 a. Festiv \\
\hline 161 & 2016-07-09 a. Festiv \\
\hline 162 & 2016-07-09 a. Festiv \\
\hline 163 & 2016-07-09 b. Festiv \\
\hline 164 & 2016-07-09 b. Festiv \\
\hline 165 & 2016-07-09 a. Festiv \\
\hline 166 & 2016-07-09 a. Festiv \\
\hline 167 & 2016-07-09 c. Festival \\
\hline 168 & 2016-07-09 c. Festival \\
\hline 169 & 2016-07-09 c. Festiv \\
\hline 170 & 2016-07-09 b. Festiv \\
\hline 171 & 2016-07-08 a. Festiv \\
\hline 172 & 2016-07-08 b. Festiv \\
\hline 173 & 2016-07-08 a. Festiv \\
\hline 174 & 2016-07-08 a. Festiv \\
\hline 175 & 2016-07-08 c. Festival \\
\hline 176 & 2016-07-08 a. Festiv \\
\hline 177 & 2016-07-08 a. Festiv \\
\hline 178 & 2016-07-08 c. Festival \\
\hline 179 & 2016-07-08 c. Festival \\
\hline 180 & 500070 \\
\hline 181 & 2016-07-08 a. Festiv \\
\hline 182 & 2016-07-08 b. Festiv \\
\hline
\end{tabular}




\section{Appendix F: Online Survey Consent Form}

\section{Purpose of Study}

My name is Brittany Jenkins. I am a Masters student in the Environmental Applied Science and Management Program at Ryerson University, working with my supervisor Dr. Rachel Dodds in the Environmental Science and Manage. I would like to invite attendees of Mariposa Folk Festival in Orillia, ON to take part in my research study. This study seeks to answer the following research questions: i) will festival attendees of Mariposa Folk Festival will pay a premium for fair trade and organic cotton festival t-shirts, and ii) what variables influence one's decision to purchase fair trade or organic t-shirts. This information will provide insight regarding the degree to which consumers are engaged in environmentally responsible clothing consumption and will aid the industry in developing strategies to promote these behaviors.

\section{What Are You Being Asked To Do}

You are being asked to voluntarily complete this on-line survey. It involves questions about your environmental concerns, willingness to pay for environmentally responsible apparel, and purchasing behaviour, and should take about 5 minutes to complete. In order for all of your answers to be collected you must go to the end of the survey and click 'submit survey'. This will demonstrate your full consent to participation. For the purpose of this study, environmentally responsible apparel is clothing sourced from a fair trade manufacturer and made with eco-cotton.

\section{Potential Benefits}

The results of this study have the potential to be of significant benefit to event organizers and participants alike, as it is an opportunity to demonstrate environmentally responsible behaviour. Moreover, the procurement and sale of 'green' event apparel will positively contribute to the festivals' environmental management initiatives. This study will also help event organizers determine how much of a premium their attendees are willing to pay for environmentally responsible event apparel. Please note that this research may not directly benefit the participants.

\section{Potential Risks to Participants}

If you do not wish to answer any of the survey questions you are free to decline to answer, or stop participating at any time by closing your browser. If you close your browser before getting to the end of the survey and do not confirm your consent to participate at the end of the survey by clicking the 'submit' button your information collected up to that point will not be used. 


\section{Anonymity}

The survey is anonymous and as such will not be collecting information that will easily identify you, like your name or other unique identifiers. Although your Internet Protocol (IP) address can be tracked through the survey platform, the researcher/s will not be collecting this information. Your IP address may be observed only to ensure that one individual is not completing the survey multiple times.

\section{How Your Information Will Be Protected and Stored}

This survey uses Qualtrics ${ }^{\mathrm{TM}}$ which is a United States of American (USA) company. Consequently, USA authorities under the provisions of the Patriot Act may access the survey data. If you would rather participate with an email or paper-based survey please contact the researchers. Please note email or paper-based surveys may allow your identity to be known to the researcher/s but if you select this option your information will be kept confidential. To further protect your information, data stored by the researcher will be password protected and/or encrypted. Only the researcher/s named in this study will have access to the data as collected. Any future publications will include collective information (i.e., aggregate data). Your individual responses (i.e. raw data) will not be shared with anyone outside of the research team. The data from this survey will be terminated upon completion of the study.

\section{Rights as a Research Participant}

Participation in research is completely voluntary and you can withdraw your consent at any point up to clicking the submit button at the end of the survey. However, because the survey is anonymous, once you click the submit button at the end of the survey the researchers will not be able to determine which survey answers belong to you so your information cannot be withdrawn after that point. Please note that by clicking submit at the end of the study you are providing your consent for participation. By consenting to participate you are not waiving any of your legal rights as a research participant.

\section{Contact Information}

This research project has been reviewed by Ryerson's Research Ethics Board. If you have any questions about this research, please feel free to contact myself or my supervisor:

Brittany Jenkins, BSc

(905) 849-7287

bjenkins@ryerson.ca

Dr. Rachel Dodds, Professor

Ted Rogers School Management, Ryerson University

(416) 979-5000 ext. 7227

r2dodds@ryerson.ca 


\section{References}

Adrangi, B., Dhanda, K. K., and Hill, R. P. (2004). A model of consumption and environmental degradation: Making the case for sustainable consumer behaviour. Journal of Human Development, 5(3), 417-432.

doi:10.1080/1464988042000277279

Alden, D. L., Steenkamp, J. E. M., and Batra, R. (2006). Consumer attitudes toward marketplace globalization: Structure, antecedents and consequences. International Journal of Research in Marketing, 23(3), 227-239. doi:10.1016/j.ijresmar.2006.01.010

Alsamawi, A., Murray, J., Lenzen, M., Moran, D., and Kanemoto, K. (2014). The inequality footprints of nations: A novel approach to quantitative accounting of income inequality. Public Library of Science 9(10). doi:http://dx.doi.org/10.1371/journal.pone.0110881

Andorfer, V. A., and Liebe, U. (2012). Research on fair trade consumption - A review. Journal of Business Ethics, 106(4), 415-435. doi:10.1007/s10551-011-1008-5

Andorfer, V. A., and Liebe, U. (2015). Do information, price, or morals influence ethical consumption? A natural field experiment and customer survey on the purchase of fair trade coffee. Social Science Research, 52, 330-350. doi:10.1016/j.ssresearch.2015.02.007

Arcidiacono, C., Procentese, F., and di Napoli, I. (2009). Qualitative and quantitative research: An ecological approach. International Journal of Multiple Research Approaches, 3(2), 163-176. doi:10.5172/mra.3.2.163

Arnot, C., Boxall, P. C., and Cash, S. B. (2006). Do ethical consumers care about price? A revealed preference analysis of Fair trade coffee purchases. Canadian Journal of Agricultural Economics, 54, 555-565

Barbarossa, C., and Pastore, A. (2015). Why environmentally conscious consumers do not purchase green products: A cognitive mapping approach. Qualitative Market Research: An International Journal, 18(2), 188-209. doi:10.1108/QMR-06-20120030

Barnett, E., Valdero, T., Mainieri, T., Oskamp, S., and Unipan, J. (1997). Green buying: The influence of environmental concern on consumer behaviour. The Journal of Social Psychology, 137(2), 189-204. doi:10.1080/00224549709595430 
Bartlett, I., Kotrlik, J. W., and Higgins, C. (2001). Organizational research: determining appropriate sample size in survey research. Information Technology, Learning, and Performance Journal, 19(1), 43-50.

Becker, G. M., Degroot, M. H. and Marschak, J. (1964), Measuring utility by a single-response sequential method. Systematic Research, 9, 226-232. doi:10.1002/bs.3830090304

Birtwistle, G., and Moore, C. M. (2007). Fashion clothing: Where does it all end up? International Journal of Retail \& Distribution Management, 35(3), 210-216. doi:10.1108/09590550710735068

Carrier, J. G. (2007). Ethical consumption. Anthropology Today, 23(4), 1-2. doi:10.1111/j.1467-8322.2007.00520.x

Cepolina, S. E. (2012). Textile and clothing industry: An approach towards sustainable life cycle production. International Journal of Trade, Economics and Finance, 3(1), 7-13. doi:10.7763/IJTEF.2012.V3.164

Chang, H., Zhang, L., and Xie, G. (2015). Message framing in green advertising: The effect of construal level and consumer environmental concern. International Journal of Advertising, 34(1), 158. doi:10.1080/02650487.2014.994731

Cheek, W. K., and Moore, C. E. (2003). Apparel sweatshops at home and abroad: Global and ethical issues. Journal of Family and Consumer Sciences, 95(1), 9

Chen, H. L., and Burns, L. D. (2006). Environmental analysis of textile products. Clothing and Textiles Research Journal, 24(3), 248-261. doi:10.1177/0887302X06293065

Chen, N., and Wei, S. (2012). Ends justify means? Organic cotton products' purchasing motivations. Agribusiness, 28(4), 440-450. doi:10.1002/agr.21308

Cherrett, N., Barrett, J., Clemett, A., Chadwick, M. and Chadwick, M.J. (2005), Ecological footprint and water analysis of cotton, hemp and polyester, Stockholm Environment Institute. Stockholm, Sweden.

Claudio, L. (2007). Waste couture: Environmental impact of the clothing industry. Environmental Health Perspectives, 115(9), A448-A454.

Cooper, H. M., (1984). The integrative research review: A systematic approach. Applied Social Research Methods Series, 2.

Corrigan, J. R., Kling, C. L., and Zhao, J. (2008). Willingness to pay and the cost of commitment: An empirical specification and test. Environmental and Resource Economics, 40(2), 285-298. doi:10.1007/s10640-007-9153-0 
d'Astous, A., and Mathieu, S. (2008). Inciting consumers to buy fairly-traded products: A field experiment. Journal of Consumer Marketing, 25, 149-157

Dahl, R. (2010). Green washing: Do you know what you're buying? Environmental Health Perspectives, 118(6), A246.

Deci, E. L., and Ryan, R. M. (1985). The general causality orientations scale: Selfdetermination in personality. Journal of research in personality, 19(2), 109-134.

Dickson, M. A. (2001). The utility of no sweat labels for apparel consumers: Profiling label users and predicting their purchases. The Journal of Consumer Affairs, 35, 96-119.

Didier, T., and Lucie, S. (2008). Measuring consumer's willingness to pay for organic and fair trade products. International Journal of Consumer Studies, 32(5), 479-490. doi:10.1111/j.1470-6431.2008.00714.x

Dodds, R., \& Graci, S. (2012). Greening of the Pride Toronto Festival: Lessons Learned. Tourism, Culture, and Communication, 12 (1), 29-38

Dodds, R., Pitts, R., and Smith, W. (2016). Willingness to pay for environmentally linked clothing at an event: Visibility, environmental certification and level of environmental concern. Tourism Recreation Research, 41(3), 283-290. doi:10.1080/02508281.2016.1196029

Donaldson, T. (2015). Labor department raises 'serious' concerns for workers in Honduras. Sourcing Journal. Retrieved February 2017 from https://sourcingjournalonline.com/us-department-labor-issues-report-seriouslabor-concerns-honduras-td/

Ellis, J. L., McCracken, V. A., and Skuza, N. (2012). Insights into willingness to pay for organic cotton apparel. Journal of Fashion Marketing and Management, 16(3), 290-305. doi:10.1108/13612021211246053

Fischer, A., and Dam, Y. (2015). Buying green without being seen. Environment and Behaviour, 47(3), 328-356.

Franke, T. M., Ho, T., and Christie, C. A. (2012). The chi-square test: Often used and more often misinterpreted. American Journal of Evaluation, 33(3), 448-458. doi:10.1177/1098214011426594

Gershoff, A. D., and Frels, J.K. (2015). What makes it green? The role of centrality of green attributes in evaluations of the greenness of products. Journal of Marketing, 79(1), 97. doi:10.1509/jm.13.0303 
Gibson, C., and Wong, C. (2011). Greening rural festivals: Ecology, sustainability and human-nature relations. Bristol, Australia: Channel View Publications, 92-105.

Government of Canada. 2017. Apparel industry profile. Retrieved October, 2016 from https://www.ic.gc.ca/eic/site/026.nsf/eng/h_00070.html

Guagnano, G. A. (2001). Altruism and market-like behaviour: An analysis of willingness to pay for recycled paper products. Population and Environment, 22(4), 425-438. doi:10.1023/A:1006753823611

Gupta, S., and Ogden, D. (2009). To buy or not to buy? A social dilemma perspective on green buying. Journal of Consumer Marketing, 26(6), 376-391.

Habel, J., Schons, L. M., Alavi, S., and Wieseke, J. (2016). Warm glow or extra charge? The ambivalent effect of corporate social responsibility activities on customers' perceived price fairness. Journal of Marketing, 80(1), 84.

Ha-Brookshire, J. E., and Norum, P. S. (2011). Willingness to pay for socially responsible products: Case of cotton apparel. Journal of Consumer Marketing, 28(5), 344-353. doi:10.1108/07363761111149992

Hiller-Connell, K. Y. (2010), Internal and external barriers to eco-conscious apparel acquisition. International Journal of Consumer Studies, 34, 279-286. doi:10.1111/j.1470-6431.2010.00865.x

Hiller-Connell, K. Y. (2011). Exploring consumers' perceptions of eco-conscious apparel acquisition behaviours. Social Responsibility Journal, 7(1), 61-73. doi:10.1108/17471111111114549

Hoek, J., Roling, N., and Holdsworth, D. (2013). Ethical claims and labelling: An analysis of consumers' beliefs and choice behaviours. Journal of Marketing Management, 29(78), 772-792.

Hustvedt, G., and Bernard, J. (2010). Effects of social responsibility labelling and brand on willingness to pay for apparel. International Journal of Consumer Studies, 34(6), 619626. doi:10.1111/j.1470-6431.2010.00870.x

Hustvedt, G., and Dickson, M.A. (2009). Consumer likelihood of purchasing organic cotton apparel: Influence of attitudes and self-identity. Journal of Fashion Marketing and Management, 13(1), 49-65.doi:10.1108/13612020910939879

International Apparel Federation. (2015). Industry Statistics. Retrieved September, 2016 from http://iafnet.eu/industry-statistics/ 
International Cotton Advisory Committee. (2013). World apparel fibre consumption survey. Retrieved May, 2016 from https://www.icac.org/cotton_info/publications/statistics/world-apparelsurvey/FAO-ICAC-Survey-2013-Update-and-2011-Text.pdf

International Cotton Advisory Committee (ICAC). (2015). Cotton report: 6th dedicated discussion of the relevant trade related developments on cotton. Retrieved June, 2016 from https://www.wto.org/english/news_e/news16_e/cdac_23nov16_e.pdf

International Labour Organization. (2014). Wages and working hours in the textiles, clothing, leather and footwear industries. Retrieved November, 2016 from http://www.ilo.org/wcmsp5/groups/public/@ed_dialogue/@sector/documents/p ublication/wcms_300463.pdf

Joergens, C. (2006). Ethical fashion: myth of future trend? Journal of Fashion Marketing and Management, 10(3), 360-371.

Johnstone, M., and Tan, L. P. (2015). An exploration of environmentally-conscious consumers and the reasons why they do not buy green products. Marketing Intelligence and Planning, 33(5), 804-825. doi:10.1108/MIP-09-2013-0159

Jones, A. R. W., and Williams, G. (2012). Perceptions of fair trade labelling and certification: Three case studies. Journal of Fashion Marketing and Management, 16(2), 246-265. doi:10.1108/13612021211222851

Kilbourne, W. E., and Beckmann, S. C. (1998). Review and critical assessment of research on marketing and the environment. Journal of Marketing Management, 14(6), 513-532. doi:10.1362/026725798784867716

Kilbourne, W., and Pickett, G. (2008). How materialism affects environmental beliefs, concern, \& environmentally responsible behaviour. Journal of Business Research, 61(9), 885-893. doi:10.1016/j.jbusres.2007.09.016

Kozar, J. M., and Hiller-Connell, K. Y. (2013). Socially and environmentally responsible apparel consumption: Knowledge, attitudes, \& behaviours. Social Responsibility Journal, 9(2), 315-324. doi:10.1108/SRJ-09-2011-0076

$\mathrm{Ku}, \mathrm{L}$. , and Zaroff, C. (2014). How far is your money from your mouth? The effects of intrinsic relative to extrinsic values on willingness to pay and protect the environment. Journal of Environmental Psychology, 40, 472-483.

doi:10.1016/j.jenvp.2014.10.008 
Kumar, P., and Ghodeswar, B. M. (2015). Factors affecting consumers' green product purchase decisions. Marketing Intelligence and Planning, 33(3), 330-347. doi:10.1108/MIP-03-2014-0068

Kutucuoglu, K. Y., Arikan Saltik, I., Firat, A., \& Tuncel, O. (2013). Consumption, consumer culture, and consumer society. Journal of Community Positive Practices, 13(1), 182203.

Laing, J., and Frost, W. (2010). How green was my festival: Exploring challenges and opportunities associated with staging green events. International Journal of Hospitality Management, 29(2), 261-267.

Laing, J., and Mair, J. (2012). The greening of music festivals: Motivations, barriers and outcomes. Journal of Sustainable Tourism, 20 (5), 683. doi:10.1080/09669582.2011.636819

Leech, N. L., and Onwuegbuzie, A. J. (2009). A typology of mixed methods research designs. Quality and Quantity, 43(2), 265-275. doi:10.1007/s11135-007-9105-3

Livesey, B. (2014). Gildan workers in Haiti, Honduras complain of harassment, pay too meagre to live on. The Globe and Mail. Retrieved June, 2016 from http://www.theglobeandmail.com/report-on-business/rob-magazine/do-youknow-where-your-t-shirt-came-from/article21818609/

Low, W., and Davenport, E. (2009). Organizational leadership, ethics and the challenges of marketing fair and ethical trade. Journal of Business Ethics, 86, 97-108.

Lundblad, L., and Davies, I. (2015). The values and motivations behind sustainable fashion consumption. Journal of Consumer Behaviour, 2(15), 149-162. doi: 10.1002/cb.1559

Mair, J., and Laing, J. H. (2013). Encouraging pro-environmental behaviour: The role of sustainability-focused events. Journal of Sustainable Tourism, 21(8), 1113.

Mair, S., Druckman, A., and Jackson, T. (2016). Global inequities and emissions in western european textiles and clothing consumption. Journal of Cleaner Production, 132, 5769. doi:10.1016/j.jclepro.2015.08.082

Mariposa Folk Foundation (2016). Greening Mariposa. Retrieved May, 2016 from http://www.mariposafolk.com/the-festival/greening-mariposa/

Michaud, C., and Llerena, D. (2011). Green consumer behaviour: An experimental analysis of willingness to pay for remanufactured products. Business Strategy and the Environment, 20(6), 408-420. doi:10.1002/bse.703 
Neuman, L. W. (2002). Social research methods: Qualitative and quantitative approaches. Essex, England: Pearson Education Ltd.

Niinimäki, K., and Hassi, L. (2011). Emerging design strategies in sustainable production and consumption of textiles and clothing. Journal of Cleaner Production, 19(16), 1876-1883. doi:10.1016/j.jclepro.2011.04.020

Organic Trade Association (OTA). (2015). U.S. Organic Cotton Production \& Marketing Trends. Retrieved May 12, 2016 from http://ota.com/sites/default/files/indexed_files/2013\%20and\%202014\%200rgani c\%20Cotton\%20Report.pdf

Osbaldiston, R., and Sheldon, K. M. (2003). Promoting internalized motivation for environmentally responsible behaviour: A prospective study of environmental goals. Journal of Environmental Psychology, 23(4), 349-357. doi:10.1016/S02724944(03)00035-5

Ozdamar Ertekin, Z., and Atik, D. (2015). Sustainable markets: Motivating factors, barriers, and remedies for mobilization of slow fashion. Journal of Macro Marketing, 35(1), 53-69. doi:10.1177/0276146714535932

Paluck, E. (2010). The promising integration of qualitative methods and field experiments. The Annals of the American Academy of Political and Social Science, 628(1), 59-71. doi:10.1177/0002716209351510

Parab, S., and Bhalerao, S. (2010). Choosing statistical test. International Journal of Ayurveda Research, 1(3), 187. doi:10.4103/0974-7788.72494

Pelletier, L. G., Tuson, K., Green-Demers, I., Noels, K., and Beaton, A. (1998). Why are you doing things for the environment? The motivation toward the environment scale (MTES). Journal of Applied Social Psychology, 28, 437-468.

Pennsylvania State University. (2017). Chi-square distribution table. Retrieved September, 2016 from http://sites.stat.psu.edu/ mga/401/tables/Chi-square-table.pdf

Pennsylvania State University. (2017). Comparing two proportions. Retrieved September, 2016 from https://onlinecourses.science.psu.edu/stat414/node/268

Pickett-Baker, J., and Ozaki, R. (2008). Pro-environmental products: Marketing influence on consumer purchase decision. Journal of Consumer Marketing, 25(5), 281 - 293. doi:10.1108/07363760810890516

Randolph, J. (2009). A guide to writing the dissertation literature review. Practical Assessment, Research \& Evaluation, 14(13), 1-13. 
Reynolds, T., Murray, B. T., Kolodinsky, J., and Howell, J. (2015). Contrasting self-reported willingness to pay and demonstrated purchase behavior for energy-saving technologies in a small island developing state. Energy for Sustainable Development, 27, 18-27. doi:10.1016/j.esd.2015.04.001

Statistics Canada. (2016). Retail sales, by industry. Retrieved September, 2016 from http://www.statcan.gc.ca/tables-tableaux/sum-som/l01/cst01/trad15a-eng.htm

Stern, P. C., Dietz, T., Abel, T. D., Guagnano, G. A., and Kalof, L. (1999). A value-belief-norm theory of support for social movements: The case of environmentalism. Human Ecology Review, 6(2), 81-97.

Thieme, J., Royne, M. B., Jha, S., Levy, M., and Barnes McEntee, W. (2015). Factors affecting the relationship between environmental concern and behaviors. Marketing Intelligence \& Planning, 33(5), 675-690. doi:10.1108/MIP-08-2014-0149

Tourism Industry Association of Ontario. (2016). 2015 Winners: Tourism industry awards of excellence. Retrieved May 2016 from http://www.tiaontario.ca/ontariotourismsummit/awards/tiao/2015winners/

Trentmann, F. (2009). Crossing divides: consumption and globalization in history. Journal of Consumer Culture, 9(2), 187-220.

Tucker, E., Rifon, N., Lee, E., and Reece, B. (2012). Consumer receptivity to green ads: A test of green claim types and the role of individual consumer characteristics for green ad response. Journal of Advertising, 41(4), 9. doi:10.2753/JOA0091-3367410401

Turcotte, M., de Bellefeuille, S., and den Hond, F. (2007). Gildan inc: Influencing corporate governance in the textile sector. The Journal of Corporate Citizenship, 27, 23-36.

United Nations Statistics Division. (2016). Individual consumption expenditure of households, NPISHs, and general government at current prices. Retrieved February 2017 from http://data.un.org/Data.aspx?d=SNA\&f=group_code\%3A302

United Nations. (2013). Inequality matters: Report of the world social situation. Retrieved January, 2017 from http://www.un.org/esa/socdev/documents/reports/InequalityMatters.pdf

United Nations. (1992). United Nations Conference on Environment \& Development Rio de Janerio, Brazil. Retrieved September, 2016 from https://sustainabledevelopment.un.org/content/documents/Agenda21.pdf 
Waite, M. (2009). Sustainable textiles: the role of bamboo and a comparison of bamboo textile properties-Part 1. Journal of Textile and Apparel, Technology and Management, 6(2).

Webster, J., and Watson, R. (2002). Analyzing the past to prepare for the future: Writing a literature review. Management Information Systems Quarterly, 26(2), xiii-xxiii.

Wertenbroch, K., and Skiera, B. (2002). Measuring consumers' willingness to pay at the point of purchase. Journal of Marketing Research, 39(2), 228-241. doi:10.1509/jmkr.39.2.228.19086

Wong, I. A., Wan, Y., and Qi, S. (2015). Green events, value perceptions, \& the role of consumer involvement in festival design and performance. Journal of Sustainable Tourism, 23(2), 294-315. doi:10.1080/09669582.2014.953542

World Bank. (2016). World Bank Data. Retrieved January, 2017 from http://data.worldbank.org/indicator/NY.GDP.MKTP.CD?end=2015\&start=1960\&vie $\mathrm{w}=$ chart

World Trade Organization (WT0). (2015). International Trade Statistics 2015. Retrieved September, 2016 from https://www.wto.org/english/res_e/statis_e/its2015_e/its2015_e.pdf

World Wildlife Fund. (2016). Cotton Farming. Retrieved June, 2016 from http://wwf.panda.org/about_our_earth/about_freshwater/freshwater_problems/th irsty_crops/cotton/

Yan, R., Hyllegard, K., and Blaesi, L. (2012). Marketing eco-fashion: The influence of brand name and message explicitness. Journal of Marketing Communications, 18(2), 151168.

Zhang, Y., Liu, X., Xiao, R., \& Yuan, Z. (2015). Life cycle assessment of cotton T-shirts in china. The International Journal of Life Cycle Assessment, 20(7), 994-1004. doi:10.1007/s11367-015-0889-4 